\title{
The effects of age, instructions, and problem content on everyday problem -solving outcome using two scoring procedures
}

\author{
Tara L. Neely \\ West Virginia University
}

Follow this and additional works at: https://researchrepository.wvu.edu/etd

\section{Recommended Citation}

Neely, Tara L., "The effects of age, instructions, and problem content on everyday problem -solving outcome using two scoring procedures" (2006). Graduate Theses, Dissertations, and Problem Reports. 2507.

https://researchrepository.wvu.edu/etd/2507

This Dissertation is protected by copyright and/or related rights. It has been brought to you by the The Research Repository @ WVU with permission from the rights-holder(s). You are free to use this Dissertation in any way that is permitted by the copyright and related rights legislation that applies to your use. For other uses you must obtain permission from the rights-holder(s) directly, unless additional rights are indicated by a Creative Commons license in the record and/ or on the work itself. This Dissertation has been accepted for inclusion in WVU Graduate Theses, Dissertations, and Problem Reports collection by an authorized administrator of The Research Repository @ WVU.

For more information, please contact researchrepository@mail.wvu.edu. 
The Effects of Age, Instructions, and Problem Content on Everyday Problem-solving Outcome Using Two Scoring Procedures

Tara L. Neely

\author{
Dissertation submitted to the \\ Eberly College of Arts and Sciences \\ at West Virginia University \\ in partial fulfillment of the requirements \\ for the degree of
}
Doctor of Philosophy
in
Psychology
Jennifer A. Margrett, Ph.D., Chair JoNell Strough, Ph.D., Chair Julie Hicks Patrick, Ph.D. Barry Edelstein, Ph.D. Anne Nardi, Ph.D.

\title{
Department of Psychology
}

\section{Morgantown, West Virginia 2006}

Keywords: adulthood, everyday problem solving, everyday cognition, methodology Copyright 2006 Tara L. Neely 


\begin{abstract}
The Effects of Age, Instructions, and Problem Content on Everyday Problem-solving Outcome Using Two Scoring Procedures
\end{abstract}

Tara L. Neely

Prior literature has relied on varied methodology to infer conclusions about adult problem solvers; possibly leading to erroneous assumptions about everyday problem-solving performance in adulthood. The present study examined everyday problem-solving performance of 133 younger, middle-aged, and older adults. The goal of the study was to investigate whether different scoring procedures (number vs. strategy type) or participant instructions (self target vs. others target) affected how adults performed on two types of open-ended problem-solving vignettes (home vs. friend problem domains). Differential age patterns were found when comparing the number and types of strategies reported. When assessing total number of solutions generated, middle-aged adults tended to record the most solutions, particularly when completing home problems or after given the others-target instructions. In terms of strategy type, older adults reported a higher proportion of proactive responses (problem-focused and cognitive-analytical strategies) than younger adults on friend problems. Cluster analysis revealed three types of problem solvers (i.e., most proactive; commentary; least proactive) based on reported strategies. Individuals comprising the least proactive group performed better on an inductive reasoning task and generated more overall solutions than individuals in the most proactive group. Findings from the study should compel researchers to be cautious when focusing on a particular scoring method as an index for effective problem solving, as the findings can differ based on scoring. 


\section{ACKNOWLEDGEMENTS}

I would like to thank all of the members on my dissertation committee: Drs. Jennifer A. Margrett, JoNell Strough, Julie Hicks Patrick, Barry Edelstein, and Anne Nardi. Throughout the entirety of this project, these committee members offered valuable guidance and assistance, which was greatly appreciated. The insight provided from my mentor, Dr. Jennifer Margrett, was especially helpful and respected. She provided a significant amount of time and professional advice, which assisted enormously throughout the course of this study. In addition to her professional support, Dr. Margrett also displayed optimism and encouragement, which motivated me and aided in developing my passion for research and to speak enthusiastically about this area of study. I'm proud to recognize every one of her generous contributions to this research project.

I was also fortunate to be surrounded by many ambitious researchers in the area of adulthood and aging at West Virginia University. The last four years have been extremely valuable, and I am truly appreciative for the faculty who has shared their knowledge with me throughout the course of this project. I would like to thank my fellow colleagues, particularly Kristopher Kimbler, Brian Ayotte, and Eric Goedereis, who have provided many hours of social support, friendship, and collegial advice. All of the professional support from my colleagues has been inspiring, and I am truly grateful for them.

I would particularly like to thank the Everyday Life (EDL) project team: Suzan Clemens, Loren Brainard, Carissa Wright, and Candance Facemyer, who dedicated many intense hours to make the completion of this project manageable in a year's time. Their persistence and assertiveness in all areas of data collection and management was greatly appreciated. In addition, I would also like to thank the individuals who participated in the study and shared their experiences with the team. 
Family and friends have also encouraged me, aided in recruitment, and provided various forms of support in my attainment of this goal, especially my parents K. Bruce and Terri L. Neely. I would also like to kindly thank Andrew Johnson and his parents, Dick and Paula Johnson, for their help with recruiting numerous friends, family, and coworkers for the study. Everyone's encouragement, enthusiasm, and scholarly excellence will continue to serve as an inspiration in my future endeavors. Thank you all. 
TABLE OF CONTENTS

TITLE PAGE .

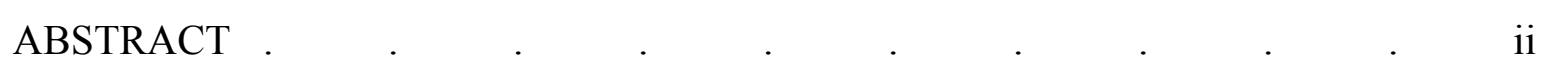

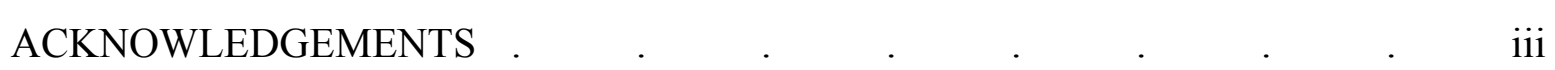

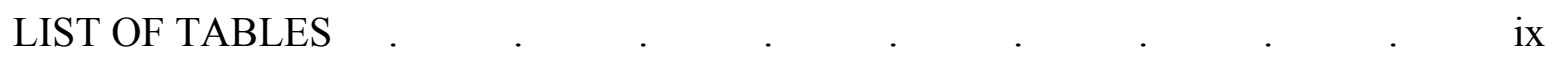

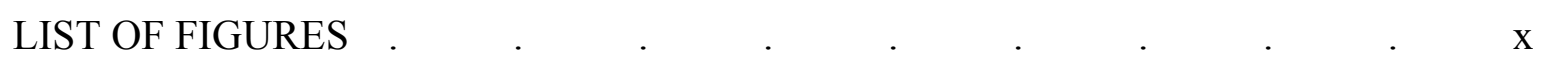

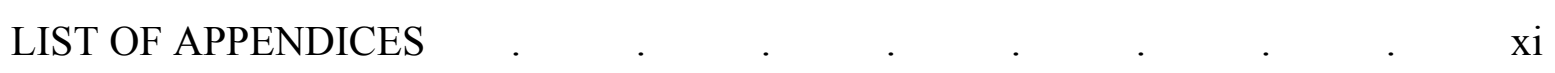

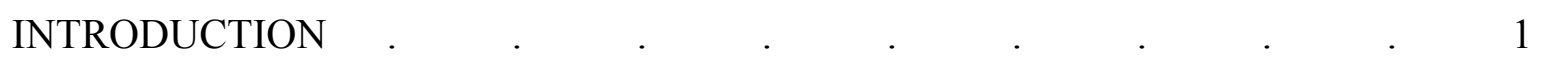

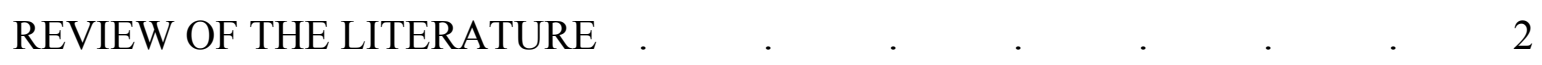

Cognitive Performance and Everyday Problem Solving . $\quad . \quad$. 2

Scoring Procedures Used to Assess Everyday Task Performance . $\quad$. 5

Age Differences in the Fluency of Everyday Solutions $\quad$. $\quad$. 6

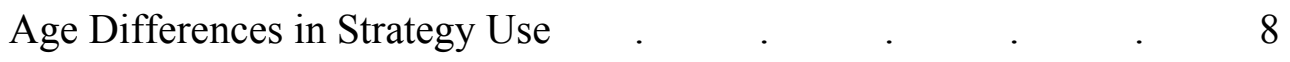

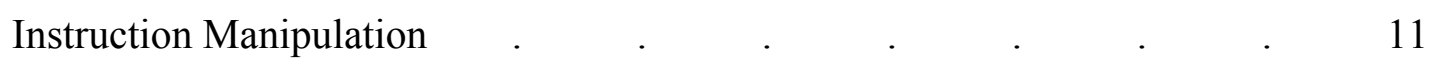

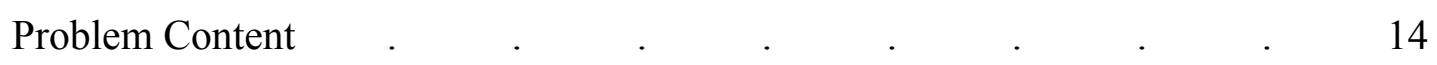

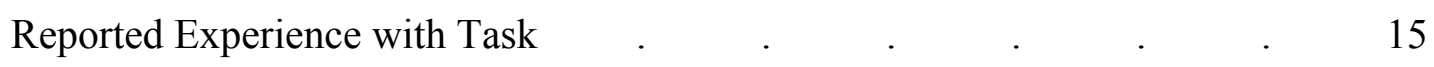

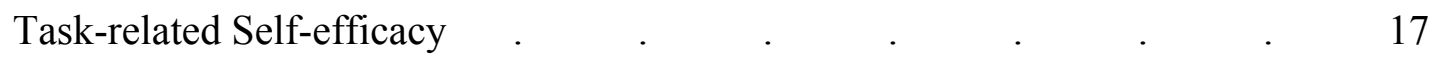

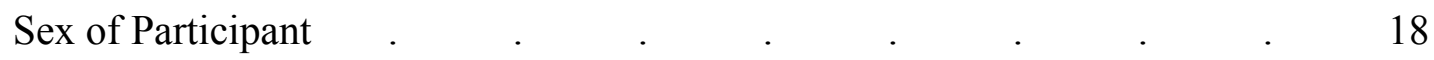

Education and Fundamental Cognitive Ability $\quad . \quad$. $\quad . \quad$. $\quad 20$

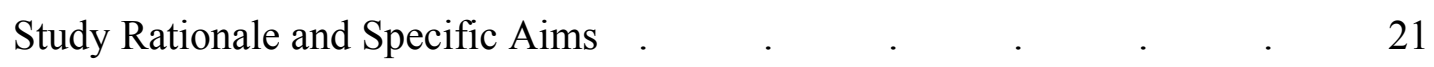

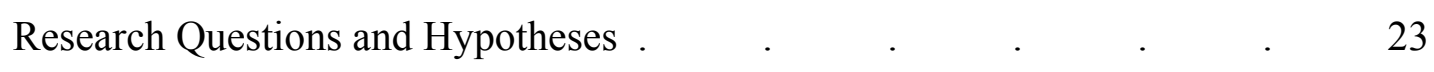

RQ1: Group Differences in Fluency and Strategy Type $\quad$. $\quad$. 23

RQ2: Classifying Problem solvers $\quad . \quad$. $\quad . \quad$. $\quad . \quad 25$ 
RQ3: Relations between Selected Factors, Fluency

Outcome, and Problem-solver Subgroups

METHOD

Design

Procedure

Instruction Group

Participants

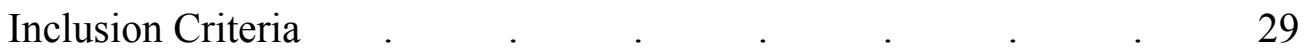

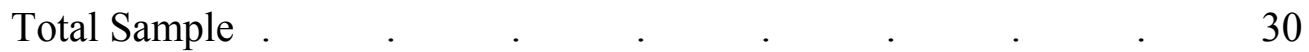

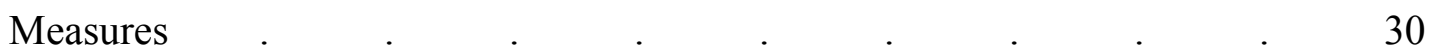

Telephone Screening and Demographics $\quad . \quad$. $\quad$. $\quad$. 31

Everyday Problem Vignettes: Primary Outcome. . . . . 31

Description of Original Assessment . $\quad . \quad$. $\quad . \quad 31$

Description of Current Study Vignettes _ . $\quad$. $\quad$. 32

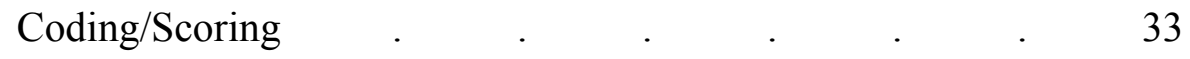

Bracketing/Fluency Coding . . . . . . . $\quad$. 33

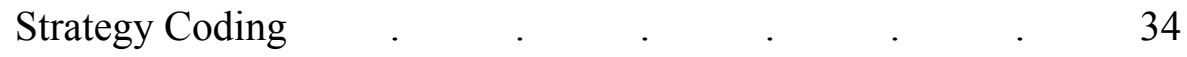

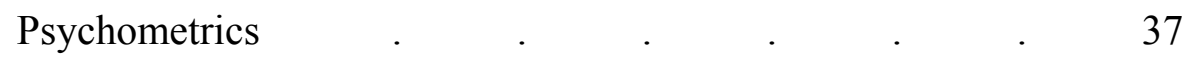

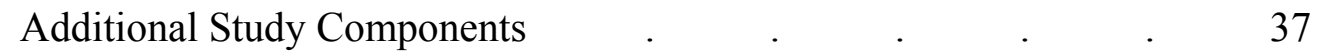

Fundamental Cognitive Abilities $\quad . \quad$. $\quad . \quad$. $\quad 37$

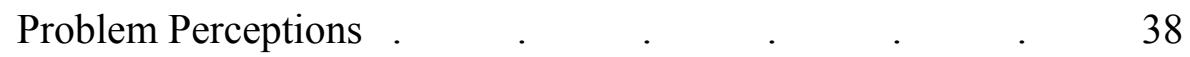

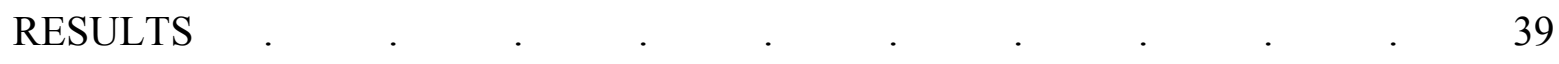

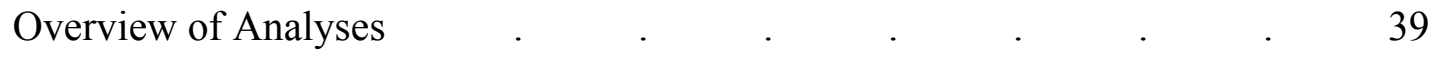

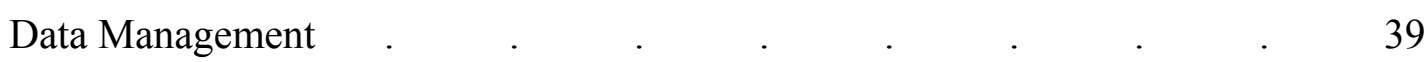




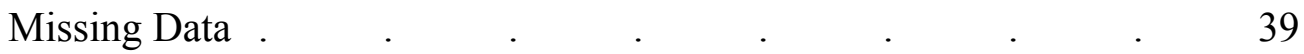

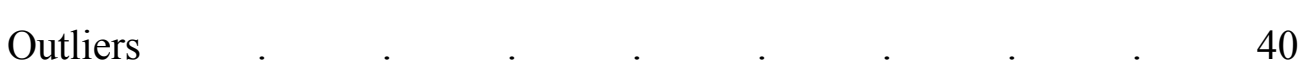

RQ1: Group Differences in Problem-solving Outcome $\quad . \quad$. $\quad$. 41

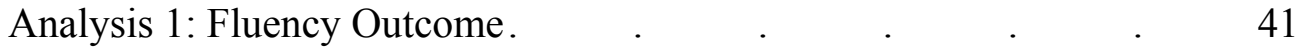

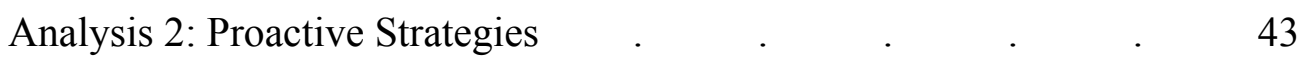

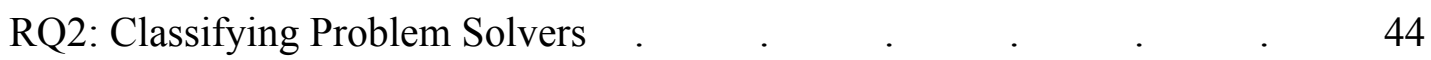

Analysis 3: Problem-solver Subgroups and Profiles . $\quad$. $\quad$. 44

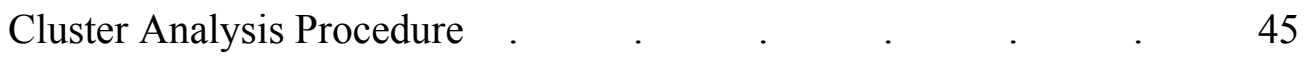

Number, Size, and Profiles of Subgroups $\quad$. $\quad$ _ $\quad$. $\quad$. $\quad 47$

RQ3: Relationship between Selected Factors and Outcome . $\quad . \quad$. $\quad 49$

Analysis 4: Predicting Fluency Outcome $\quad$. $\quad$. $\quad$. $\quad$. $\quad 49$

Analysis 5: Meaningful Characteristics of Subgroups $\quad . \quad$. $\quad 50$

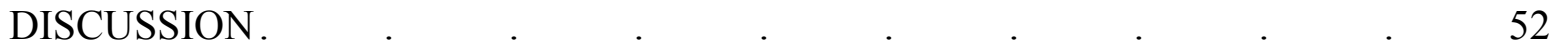

Review of Research Questions and Hypotheses $\quad . \quad$. $\quad . \quad$. $\quad 52$

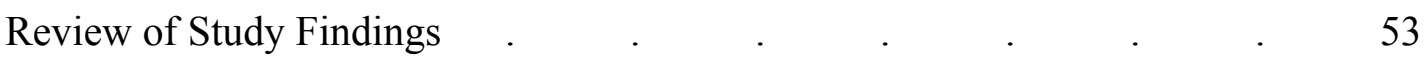

Differential Group Differences based on Scoring _ . $\quad$. $\quad$. 54

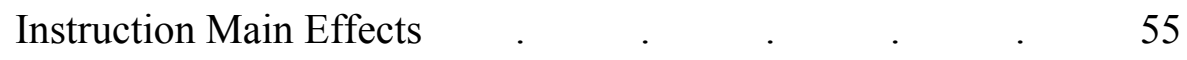

Problem Content Main Effects $\quad$. $\quad$. $\quad$. $\quad$. $\quad 55$

Age x Problem Content Interactions . $\quad . \quad$. $\quad . \quad 56$

Age x Instruction Interactions. $\quad . \quad \ldots \quad$. $\quad . \quad$. 57

$\begin{array}{llllllllllll}\text { Subgroups of Problem Solvers } \quad . \quad & \text {. } & \text {. } & \text {. } & & 57\end{array}$

Predicting Instrumental and Interpersonal Fluency . $\quad$. $\quad$. 59

Implications and Published Research . $\quad . \quad \ldots \quad$. $\quad . \quad$. 60 
Differential Group Differences based on Scoring _ . $\quad$. $\quad$. 61

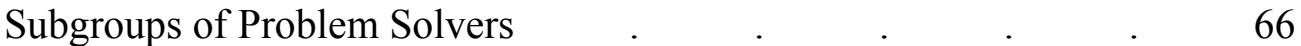

Predicting Instrumental and Interpersonal Fluency . $\quad$. . $\quad 67$

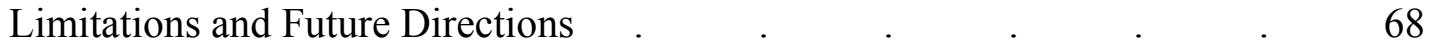

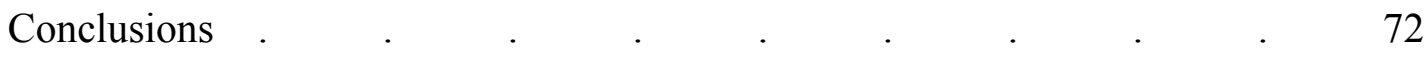

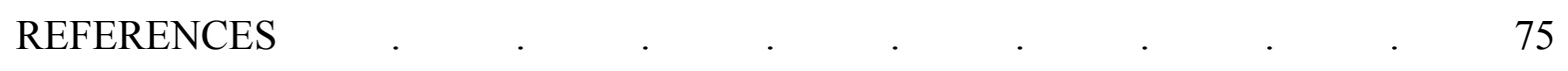




\section{LIST OF TABLES}

1. Subsample Characteristics by Testing Group Size . $\quad$. $\quad$. $\quad$. 82

2. Subsample Characteristics by Testing Location $\quad . \quad \ldots \quad$. $\quad$. $\quad 83$

3. Subsample Characteristics by Instruction Group Status _ . $\quad$. $\quad 84$

4. Descriptive Statistics of Background

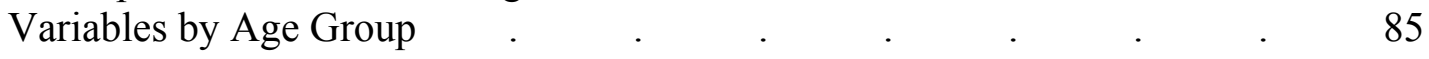

5. Descriptive Statistics of Outcome

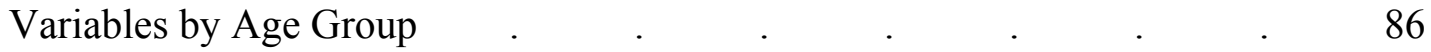

6. Percent Agreement During

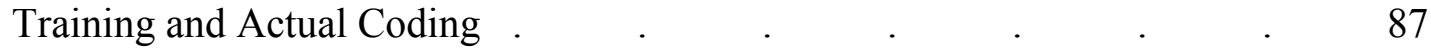

7. Means and Standard Deviations of Younger, Middle-aged, and Older Adult Groups on Problem-solving Performance Outcome $\quad$. $\quad 88$

8. Analysis of Variance Examining Group

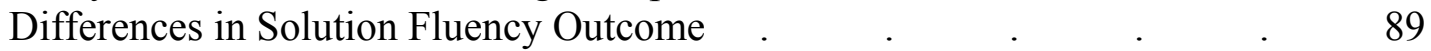

9. Analysis of Variance Examining Group

Differences in Proactive Response Style Proportions $\quad$. $\quad$. $\quad$. 90

10. The 5 Subgroups Extracted from Cluster

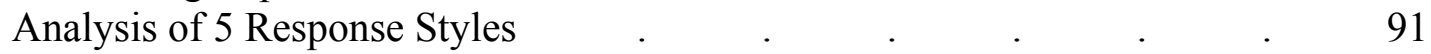

11. Proportion Profile Means for the 5 Subgroups

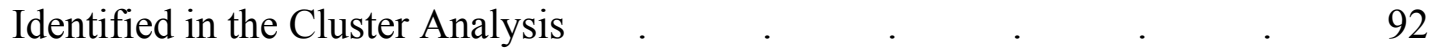

12. Regression Indices for Instrumental Fluency Outcome $\quad$ • $\quad$ • $\quad 93$

13. Regression Indices for Interpersonal Fluency Outcome $\quad$. $\quad$. $\quad 94$

14. Cluster Composition (in \%) of Status Variables _ . . . . . . 95

15. Cluster Membership Means on Selected Factors . 96

16. Power Analyses for the Fluency Analysis of

Variance Test in the Current Study . $\quad . \quad \ldots \quad$. $\quad . \quad$. $\quad . \quad 97$

17. Power Analyses for the Proactive Proportion Analysis
of Variance Test in the Current Stud . . . . . . . . 98 


\section{LIST OF FIGURES}

1. General Session Procedure and Measures Used $\quad$. $\quad$. $\quad$. 99

2. Age x Instruction Group Interaction for Fluency Outcome . . . 100

3. Age x Problem Content Interaction for Fluency Outcome . $\quad$. $\quad$. 101

4. Age $\mathrm{x}$ Problem Content Interaction for Proactive Proportion . . 102 


\section{LIST OF APPENDICES}

APPENDIX A: Everyday Problem-solving Methodologies for Tasks, Instructions, and Scoring Procedures $\quad . \quad$. $\quad . \quad$. $\quad 103$

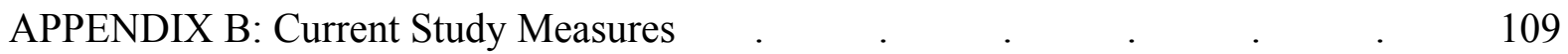

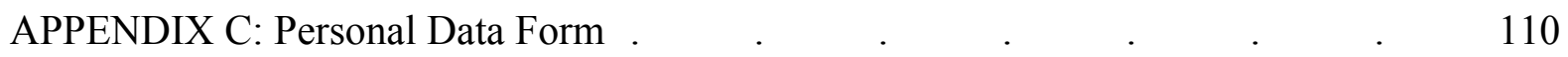

APPENDIX D: Everyday Problem Solving Inventory Self Form ～. . 117

APPENDIX E: Everyday Problem Solving Inventory Others Form . $\quad$ 134

APPENDIX F: Directions/Guidelines for Bracketing EPSI Forms. . $\quad$. . . 151

APPENDIX G: Fluency Coding and Data Entry Guidelines . $\quad$ 155

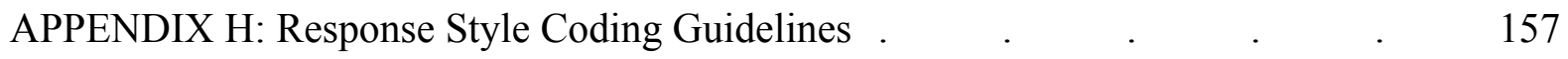

APPENDIX I: Exemplar Solutions to EPSI “Chore” Problem — . . 160

APPENDIX J: Problem Perception Questionnaire Items . $\quad$. $\quad$. $\quad 162$ 


\section{Introduction}

The importance of examining everyday cognition stems from the proposition that traditional laboratory-based measures of cognition may not adequately capture older adults' ability to perform tasks of daily living (Denney \& Pearce, 1989). As opposed to traditional cognitive assessments, everyday problem solving may be more representative of real-life tasks encountered during daily functioning. The methods used to examine everyday problem solving vary across laboratories, yet the influence of these various methods on everyday cognitive performance has not been adequately addressed in the published literature (Thornton \& Dumke, 2005). Due to these varied methods, the ability of current measures and designs to capture the true nature of group differences (e.g., age) is questionable. If different procedural and scoring methods elicit different conclusions about adult problem solvers, considerations of precise design in future studies is needed. If different methods produce similar conclusions about adult problem-solvers, this would suggest that the reliability of current methodologies and the assumptions about adult problem-solvers are concrete and plausible. Therefore, one area warranting further exploration is how aspects of research design and methodology affect age differences on everyday task performance.

There is support from previous research that methodological factors such as problem content (Thornton \& Dumke, 2005), scoring criteria (Neely, 2005; Thornton \& Dumke), and instruction (Denney, Tozier, \& Schlotthauer, 1992) may affect problem-solving outcome. Individual factors may also affect everyday cognitive performance. These factors include past and current experience with a problem (Berg, Meegan, Klaczynski, 1999), perceived ability to complete a problem (Artistico, Cervone, \& Pezzuti, 2003; Haught, Hill, Nardi, \& Walls, 2000), fundamental cognitive abilities (Allaire \& Marsiske, 1999, Kimbler, 2006; Margrett, 1999), 
education (Thornton \& Dumke), sex (Margrett \& Marsiske, 2002; Neely), and age (BlanchardFields, Chen, \& Norris, 1997; Crawford \& Channon, 2002; Denney \& Pearce, 1989). The majority of these cited studies place an emphasis on how these individual characteristics affect problem solving in older adulthood. It is less unclear whether these same factors influence problem-solving performance in younger and middle-aged adults.

The current study examined how methodological and individual factors affected everyday cognitive performance in three adult age groups (younger, middle-aged, and older). Everyday cognitive performance was assessed in two ways to examine differential patterns of responding based on scoring: summing the number of unique solutions generated (i.e., fluency) and categorizing strategy types (i.e., response styles). A similar coding scheme was used as in a previous study (e.g., Cornelius \& Caspi, 1987). The current study also explored how individuals grouped together in terms of their overall way of responding to problems and noted whether problem solver subgroups differed in meaningful ways.

The first section of the literature review highlights cognitive performance in adulthood emphasizing everyday tasks as opposed to traditional cognitive measures. This section is followed by a discussion regarding age differences in everyday problem-solving fluency and strategy use. Lastly, there is a review of methodological and individuals factors that may influence problem-solving outcome.

\section{Cognitive Performance and Everyday Problem Solving}

The cognitive aging literature suggests that a normative process of aging includes declines in visualization abilities or fluid abilities (e.g., Bosworth \& Schaie, 1999; Salthouse, 1991; Schaie, 1989, 1993), which may include tasks involving spatial orientation, memory, comparing numbers, or inductive reasoning skills. Although this downward process occurs 
gradually after early adulthood, a steeper decrement begins around age 60 and is particularly notable by 70 years of age (Schaie, 1996). Crystallized abilities (e.g., verbal ability, general knowledge, logical reasoning), however, involve skills that people acquire through experience and show less pronounced declines until one is closer to mortality (Bosworth \& Schaie, 1999). One critical question is whether researchers should rely on traditional cognitive assessments that heavily focus on fluid and crystallized abilities to understand functioning in day-to-day life, or conversely, whether everyday cognitive measures utilizing realistic stimuli better reflect one's actual everyday functioning.

Questioning the ability of intelligence testing to predict job and academic performance, McClelland (1973) was one of the first researchers to express concern about traditional measures. He urged researchers to assess competence over intelligence and believed that traditional placement measures (e.g., grades) do not necessarily relate to future performance (e.g., job performance). This classic argument sparked concerns that traditional, laboratory-based assessments of fundamental cognitive abilities may not adequately represent one's ability to solve problems in everyday life (e.g., Denney, 1989; Diehl, 1998; Heidrich \& Denney, 1994, Willis, 1996).

Despite declines on traditional cognitive tests, some older adults function exceptionally well in later life. Therefore, researchers have been trying to devise assessments to better represent cognitive processes used by older adults in daily life. Several of these everyday assessments have been linked to fundamental cognitive performance (inductive reasoning, verbal ability, working memory; Allaire \& Marsiske, 1999, 2002; inductive reasoning, verbal ability; Cornelius \& Caspi, 1987; speed, memory, fluid and crystallized abilities; Diehl, Willis, \& Schaie, 1995). The interesting findings are those that suggest that fundamental cognitive abilities 
are essential, but not completely adequate, for solving everyday problems. For example, Diehl and colleagues state that areas such as domain-specific knowledge (information accumulated in a specific content area) are important when understanding everyday cognitive performance. Furthermore, Allaire and Marsiske (2002) found that everyday cognition accounted for variance in functional ability (e.g., instrumental activities of daily living) above and beyond performance on traditional cognitive tasks, suggesting the importance of everyday over basic cognitive ability.

Based on the evidence that fundamental cognitive abilities may not be sufficient to explain functioning in daily life, there is often a distinction between traditional cognitive tasks and everyday problem solving tasks. Everyday cognition researchers rely less on using traditional cognitive measures and more on everyday problem solving as predictors of everyday functioning (see Thornton \& Dumke, 2005 for a review). Whether the assessments used in current studies adequately simulate actual problem solving in real life is yet to be uncovered (Marsiske \& Margrett, 2006).

The everyday tasks used in the published literature typically target domains that individuals may encounter during daily routines. These tasks may include open-ended questions with multiple solutions or strategies (e.g., Practical Problems Test, Denney \& Pearce, 1989; Everyday Problem Solving Inventory, Cornelius \& Caspi, 1987) or well-defined tasks with one correct solution (Everyday Cognition Battery, Allaire \& Marsiske, 1999; Everyday Problems Test, Willis \& Marsiske, 1997; Observed Tasks of Daily Living, Diehl, et al., 1995). These tasks also tend to target either interpersonal contexts (e.g., social dilemmas with friends, family, coworkers) or involve content that is instrumental or practical in nature (e.g., taking medication, understanding labels). 
Both types of assessments and problem types are germane to adults' everyday lives. In terms of the two assessment types, there may be situations in which adults must generate the correct response to function appropriately in daily life, or there may be incidences where an individual has many options to consider before following through with a strategy. For example, it would be crucial for an individual to understand the dosage of medication necessary to live healthily. On the other hand, if a family member irritates that individual, he or she may need to consider and weigh various options before acting (or not acting) on the situation. Various problem types are also important to consider because they target a wide range of situations that adults may encounter during daily living. Responses are likely to vary by problem domain.

Due to the various everyday assessments employed in previous literature and the potential for individual characteristics to effect problem-solving outcome, the impact of individual and methodological factors on everyday cognitive performance was investigated. For clarification, the current study defined everyday problem solving as completing tasks that pertain to an issue that may commonly occur in life which requires an individual to generate solutions (Thornton \& Dumke, 2005).

\section{Scoring Procedures Used to Assess Everyday Task Performance}

In addition to deciding which format and problem content to examine in a study, researchers must also make a decision about scoring, particularly for open-ended assessments. Most frequently, researchers will rely on fluency, which involves summing up the total number of solutions one generates. Others may choose to examine strategies, which assesses the type of one's responses. Therefore, one method focuses on quantity, whereas the other may attempt to target quality. To date, researchers have not addressed how conclusions about age differences in everyday cognitive performance may vary based on the type of scoring procedure used. The 
current study compared findings based on both fluency outcome and strategy types in hopes to better address the assumptions regarding age differences discussed in the published literature.

\section{Age Differences in the Fluency of Everyday Solutions}

A common statement regarding age differences found in the laboratory is that younger adults are better problem solvers than older adults in everyday situations (e.g., Berg, et al., 1999; Denney \& Pearce, 1989; Denney, Pearce, \& Palmer, 1982). This type of statement regarding age differences is evident primarily when everyday problem-solving scoring is based on fluency outcome (summing the total number of solutions generated on a task), which appears to be the most commonly used method of assessing everyday cognitive performance on open-ended assessments.

Denney and colleagues conducted a prominent line of research examining age differences in fluency using practical problems (e.g., "A woman is frying a chicken when all of a sudden a grease fire breaks out on the stove. What should she do?”). Denney and colleagues (1982) instructed various younger, middle-aged, and older adults to solve hypothetical vignettes similar to the example above. Participants received researcher-generated problems that were considered to be "younger adult problems", "middle-aged adult problems", and "older adult problems". Older participants did not perform as well as the younger and middle-aged adults, even when presented with problems considered to be personally relevant to older adults. The results of their study indicated an inverted U-shaped curve to denote performance across adulthood. Performance peaked in the middle-aged group and was worst in the older adult group.

In a subsequent study, Denney and Pearce (1989) instructed older adults to create their own problems to assess whether giving older adults a presumed advantage would permit them to outperform their younger counterparts. Problems that were supposedly relevant to younger and 
middle-aged adults (see Denney, et al., 1982) were also used in this study and administered to all three age groups. Although the older participants generated a similar number of solutions as younger adults on the "older adult-generated problems", middle-aged adults performed the best on these problems. When completing "younger adult problems", older adults generated fewer solutions than the other age groups. Therefore, even when given a presumed advantage with personally relevant problems, older adults did not perform better than other age groups, yet age differences were significantly minimized during practical problem solving when compared to performance on traditional measures of cognition. Because older adults performed just as well as younger adults, these findings suggest that experience with common problems may allow some older adults to compensate for age-related declines in fundamental cognitive abilities. Nonetheless, compensation (i.e., experience) may not override fundamental cognitive declines because even on problems in which older adults have experience, they did not generate more solutions than younger or middle-aged adults.

Recent studies have found similar age-related differences in everyday problem-solving fluency. Berg and colleagues (1999) prompted participants to generate solutions to two problems related to a dinner party and doctor visit. Age was a significant predictor of fluency on the problems; younger adults generated more solutions than older adults. Similarly, Crawford and Channon (2002) administered a task involving a range of social relationship predicaments to younger and older adults to assess both the number of solutions and the quality of responses generated for each situation. Results revealed that older adults produced fewer solutions than younger adults. However, the quality (i.e., appreciation of the problem, social appropriateness, and effectiveness) of older adult responses surpassed that of younger adults. The quality finding by Crawford and Channon, along with the argument that several solutions are not necessarily 
better than one effective strategy (e.g., Berg, et al.), illustrate the importance of going beyond fluency scoring when investigating age differences in everyday problem solving.

Additionally, perhaps fluency is a form of fluid intelligence because respondents are required to quickly and flexibly manipulate ideas and use active reasoning skills to generate a number of solutions to a given problem. As previously mentioned, fluid abilities typically decline at an earlier age than crystallized abilities (Bosworth \& Schaie, 1999; Schaie, 1993), and older adults have difficulties sifting through large amounts of information when considering, choosing, and executing solutions to problems (Arenberg, 1982). For these reasons, it is not surprising that younger adults generally outperform older adults on fluency assessments in the everyday cognitive literature. Thus, it may be important to examine strategy types to fully understand age differences in everyday cognition and to better inform the literature. A stronger emphasis is typically placed on fluency when making assumptions about adult problem-solving performance, but the next section reviews the line of research on strategy coding.

\section{Age Differences in Strategy Use}

Although fluency emphasizes flexibility when a solution fails and a back up solution is needed, fluency may not sufficiently capture one's ability to solve a problem effectively. Based on the current literature's reliance on using fluency scoring to identify age differences in problem-solving ability, older adults may be erroneously viewed as less effective problem solvers compared to their younger counterparts. It has been suggested that older adults may make more conscious appraisals of a situation than younger adults, they may note which solutions were most effective in the past, and as a result of this reasoning process, older adults may limit the number of strategies they report on fluency measures (e.g., Berg, et al., 1999; Labouvie-Vief, Hakim-Larson, \& Hobart, 1987). In other words, older adults may write down only the best 
solutions (e.g., what worked for them in the past) and may purposely exclude other potential solutions (e.g., solutions they would not implement), even when instructed to generate as many strategies as possible.

By examining the various strategies reported on everyday problems, it is possible to illustrate how individuals approach problems similarly or differently across age groups. This information may help elucidate the age differences noted in fluency outcome to determine whether generating more solutions affects the types of strategies reported. Perhaps older adults are just as effective or creative during problem solving as younger adults, but relying on fluency outcome does not allow researchers to examine this possibility. Older adults may produce fewer solutions during problem solving tasks, but they may report quite effective strategies to everyday situations.

One study examined problem-solving quality by asking participants to rate the likelihood that they would use given response strategies (Cornelius \& Caspi, 1987). After assessing participants' endorsements of four response categories (i.e., problem-focused, cognitiveanalytical, avoidant-denial, passive-dependent), Cornelius and Caspi found that problem-solving ability (based on judges' ratings of the efficacy of the response category) may increase with age. Older adults in their study endorsed more efficient responses (i.e., problem-focused and cognitive-analytical strategies) to hypothetical situations than the younger adults. This finding is particularly relevant to the argument that fluency may not adequately capture the true nature of effective problem solving. Despite reported older adult deficits in strategy fluency in the extant literature, Cornelius and Caspi provided evidence that older adults can be effective problem solvers, and perhaps more so than younger adults. 
Blanchard-Fields, Jahnke, and Camp (1995) also found that older adults reported a variety of strategies when completing everyday problems. They asked participants to write essays about how everyday problems should be solved. Each participant response received four scores [(one for each response category: see Cornelius \& Caspi, 1987), ranging from 1 (no use) to 4 (major use)]. All age groups reported problem-focused strategies more often than other strategies. Based on the idea that problem-focused strategies constitute proactive problem solving, this finding suggests that older adults, like their younger counterparts, are proactive problem solvers. Additionally, older adults reported more passive-dependent and avoidant-denial strategies, signifying that older adults may prefer various strategies to cope with different problems.

In other areas of work, researchers also found that older adults preferred a variety of strategy types. Heckhausen and Schulz (1995) suggested that most people prefer primary response styles (e.g., controlling one's environment), but oftentimes biological limitations (e.g., physical or mental constraints) require older adults to use strategies that rely on others. Although this may be true for some individuals, Berg, Strough, Calderone, Sansone, and Weir (1998) found that older adults actually reported more self-initiated strategies (solving problem alone) than younger adults. These studies highlight the variety of strategy types that older adults do possess, which is not evident in studies that focus solely on fluency outcome.

Few studies actually find that older adults report ineffective strategies when solving a problem. For instance, D'Zurilla, Maydeu-Olivares, and Kant (1998) found that middle-aged adults reported more rational problem-solving strategies (e.g., deliberate/systematic skills, alternative solutions) than younger adults. Older adults reported more negative-orientation styles (e.g., threatening appraisal of problem, doubting abilities, expect poor outcomes) than younger 
adults. Therefore, the quality of responses peaked in the middle-aged adults and was the lowest with the older age group.

Given the findings reviewed above, older adults are capable of thinking about and reporting many different types of strategies during problem solving despite, perhaps, producing fewer solutions during a task. Thus, the scoring procedures used in everyday cognitive studies should be considered when making assumptions about adult problem solvers. In addition to how one scores an everyday task, researchers should also pay attention to other methodological factors that could affect everyday problem-solving outcome such as how instructions are delivered.

\section{Instruction Manipulation}

Very little is known about the effects of various instructional methods on everyday problem-solving outcome. This is an important area to acknowledge because there appears to be a very diverse set of instructions delivered to respondents who participate in everyday problemsolving studies. Based on this review, instructions tend to vary on two main dimensions: the type of solutions expected (i.e., safe and effective, solutions the reader would use, solutions anyone could use, as many solutions as possible) and the target of the problem (i.e. self, others, or a specific person).

In terms of the type of solutions expected, some participants have been told to "generate as many safe and effective solutions for each item" on an everyday problem-solving task (e.g., Margrett \& Marsiske, 2002; Marsiske \& Willis, 1995; Neely, 2005). These instructions emphasize fluency but also stress quality solutions that are both safe and effective. A similar method has asked participants to generate as many potential solutions as possible to a problemsolving task (Crawford \& Channon, 2002). This method differs slightly in that these instructions 
may elicit solutions not considered to be safe and effective but attempt to target one's entire problem-solving repertoire.

When noting the target of the problem, some researchers ask, "How would you deal with this problem?" or to think about how they would act in a situation (e.g., Berg, et al., 1999; Cornelius \& Caspi, 1987). This method focuses on what the individual (the participant) would do to solve the problem. Some instructions have also emphasized what other people might do by presenting a problem about a person and then asking participants, "What should he/she do" (e.g., Denney \& Pearce, 1989; Denney, et al., 1982). This wording does not limit the participant to only solutions they would do themselves. To target what the respondent might do as well as what others may do, some participants have been asked to "provide as many relevant solutions as possible, even if it is one that you would not choose to adopt" (Artistico, et al., 2003). This wording appears to truly target one's overall repertoire of strategy use. Artistico and colleagues also provided a prompt after the participants claimed to be finished, "Can you think of any additional solutions." For information regarding the differences in the wording of the instructions across various studies, see Appendix A.

It appears that very few everyday problem-solving studies assess the effects of instructions on performance outcome. In a study of practical problem solving among younger, middle-aged, and older adults, Denney and colleagues (1992) provided half of the participants with standard directions and the other half with explicit directions. The standard directions were general instructions that told participants that they should just complete the task, whereas the explicit directions informed participants that they should complete the problems to the best of their ability. Middle-aged and older adults performed better than younger adults when standard instructions were given. However, when explicitly instructed to execute the best performance, 
there were no differences between the age groups. It could be concluded that younger adults, as opposed to middle-aged and older adults, exert the most effort on a task only when explicitly told to do so.

A recent study conducted by Kimbler (2006) examined whether varied instructional supportive messages affected everyday problem-solving performance. Some participants received instructions that provided an emotionally-supportive context. The researcher stressed how important participant contribution was to research and how much their help was appreciated. A second group received instructions that offered practical help. The researcher told the participants that he/she would be available in the other room for assistance. A third group received "standard" instructions without an added supportive message. All participants completed the Everyday Problems Test (EPT, Willis \& Marsiske, 1997), which is a task where this is only one correct solution to a problem. Results of this study suggested that emotionallysupportive messages were more beneficial to everyday problem-solving performance than practical support. The studies reviewed in this section suggest that by simply manipulating wording of everyday tasks, performance outcome may be affected.

Given the diverse directions used in the everyday problem-solving literature, it is difficult to decipher whether respondents are trying to generate as many solutions as possible, generating only effective solutions, reporting solutions that they would consider, or are generating responses that others should consider. Although many everyday problem-solving studies do not report the explicit directions used, there is some evidence that investigators across laboratories vary in the instructions delivered to participants. Addressing this limitation is important because prompting individuals in different ways could affect problem-solving performance, and thus group differences from study-to-study may not be comparable. Varying types of instructions may elicit 
different numbers and types of strategies to everyday problems. The next methodological issue considered is the effects of problem content on problem-solving outcome.

\section{Problem Content}

In addition to the types of instructions delivered, the content of everyday problems also affects how persons from different age groups approach problems. Berg and colleagues (1998) asked participants to report a problem that they have experienced and found that individuals, regardless of their age, indicated strategies that matched the types of problems they described. For example, if participants reported interpersonal problems (e.g., trying to get along with Sara), they tended to report interpersonal strategies (e.g., get Sara to see my point of view). Therefore, strategies generated to solve everyday problems related to the content domain of the problem.

Blanchard-Fields and colleagues (1997) manipulated whether participants received problems considered to be instrumental or interpersonal in nature and assessed the endorsement of strategies based on the four response strategies proposed by Cornelius and Caspi (1987). Interpersonal items dealt with friend conflicts, whereas instrumental items focused on consumerism matters or home maintenance. Findings revealed that response strategies were endorsed differently based on the content of the problem and the age of the participant. For the instrumental domain, middle-aged and older adults endorsed more problem-focused and cognitive-analytical strategies than adolescents and younger adults. Furthermore, passivedependent and avoidant-denial strategies were highly endorsed among the adolescents and younger adults compared to older participants. In the interpersonal domain, there were no age differences in problem-focused strategies, but avoidant-denial strategies were endorsed more often among older adults compared to younger adults. These patterns of findings suggest that problem content and age may interact to affect the types of strategies endorsed. 
Related to the idea that problem content may affect everyday problem-solving performance are the findings from the stress and coping literature which suggests that controllability is important. Specifically, individuals who feel that they are able to change the situation, tend to report more problem-focused strategies than emotion-focused strategies (Vitaliano, DeWolfe, Maiuro, Russo, \& Katon, 1990). Individuals who perceive the problem as unchangeable may indicate more emotion-focused strategies than problem-focused strategies (Vitaliano, et al.). This idea of controllability suggests that the problem at hand, along with individual perceptions, may influence strategy use.

Based on the review, there is relatively little known about the potential affects of methodology on everyday problem-solving outcome, particularly in the areas of scoring, instruction manipulation, and problem content. Published research, however, is more informed about the potential effects of individual characteristics on problem-solving outcome. Although the methodological findings from the current study may help researchers refine their use of scoring methods, instructions, and problem types when assessing age differences in problem solving, individual factors may also explain why differences exist. In addition to age as an individual factor, the current study examined other characteristics that may be related to problem-solving performance: individual experience with a task, task-related self-efficacy, sex, education, and fundamental cognitive abilities.

\section{Reported Experience with Task}

Some experts in the field believe that increasing age is accompanied by an increase in everyday problem-solving expertise (Baltes, 1993) and that older adults use their experience as a compensatory mechanism to allay cognitive declines (Denney \& Pearce, 1989). Therefore, a greater experience with a task, which is likely to be linearly related to age, may positively affect 
problem-solving performance. Theoretical positions may differ and the published findings are equivocal, which warrants further analysis on the effects of experience on everyday problemsolving outcome.

Berg and colleagues (1999) examined whether younger and older adults differed in problem-solving performance on two types of problems (dinner parties vs. doctor visits). They found that younger and older participants did not differ in their reported experience with the two problems. They also found that overall experience did not significantly predict fluency outcome, but older adults did tend to interpret the problem situation based on prior experience more often than younger adults.

Cornelius and Caspi (1987) examined whether experience was related to problem solving. They found that the age groups differed in the level of experience reported, and that in general, older adults reported less experience with problems than younger and middle-aged adults. This difference occurred across various domains (i.e., home, consumer, information, friend, family, coworkers); however, experience was not related to one's endorsement of response strategies.

Lastly, Strough, Patrick, and Swenson (2003) examined hypothetical problem solving related to the neglect of a grandchild and whether experience was related to problem-solving outcome. Although experience did not affect fluency outcome, it did relate to strategy type. Specifically, seeking help strategies (i.e., getting advice or seeking services) were positively related to experience with a problem. Controlling strategies (i.e., change others' behaviors, feelings, or beliefs) was negatively related to experience with a problem.

These studies suggest that there may or may not be age differences in experience on certain problem types, and that experience may or may not predict problem-solving performance. 
Experience may be especially meaningful when assessing both fluency and strategy types.

Experience could explain why individuals report certain types of strategies over others, and perhaps be an explanation for why some individuals score low on fluency outcome assessments. For example, experience may inform an individual that an avoidant-denial strategy did or did not work in the past for a certain type of problem. If the participant knows that it did not work in the past (due to experience), they may not include that strategy on a fluency assessment. The inconsistent findings regarding the role of experience and the importance of determining whether everyday problem-solving tasks have the benefit of experience to protect against age-related declines in fundamental cognition highlight the need to examine individual experience more closely. The next section highlights the importance of self-efficacy on performance, which could potentially relate to experience.

\section{Task-related Self-efficacy}

Self-efficacy may be defined as the subjective appraisal of the extent to which one is capable of performing in a given situation, which is typically based on an individual's past experiences (e.g., Bandura, 1977). Several studies have demonstrated a positive link between self-efficacy and performance on cognitive tasks (e.g., memory; Berry, West, \& Dennehey, 1989; verbal ability; Seeman, McAvay, Merrill, Albert, \& Rodin, 1996). Individuals reporting higher levels of self-efficacy in certain domains tended to attain superior performance in that domain. Therefore, it is likely that individuals with greater task-related self-efficacy would perform better on everyday problem-solving tasks.

Haught and colleagues (2000) examined perceived problem-solving ability as a predictor of practical problem solving. Contrary to the findings that older adults are poorer problem solvers than younger adults (e.g., Denney \& Pearce, 1989), results revealed that older adults 
performed similarly to younger and middle-aged adults in fluency outcome and the quality of their solutions. A possible explanation for this finding could be participant self-efficacy. Older adults were more confident about solving the problems than the other age groups. The authors suggest that the confidence levels among older adults led them to exert more effort compared to younger and middle-aged adults, resulting in a balanced performance of the age groups. On the other hand, the lower levels of confidence in the younger and middle-aged adults could have also affected effort levels and subsequent performance outcome. The overall findings of this study suggest that participants who were more confident about problem solving, despite age, performed better on the practical problems compared to those who were less confident.

Another study assessed perceived self-efficacy between younger and older adults and examined the relation between perceptions and actual problem-solving performance (Artistico, et al., 2003). Some problems were designed to be age relevant for younger adults, and others were designed to be age relevant for older adults. Participants reported higher levels of self-efficacy and performed better on tasks that were relevant to their age group. Specifically, on younger adult problems, younger adults outperformed older adults, and on older adult problems, older adults outperformed younger adults. Thus, subjective appraisals of ability affected cognitive performance.

\section{Sex of Participant}

Several everyday problem-solving studies have examined sex differences in relation to problem-solving performance. The majority of the studies focused on sex differences in strategy types and less often on sex differences in fluency outcome. One study conducted by Neely (2005) addressed both types of outcome. Sex differences were examined between husbands and wives during individual and collaborative problem solving on an open-ended task. Participants 
were instructed to generate as many safe and effective solutions as possible to each hypothetical situation. Results indicated that performance varied by sex on both fluency and strategy effectiveness. This effect interacted with age group: Older males tended to report more solutions when working individually than when working with their wives. Younger females tended to report a more solutions when working individually than when working with their husbands. In terms of the effectiveness of strategies reported, there were no age differences among females, but older males' solutions were safer and more effective than younger males' solutions.

Watson \& Blanchard-Fields (1999) presented participants with a variety of potential responses to family-related problems and asked them to rank the effectiveness of solutions using a Q-sort methodology. Overall, men tended to choose problem-focused and self-oriented strategies to a greater extent than women. Depending on the specific type of family problem described (i.e., teen, relative, spouse, parent), strategy preference differed between males and females. The greatest sex difference occurred for problems where conflict was likely to occur. Women were less self-focused in their solutions and more likely to avoid confrontation than men. Women were also more likely to seek help and social support than men, whereas men were more likely to prefer action-oriented strategies. This finding is in line with research on coping strategies, which suggests women are more likely to use interpersonal and/or emotional strategies than men (Diehl, Coyle, Labouvie-Vief, 1996).

Despite potential sex differences in effectiveness or strategy use during problem solving, Margrett and Marsiske (2002) found that males and females differed on an open-ended problemsolving task (i.e., Everyday Problem Solving Inventory; Cornelius \& Caspi, 1987). Females tended to generate more safe and effective solutions to the open-ended task than males. Overall, 
however, males and females were similar in their problem-solving performance when other tasks were taken into consideration.

Whitfield, Baker-Thomas, Heyward, Gatto, and Williams (1998) reported similar findings in an African America sample. Using an everyday problem-solving assessment with only one correct solution, they found no differences between males and females on the accuracy of problem-solving performance. There were no sex differences within any of the task domains (i.e., house, transportation, food, health, telephone, shopping, finance).

Taken together, the findings regarding sex differences in everyday problem solving suggest that males and females perform similarly when it comes to fluency or accuracy. However, when males and females were assessed on strategy preference or reported usage, sex differences emerged. Understanding how one's sex influences everyday cognition is important, particularly when individuals seek out others, such as their spouse, to aid in routine daily tasks.

Education and Fundamental Cognitive Ability

Other individual characteristics that may influence everyday problem-solving performance include education and fundamental cognitive abilities. Cornelius and Caspi (1987) asked participants to rate the likelihood that they would use a given response strategy to solve a hypothetical situation on the Everyday Problem Solving Inventory. Judges scored the effectiveness of participant choices. Education was unrelated to everyday cognitive outcome.

Using a performance-based assessment of everyday functioning, Diehl and colleagues (1995) asked participants to perform 31 tasks in their own home. These tasks were performed using real-life stimuli such as medicine bottles and brownie mix. The researchers found sizable correlations between fundamental cognitive abilities (inductive reasoning, spatial orientation, verbal comprehension, memory, speed) and the observed performance tasks. Education affected 
performance indirectly through cognitive ability performance. In a subsequent study, Diehl, Marsiske, Horgas, Rosenberg, Sacynski, and Willis (2005) used a revised version of the performance-based measure of everyday cognition. The findings regarding the relation between fundamental cognitive abilities and education were similar to the previous study, which suggests that fundamental cognitive abilities may underlie everyday cognitive performance.

The findings reviewed in this section regarding how individual factors may or may not relate to everyday problem-solving outcome are particularly relevant to the current study. This study attempts to explicate the challenge of targeting individual factors that affect everyday problem-solving outcome. A better understanding of individual factors that affect problemsolving outcome may help to better explain potential age differences found in the published literature.

\section{Study Rationale and Specific Aims}

The empirical questions for this study were to examine whether methodological components of a study and/or characteristics of an individual affect the assumptions regarding age differences in everyday problem-solving outcome. This study also contained an exploratory component. Whether variations in strategy use can lead to separate classifications of problem solvers was investigated. These groups of problem-solvers were examined to note whether there were any systematic differences among subgroups based on individual factors such as past experience self-efficacy, age, sex, and cognitive abilities.

Published findings, particularly in fluency, highlight poorer performance in older adults' problem-solving ability because older adults typically do not generate as many solutions as their younger counterparts. This addresses an important concern, as older adults may be erroneously labeled as less effective problem solvers solely based on findings from limited scoring 
procedures. Studies that find age effects should look deeper into possible methodological and individual explanations for why one group of individuals may have an advantage over others in a laboratory setting.

Emphasizing an age difference in the everyday cognitive literature could inevitably lead to labeling older adults as ineffective problem solvers who lack an extensive repertoire of solutions when approaching problems. If the explanation of older adults' everyday cognitive performance continues to center on strategy fluency, negative stereotypes about aging may be strengthened, which could possibly interfere with collaborative interactions between younger and older adults in everyday life. As individuals continually seek others as sources of information and help in everyday life, it is imperative that accurate interpretations regarding age groups in problem-solving studies be made. Comparing various methodologies may help explicate this age-related concern.

Manipulating components of everyday tasks such as scoring procedures, instructions, and problem content, as well as examining individual characteristics such as reported experience and self-efficacy are important steps in teasing apart the assumptions about age differences mentioned in previous literature. The fact that older adults are capable problem solvers who use an array of proactive response styles needs to be highlighted, as older adults may be more selfinitiated and less dependent in everyday life situations than some may assume. The findings of the current study may increase the awareness among researchers regarding the importance of several factors on everyday cognitive performance. Additionally, these findings will acknowledge how individuals may be grouped together or separately based on the types of strategies reported on everyday tasks. 
To test the central hypothesis that individual and methodological factors significantly affect problem-solving outcome and subsequent explanations about age differences, the current study has three specific aims:

(1) Explore the effects of age, instruction manipulation, and problem content on everyday problem-solving fluency and strategy types.

(2) Investigate classifications of problem solvers based on strategy types reported

(3) Examine whether selected factors relate to everyday problem-solving fluency and problem solvers subtypes.

\section{Research Questions and Hypotheses}

The current study centered on three primary research questions. The first question addressed group differences based on age, instruction, and problem content in everyday problemsolving fluency (i.e., number) and strategy types (i.e., proactive responses). This question addressed important methodological considerations. The second question addressed whether there were identifiable subgroups in the sample that differed in problem-solving strategies. This question was exploratory. To better understand individual factors that relate to problem-solving fluency and problem-solver classifications, a third question examined whether there were meaningful relations between selected factors and fluency outcome and whether subgroups of problem solvers systematically differed in individual characteristics.

\section{RQ1: Group differences in problem-solving fluency and strategy type}

\section{Fluency Scoring}

Hypothesis 1: A main effect of Age was expected such that younger and middle-aged adults would generate more solutions than older adults (Denney \& Pearce, 1989). 
Hypothesis 2: A main effect of Instruction was expected (Denney, et al., 1992). The Others group was expected to generate more solutions than the Self group. This hypothesis was based on wording of the instructions, as it was expected that participants in the Self group would limit strategies based on what they would do rather than considering what any person could do.

Exploratory: Hypotheses regarding the two expected main effects are supported with previous literature; however, there were no a priori hypotheses regarding the effects of Problem Content on fluency outcome because this relation has not been examined in previous studies (with home and friend problems). The interaction between age, instruction, and problem content on fluency outcome was also exploratory. Congruent with prior findings (Neely, 2005), it was acknowledged that everyday problem-solving outcome could result in a three-way interaction between Age, Instruction, and Problem Content. Strategy Types

Hypothesis 3: A main effect for Age was expected with older adults producing a lower proportion of proactive strategy types (and thus higher proportion of passive strategies) than younger adults (e.g., Blanchard-Fields, et al., 1995; Berg, et al., 1998; D’Zurilla, et al., 1998).

Hypothesis 4: A main effect for Problem Content was hypothesized. Due to the possible negative consequences of acting passively or avoiding friends (e.g., losing that friend), it was expected that the proportion of proactive strategy types would be higher among the Interpersonal (friend) problems than the Instrumental (home) problems.

Hypothesis 5: An Age x Problem Content interaction was expected. Based on the findings from Blanchard-Fields and colleagues (1997), it was expected that when completing Instrumental (home) problems, middle-aged and older adults would generate a higher proportion 
of proactive strategies than younger adults. In regard to Interpersonal (friend) problems, no age differences in proactive strategies were expected (Blanchard-Fields, et al., 1997).

Exploratory: Based on the limitation in the published literature regarding the effects of instruction methods on everyday problem-solving performance, no a priori hypotheses regarding instruction were devised.

RQ2: Classifying problem solvers based on five proportions of strategy types

Hypothesis 6: Due to the various strategy types that individuals use to solve problems, as well as differing ability levels, it was expected that different subgroups of problem solvers would emerge based on the four response strategies used in Cornelius and Caspi (1987) and the addition of a commentary remark category in the current study. These subgroups were expected to differ in their patterns of high and low proportions of strategies, which would permit the ranking of the classifications from least proactive (passive-dependent, avoidant-denial) to most proactive (problem-focused, cognitive-analytical) problem solvers. The number and subtypes of problem solvers was exploratory.

RQ3: Relations between selected factors, fluency outcome, and problem-solver subgroups

\section{Fluency Outcome}

Hypothesis 7: Individual factors such as age, education, cognitive ability, experience, and self-efficacy were expected to predict both Instrumental and Interpersonal problem-solving fluency (e.g., Haught, et al., 2000; Margrett, 1999).

\section{Problem-solver Subgroups}

Hypothesis 8: Based on the literature regarding fluency, individual factors (e.g., age, experience, self-efficacy) were expected to demonstrate meaningful relations to problem-solver subgroups (Blanchard-Fields, 1986; Blanchard-Fields, et al., 1995; Haught, et al., 2000). It was 
also expected that status variables (e.g., sex, age group) would significantly differentiate the subgroups.

\section{Method}

\section{Design}

The design of the study included one within-subjects factor (Problem Content) and two between-subjects factors (Age and Instruction). The within-subjects factor, Problem Content, referred to the type of problem to be solved and consisted of two levels or domains (Interpersonal and Instrumental). Interpersonal items included problems related to conflicts with friends, whereas Instrumental items included problems related to home management. The first between-subjects factor, Age, consisted of three levels and represented the three age groups in the study (younger, middle-aged, older adults). The second between-subjects factor, Instruction, consisted of two levels and involved the manipulation of the task directions (i.e., Self, Others; see the Instruction group section in the Procedure for a description). Participants were randomly assigned to the Instruction Group.

\section{Procedure}

Participants were initially asked questions regarding basic demographic information (i.e., age, sex) and whether or not they were willing and able to read and write. These questions determined eligibility for the study. Screening was done via telephone, electronic mail, or inperson. Persons who qualified for the study were then scheduled during designated available times.

Testing sessions occurred either individually $(N=25)$ or in a group setting $(N=108)$ with one or two administrators present. There was a total of 19 group sessions. There were no group differences between individual and group testing in basic demographic information or 
fundamental cognitive abilities (see Table 1). Testing sessions were also held at either community centers, meeting rooms at various organizations, or university offices, classrooms, or laboratories. Participant characteristics of those tested at home or in a public setting may be seen in Table 2. Participants were randomly assigned to one of two Instruction conditions. One half of the participants received Self Instructions, and one half of the participants received Others Instructions. Table 3 compares the characteristics of the participants in the two instruction conditions.

During in-person sessions, participants individually completed all of the paper and pencil questionnaires, problem-solving tasks, and covariate assessments. Figure 1 depicts the general session procedure, measures used, and the number of participants in each condition. First, participants completed two timed cognitive assessments, which took approximately 15 minutes. After the completion of the timed measures, the remainder of the study involved participants working at their own pace. They completed a demographics questionnaire (e.g., age, education, income), which took about 10 minutes, and then participants completed the problem-solving portion of the study followed by the remaining covariate assessments.

During the problem-solving portion, participants were given four everyday vignettes to solve. They were instructed to thoroughly read the directions on the cover sheet of each measure. Each vignette was presented on a separate page and included a reminder of the appropriate instructions (based on the randomly assigned condition) at the top of each page. Participants generated and listed solutions to each of the four vignettes. The problem-solving portion of the study lasted approximately 30 minutes. Finally, participants completed the remaining covariate assessments consisting of questions related to past experience, whether the situation was currently a problem, and perception of one's ability to solve the problems (i.e., self efficacy). 
The covariate assessments took approximately 15 minutes to complete. Procedural elements related to instruction group assignment are discussed below.

\section{Instruction Group}

Each participant individually completed everyday problem-solving vignettes from the Everyday Problem Solving Inventory (EPSI; Cornelius \& Caspi, 1987). All participants completed the same four problems, which were counterbalanced. Counterbalancing resulted in four different forms with alternating home and friend problems. Each of the four problems occurred both first and last across the four forms. Although this is not a true counterbalancing, it served the intentional purpose of minimizing the effects of practice or fatigue on any given problem.

The instructions varied between groups based on random assignment to an Instruction condition. Therefore, the experimental manipulation was the type of instructions given to the participant. The instructions were typed at the top of each page with the vignette below it. The rationale for placing the directions before each item was to prompt the participant each time they completed a problem to be certain that they were reading and understanding the directions. There was a Self Instruction group and an Others Instruction group. Both instruction groups were comparable to prior everyday problem-solving studies (See Appendix A) and assessed the effects of instruction delivery on participants' fluency scores and strategy types.

Self Instruction Group. The Self Instruction group was instructed, “After you imagine how you would approach the problem, write down as many solutions as possible to the problem." This condition focused on the individual and is similar to studies that ask participants what they would do, how they would deal with the situation, or what they would consider when 
solving a problem (e.g., Berg, et al., 1999; Cornelius \& Caspi, 1987; Denney, et al., 1982, Marsiske \& Willis, 1995).

Others Instruction Group. For the Others Instruction group, participants were instructed, "After you imagine how the person could approach the problem, write down as many solutions as possible to the problem." This condition focused on what any person could do and is similar to studies that provide a scenario about a person and ask the participant what he/she (the character in the vignette) could do to solve the problem (e.g., Artistico, et al., 2003; Blanchard-Fields, et al., 1995; Denney \& Pearce, 1989; Flinn, 2006; Haught, et al., 2000; Heidrich \& Denney, 1994; Strough, et al., 2003; Staudinger \& Baltes, 1996; Watson \& Blanchard-Fields, 1998).

\section{Participants}

A total of 133 individuals (54 males, 79 females) participated in the study. These participants included 52 younger, 41 middle-aged, and 40 older adults from West Virginia and Pennsylvania. The younger adult group was comprised primarily of college students. Individuals were recruited through community centers, media advertising, religious affiliations, participant referral, and personal contacts. Participants were tested in a university setting $(N=83)$, a community center $(N=15)$, or at the participants' homes $(N=35)$. Individuals received extra credit in a psychology course or requested to have their name placed in a drawing for a $\$ 20.00$ honorarium for their participation. At the end of data collection, there were five drawings for the cash prizes.

\section{Inclusion Criteria}

There were two inclusion criteria for the study: (1) Participants had to be at least 18 years of age, as the study sought to understand everyday problem solving in an adult sample, and (2) 
Participants had to be able to read and comprehend material written in English as well as be able to write out responses to various questionnaires.

\section{Total Sample}

There were 133 participants who completed the entire study. One middle-aged male participant who was tested at home refused to finish the remainder of the study components after the timed cognitive tests. No other potential participants declined participation, and no participants were screened out of the study based on the two inclusion criteria.

The final sample for the study ranged in age from 18.11 to 85.95 years. Age was exactly calculated based on the year, month, and day of participation compared to the year, month, and day of birth. The mean age of younger, middle-aged, and older adults was $20.64(S D=3.02)$, $51.62(S D=4.88)$, and $69.92(S D=6.82)$ years, respectively. The majority of the participants were White $(93.2 \%)$, highly educated $(M=15.00$ years, $S D=3.16)$, and earned a median annual income of about $\$ 50,000$ (range $=\$ 2,000-\$ 50,000$ and above). Of the total sample, 38.3\% were single, $41.4 \%$ were married ( $M$ length of marriage $=25.88, S D=16.63$ years), $6.0 \%$ were separated or divorced, $10.5 \%$ were widowed, and 3.8\% chose an "other" category. As expected, participants in the three age groups differed significantly in age, education, and income (See Table 4). In terms of other outcome variables, participants in the three age groups also differed in verbal ability and inductive reasoning ability (See Table 5).

\section{Measures}

The current study examined group differences in everyday cognitive performance and individual predictors of problem-solving outcome. A brief summary of the measures used are provided in Appendix B. 


\section{Telephone Screening and Demographics}

Participants answered basic demographic information as part of a screening process. As previously mentioned, all participants who were interested in partaking in the study were given the chance to complete the study because they met the inclusion criteria. Several additional questions regarding background information were obtained via a demographics questionnaire at the beginning of the in-person session. Questions assessed standard demographics including age, education, income, marital status, and ethnicity. A few questions about physical and mental health were also included in this questionnaire. The Personal Data Form created for use in the current study may be found in Appendix $\mathrm{C}$ and has been used in previous studies in our laboratory.

Everyday Problem Vignettes: Primary Outcome

The Everyday Problem Solving Inventory (EPSI; Cornelius \& Caspi, 1987) is widely used in the developmental and cognitive literatures (e.g., Blanchard-Fields, et al., 1995, 1997; Cornelius \& Caspi, 1987; Dimitrov, Grafman, \& Hollnagel, 1996; Margrett \& Marsiske, 2002; Neely, 2005; Willis \& Marsiske, 1995). The items on this measure assess aspects of social and instrumental endeavors that individuals face in their daily lives, and thus it is relevant for an everyday problem-solving study.

Description of Original Assessment. The original Everyday Problem Solving Inventory (EPSI; Cornelius \& Caspi, 1987) assessed four response styles (i.e., problem-focused, cognitiveanalytical, passive-dependent, avoidant-denial) that individuals could use to solve everyday dilemmas. This original close-ended assessment by Cornelius and Caspi consisted of 48 hypothetical vignettes. The vignettes represented six different content domains, which included: 1) family conflict resolution, 2) friend conflict resolution, 3) coworker conflict resolution, 4) 
complex and technical information management, 5) consumerism, and 6) home management. Cornelius and Caspi instructed participants to imagine that they were experiencing the given problem, and then asked them to rate the likelihood that they would use a particular response style. There were four response styles per problem situation, and each response style was rated using a 5-point Likert-type scale, which ranged from "definitely would not do" to "definitely would do".

Description of Current Study Vignettes. The EPSI format used in the current study differs slightly from the original assessment (See Appendix D and E for current study EPSI forms). Response style options were not given to participants, as open-ended vignettes were expected to more accurately facilitate real-life problem solving and reasoning. Practically, using the original format of the EPSI would not allow for the assessment of fluency outcome or the coding of strategy types. Therefore, participants were asked to generate solutions to each problem-solving vignette in an open-ended format.

Four items from the original EPSI assessment were used (i.e., two Instrumental home and two Interpersonal friend items). The rationale for choosing the two domains included three points. First, based on the face validity and content of the problems, the items chosen should be equally relevant to younger, middle-age, and older adults (Strough, 2004). Second, a previous study concluded that the friend and home domains may be classified as Interpersonal and Instrumental domains, respectively (see Marsiske \& Willis, 1995). If there are performance differences based on the content of the problem, researchers will need to consider separately assessing problems in different domains (e.g., Instrumental vs. Interpersonal items). Third, these two domains have been used in previous studies (Blanchard-Fields, et al, 1995; Margrett \& Marsiske, 2002; Neely, 2005; Strough, 2004), allowing for comparability to prior literature. 
The Instrumental problem content involved home management issues. One Instrumental vignette stated, "A person has let their home become too cluttered with items they use infrequently but which have much sentimental value for them." The second Instrumental vignette stated, "Because of a lack of time, a person has let household chores pile up." The Interpersonal problem content involved conflicts with friends. One Interpersonal vignette stated, “A person lost or broke an expensive item they borrowed from a friend". The other Interpersonal vignette stated, "A person has done something that offended one of their friends."

Coding/Scoring to Create Fluency and Strategy Variables. Responses to the everyday problems were scored to determine the quantity (fluency) and strategy types of an individual's problem-solving repertoire. Specifically, the total number of solutions was summed for a fluency score (e.g., Crawford \& Channon, 2002; Denney \& Pearce, 1989; Denney, et al., 1982; Margrett \& Marsiske, 2002; Neely, 2005). In addition, strategy types were examined using an existing coding scheme (e.g., Blanchard-Fields, et al., 1995; Cornelius \& Caspi, 1987). Generating a greater number of solutions could be thought to promote more flexibility in problem-solving ability than generating fewer solutions; a greater number of solutions increase one's problemsolving repertoire (Denney \& Pearce, 1989; Sinnott, 1989). Strategy type, on the other hand, can provide information regarding the effectiveness of everyday problem solving (Strough, 2004).

Bracketing/Fluency Coding. Several steps were taken to determine the total number of solutions generated in each problem content type (i.e., Instrumental and Interpersonal). First, research assistants organized participant responses by placing brackets around each separate solution. For practice, bracketing was first completed with protocols from a previous study with similar problem types (Neely, 2005). Percent agreement was calculated based on whether each coder agreed or disagreed on each response that was bracketed. Once agreement reached $90 \%$, 
coders moved on to the actual study protocols. What constituted an independent solution was determined using predetermined bracketing guidelines (see Appendix F; Margrett \& Marsiske, 2002; Marsiske and Willis, 1995; Neely, 2005).

After each solution was bracketed for independence, each bracketed solution was then inspected for redundancy (whether a participant wrote down the same solution but in different words), commentary (statements about the problem or personal experience), and nonsense statements (incomprehensible or irrelevant to problem content), which did not count towards the fluency score (see Appendix G). Thus, fluency was an indicated of the total number of unique solutions reported. Responses for each item were then summed to form two fluency scores; each participant received an Instrumental fluency score and an Interpersonal fluency score. Therefore, the sum of the two home items created an Instrumental score, and the sum of the two friend items created an Interpersonal score. This fluency score is considered to represent one's ability to be flexible in responding, such that alternate solutions are available if one solution does not solve the problem (Sinnott, 1989). Percent agreement for fluency was calculated based on whether or not each coder indicated that it was a unique solution for fluency scoring or not. The overall inter-rater reliability for bracketing was $93.1 \%$, and the overall inter-rater reliability for fluency was 96.1\% (Instrumental home) and 94.9\% (Interpersonal friend). See Table 6 for a specific breakdown of coding reliability.

Strategy Coding. The coding system was based on the four response categories described in Cornelius and Caspi (1987). The four problem-solving strategies included problem-focused action, cognitive problem analysis, passive-dependent behavior, and avoidant thinking and denial. In general, problem-focused and cognitive strategies are considered to be more proactive strategies (self-initiated) than passive-dependent and avoidant-denial strategies. Problem-focused 
and cognitive strategies represent instrumental strategy types, whereas the latter two strategies represent strategies used to manage emotions (Blanchard-Fields, et al., 1995). In addition to the strategies described in Cornelius and Caspi and Blanchard-Fields and colleagues, coders in the current study also assessed for commentary remarks and nonsense remarks (See Appendix H for strategy coding guidelines).

Below is a brief description of each strategy type, which aided in the coding process (See Appendix I for exemplar solutions to the problem vignette "Because of a lack of time, a person has let household chores pile up").

Problem-Focused Action. Problem-focused actions refer to: (a) behaviors that directly target the problem and its effects and (b) behaviors that are overt and self-initiated (e.g. the individual directly takes control of the problem rather than relying on someone else).

Cognitive Problem Analysis. Cognitive analysis deals with personal perceptions of the problem. These solutions include the cognitive efforts one uses to: (a) understand the situation better, (b) make a subjective appraisal of the situation, (c) logically analyze the situation, (d) use a different perspective to interpret the problem, or (e) create a plan to solve the problem.

Passive-Dependent Behavior. The passive-dependent response style includes (a) withdrawing from the situation, (b) depending on others to solve the problem, or (c) lacking selfinitiation to alter the problem.

Avoidant Thinking and Denial. Avoidant-denial strategies involve: (a) attempting to manage the meaning of the problem through cognitive avoidance, (b) denying one's responsibility in the situation or the whole situation itself, (c) attending to something other than the problem itself, (d) suppressing one's emotional reaction to the situation, or (e) expressing one's emotional reaction to the situation. 
Commentary Remarks. Participant commentary involves comments about (a) oneself, b) the problem, or (c) the context of the problem. These commentary remarks also included participant words of wisdom. Commentary remarks did not involve an actual strategy directly related to the problem and was not used in the fluency analyses for the first research question.

Nonsense Remarks. Nonsense remarks deal with solutions that are (a) incomprehensible to the reader or (b) unfinished solutions that did not convey an idea clearly. Nonsense remarks were not considered to be actual strategies and occurred very infrequently. This response style was not used in any analyses of the study.

Other Category. The other category involved strategies that could not easily fit into the strategy types described above. The few responses reported in this category included solutions that were considered aggressive or unlawful. Due to the infrequence of this category and the interest in passive and proactive solutions, these few responses were not included in the analyses of the current study.

To determine the types of strategies participants reported to solve the hypothetical problems, two coders were trained in the seven strategy types mentioned above (BlanchardFields, et al., 1995; Cornelius and Caspi, 1987). Initial training involved using forms from a previous study that used similar problem-solving items (Neely, 2005). Percent agreement was calculated based on whether the coders coded the strategy the same or different. Once $90 \%$ agreement was reached during practice and the coders were consistent within each strategy type, they were able to move on to the actual study protocols. Regular meetings were held to assess percent agreement. During these meetings, areas of disagreement were targeted and noted on the coding guidelines. Overall inter-rater reliability was $98.9 \%$. Kappas were also calculated as a more stringent form of reliability (see Table 6 for Kappas and breakdown by strategy type). 
For reasons of the parsimony and statistical power, the problem-focused and cognitiveanalytical strategies were collapsed and labeled as "proactive" strategies and the passivedependent and avoidant-denial strategies were collapsed and labeled as "passive" strategies. This combination was justified for two reasons. First, the problem-focused and cognitive-analytical strategies were significantly correlated (friend $r=.22$; home $r=.21$ ) as well as the passivedependent and avoidant-denial strategies (friend $r=.34$; home $r=.18$ ). Second, this combination allowed us to conduct two statistical tests instead of four. To create a proactive proportion, the sum of the problem-focused and cognitive-analytical strategies was divided by the fluency score. Therefore, all participants received one proportion score for proactive strategies, which acted as the main dependent measure for the first research question. Individual strategy types were used for the second and third research questions, which examined types of problem solvers because the number of statistical tests for these research questions was not an issue.

EPSI Psychometrics. The original close-ended EPSI assessment (Cornelius \& Caspi, 1987) had a Spearman-Brown spilt-half reliability of .92. Previous studies using open-ended items of the EPSI also reported high internal consistency $(\alpha=.86$; Margrett $\&$ Marsiske, 2002, $\alpha$ $=.87$; Neely, 2005). Internal consistency for the four EPSI vignettes in the current study was .81.

\section{Additional Study Components}

Fundamental Cognitive Abilities. The fundamental cognitive abilities examined in the current study involved two common abilities tested in a traditional laboratory setting. Inductive reasoning, which is the ability to infer relationships from specific information, was assessed using the Letters Series Test (Blieszner, Willis, \& Baltes, 1981). Participants were presented with a series of letters, ranging from 7-15, which represented a pattern. Participants were asked to choose which letter comes next in the series out of the five answer choices provided. 
Participants were given 4 minutes to complete as many of the 20 items as possible. The measure was scored using the total number of correct responses in the time allotted $(\alpha=.90, n=131)$. Inductive reasoning ability significantly related to individual everyday problem-solving performance on the EPSI $(r=.29 . p<.01)$. Verbal ability was assessed using the Verbal Meaning Test (Thurstone, 1962). Participants were asked to identify the correct definition of 30 words from a list of five choices. Participants were given three minutes to complete this assessment and were told to guess when unsure of a response. The measure was scored by summing the total number of correct responses in the time allotted $(\alpha=.87, n=131)$. Verbal ability also significantly related to individual performance on the EPSI $(r=.20, p<.05)$.

Perceptions Pertaining to the Vignette. Participants were asked to answer questions gauging past and current experiences with each problem vignette as well as one's perception of his or her ability (i.e., self efficacy) to solve the problems. These questions were placed at the end of the problem-solving session to avoid biasing or interfering with fluency and strategy type while completing the vignettes.

There were four perception items, and each item required participants to endorse their response using a 5-point Likert scale. The scale ranged from (1) strongly disagree to (5) strongly agree (See Appendix $\mathrm{J}$ for perception measure/items). A correlation analysis was conducted to examine whether any of the items could be combined for reasons of parsimony in later analyses. The correlation analysis suggested that the two items assessing task-related self-efficacy were highly related within both Instrumental and Interpersonal domain; thus these two items were combined (Instrumental $r=.57$, Interpersonal $r=.64$ ). Participants received an average score for perceptions related to Instrumental home items and an average score for perceptions related to Interpersonal friend items. Therefore, each participant received a past experience score for home 
and friend problems, a current experience score for home and friend problems, and a selfefficacy combined score for home and friend problems. Higher scores represented stronger agreement with each perception statement ( $\alpha=.69$ for overall measure, $n=133)$.

Results

\section{Overview of Analyses}

The results are divided into three main sections corresponding to the primary research questions. These sections are also further subdivided by the outcome variables that the analyses address (i.e., the two scoring methods; fluency vs. strategy type). The first two sets of analyses examined group-level differences. They were conducted using the total number of solutions generated (i.e., fluency) as well as the proportion of proactive strategies (i.e., type of solution). The second set of analyses was exploratory and classified individuals into different subgroups of problem solvers based on their use of the five different strategy types (i.e., problem-focused, cognitive-analytical, passive-dependent, avoidant-denial, commentary). The last set of analyses examined predictors of problem-solving fluency and those exploratory subgroup classifications. Alpha was set equal to .05 for all analyses.

\section{Data Management}

\section{Missing Data}

To minimize the amount of possible missing data on the Everyday Problem Solving Inventory (EPSI), the researcher checked each measure for blank responses and asked the participant whether it was intentionally blank or accidentally skipped. If it was accidentally skipped, the researcher asked the participant to complete the measure. This pertained to the demographic measures and the problem perception questionnaire, as participants could not go back to complete missed information on the everyday problem-solving items. Participants were 
told to write down "I don't know" on the page if they could not think of a solution rather than leaving it blank. They were also told that by doing so the researchers would know they attempted the problem and did not accidentally skip it. As a result of these techniques, there were no missing data for the EPSI or the problem perception questions. The only missing data in the study included a few participants who refused to include their income or education.

\section{Outliers}

Prior to conducting any analyses, all data were examined for outliers that could affect the results of the study. Data from 133 individuals were examined. Outliers were detected using standardized residuals falling outside the range of -3 to +3 (Norusis, 2002). Three outliers were detected for the first analysis which examined the effects of Age and Instruction on fluency performance. These three participants, who were all middle-aged adults, reported substantially more responses compared to the rest of the sample. These data was not included in the fluency analysis $(N=130)$.

One outlier was detected for the second analysis which examined the effects of Age and Instruction on the proactive proportion. The responses of this participant were very low on the proactive category and very high on the passive category. This middle-aged participant was excluded from the response style analysis $(N=132)$.

For the clustering procedure, a total of 10 outliers were present. One middle-aged participant had extremely low problem-focused responses and extremely high avoidant-denial responses. One older adult had extremely high cognitive-analytical responses and commentary remarks. Three participants had high cognitive-analytical responses, three had high avoidantdenial responses, and two had high commentary remarks. These 10 participants were not 
included in the analysis $(N=123)$, as extreme outliers are very likely to affect the clustering procedure and should be eliminated (e.g., Borgan \& Barnett, 1987; Smith \& Baltes, 1998).

The fourth analysis used fluency outcome as the dependent variable and excluded the same three participants mentioned for analysis $1(N=130)$. The fifth analysis used problemsolver response styles and excluded the same 10 participants mentioned in the clustering procedure.

\section{RQ1: Group Differences in Problem-solving Fluency and Proactive Responses}

The purpose of this research question was to assess whether group differences varied based on the type of scoring procedure used to assess problem-solving performance. This section is divided by the two methods of scoring used in the study; beginning with the total number of solutions (i.e., fluency) followed by the proportion of proactive strategies.

Analysis 1: Group Differences in Fluency Outcome on the EPSI

Individual fluency scores were calculated by summing the total number of unique solutions across two items in each problem domain. Specifically, each participant received two separate scores (an Interpersonal score and an Instrumental score). The two interpersonal items were significantly correlated $(r=.48)$, and the two Instrumental items were significantly correlated $(r=.66)$. In addition to wanting to have more than one item of assessment for both instrumental and interpersonal domains, the significant correlations justified combining the two specific items in each domain. Interpersonal fluency scores for the sample ranged from 2 to 21 $(M=8.34, S D=3.47)$, and Instrumental fluency scores ranged from $2-28(M=10.87, S D=$

5.08). Table 7 provides the means and standard deviations of the fluency scores by age group.

To assess group-level performance differences in fluency outcome, a 3 (Age: younger, middle-aged, older) x 3 (Instruction: self, others) x 2 (Problem Content: instrumental, 
interpersonal) repeated-measures analysis of variance (ANOVA) was conducted. Problem Content referred to the within-subjects factor. Age and Instruction referred to the betweensubjects factors. The dependent measure was the fluency sum obtained on the EPSI measure.

Main effects for Age and Instruction were expected. Younger and middle-aged adults were expected to outperform older adults, and participants receiving the Others instructions were expected to outperform participants receiving the Self instructions. The interactions of Age and Instruction by Problem Content were exploratory.

The analysis revealed significant main effects for Instruction, $F(1,124)=5.52, p=.020$, $\eta=.04$, and Problem Content, $F(1,124)=47.46, p=.001, \eta=.28$. As expected, participants in the Others condition $(M=10.36)$ generated more solutions than participants in the Self condition $(M=8.87)$. For Problem Content, participants generated more solutions on the Instrumental problems $(M=10.95)$ compared to the Interpersonal $(M=8.28)$ problems. These main effects were qualified by an Age by Instruction interaction, $F(2,124)=3.86, p=.024, \eta=.06$ (see Figure 2), and an Age by Problem Content interaction, $F(2,124)=3.47, p=.013, \eta=.07$ (see Figure 3). There were no other significant findings for fluency outcome (See Table 8).

Follow-up tests were conducted to permit interpretation of the two interactions. Independent-sample $t$-tests were conducted to assess for differences between age groups. First, follow-up tests were performed for the Age by Instruction interaction. In terms of the participants in the Self Instruction group, younger adults $(M=20.35)$ generated significantly more solutions than older adults $(M=15.85)$. Middle-aged individuals $(M=17.05)$ did not differ from the other two age groups. In terms of the participants in the Others Instruction group, middle-aged individuals $(M=24.50)$ generated significantly more solutions than both younger $(M=19.35)$ and older $(M=18.30)$ adults. 
Follow-up tests were next assessed for the Age by Problem Content interaction. In terms of Instrumental problems, middle-aged adults $(M=12.40)$ generated significantly more solutions than older adults $(M=9.73)$. Younger adults $(M=10.64)$ did not differ from the other two age groups. In terms of Interpersonal problems, younger adults $(M=9.21)$ generated significantly more solutions to the Interpersonal problems than the older adults $(M=7.35)$. Middle-aged adults $(M=8.18)$ did not significantly differ from the other two age groups.

Analysis 2: Group Differences in Proactive Strategies on the EPSI

A second ANOVA also examined group-level differences but was conducted using the proactive strategy proportion as the dependent variable. The proactive strategy proportion was computed by taking the total number of problem-focused and cognitive-analytical strategies and dividing that sum by the overall total number of solutions provided (i.e., proactive sum/total overall solutions $=$ proactive proportion). Participants received a proactive proportion for both Instrumental (Home) and Interpersonal (Friend) problems. The rationale for including a proportion score rather than using the raw number of strategies produced in each category is due to the hypothesis that relying on fluency (e.g., raw scores) may penalize individuals who only include a few responses to the hypothetical situations. The purpose of this study was to examine how fluency outcome and the types of strategies used could influence age differences; thus a proportion score was used. Instrumental proactive proportions ranged from $.46-1.00(M=.79$, $S D=.14)$, and Interpersonal proactive proportions ranged from .36-1.00 $(M=.84, S D=.17)$. The means and standard deviations for the proactive proportions by age group can be seen in Table 7.

To assess group-level performance differences in proactive strategies, a 3 (Age: younger, middle-aged, older) x 3 (Instruction: self, others) x 2 (Problem Content: instrumental, 
interpersonal) repeated-measures analysis of variance (ANOVA) was conducted. For this analysis, the dependent measure was the proportion of proactive strategies reported on the EPSI measure.

A main effect for Age and Problem Content were expected. Older adults were expected to be less proactive than the other age groups, and participants were expected to be more proactive on Interpersonal problems compared to Instrumental problems. An Age by Problem Content interaction was also expected. Instructional effects were exploratory.

The analysis revealed a significant main effect for Problem Content, $F(1,126)=8.45, p$ $=.004, \eta=.06$. As expected, participants were more proactive (and less passive) on the Interpersonal problems $(M=.84)$ than the Instrumental $(M=.79)$ problems. This main effect was qualified by a significant Age by Problem Content interaction, $F(2,126)=4.01, p=.021, \eta=$ .06. (see Figure 4). There were no other significant findings for proactive responses (see Table 9).

Follow-up $t$-tests were used to interpret the Age by Problem Content interaction. These tests revealed that when completing Interpersonal Problems, older adults $(M=.89)$ were significantly more proactive than younger adults $(M=.80)$. Middle-aged individuals $(M=.83)$ did not differ from the other two age groups. The follow-up $t$-tests for proactive performance on Instrumental tasks revealed that all age groups generated similar proportions of proactive strategies (younger $=.80$, middle-aged $=.78$, older $=.79$ ).

RQ2: Classifying Problem Solvers based on the Proportions of Five Strategy Types Analysis 3: Problem-solver Subgroups and Profiles

Cluster analysis is a useful tool to identify individuals who are similar and dissimilar to each other. The purpose of this cluster analysis was to explore (a) how many subgroups of 
problem solvers would cluster together based on profiles of five different problem-solving response styles; (b) the nature of the different subgroups (e.g., whether the subgroups could be ranked as most effective to least effective problem solvers); and (c) whether there were group differences between the cluster profiles on selected factors.

Cluster Analysis Procedure. Prior to conducting the cluster analysis, several methodological options were considered (Borgen \& Barnett, 1987). First, a method for measuring the proximity between each pair of participants was determined. The Euclidean method has been the most common method used in psychological research (Borgen \& Barnett; Smith \& Baltes, 1998) and was used in the current study. Second, the type of linkage method to use was determined. According to Borgen and Barnett, Ward's minimum variance technique is the most effective and most commonly used method across various studies in psychology, particularly in conjunction with the Euclidean method. Thus, Ward's method was used in the current analysis. Third, the effectiveness of the method may be decreased by the presence of extreme outliers (Smith \& Baltes). Therefore, to avoid a potential problem with validity (misinterpretation of groups), the data were screened for outliers. Data points that fell above and below three standard residuals on the regression line were eliminated from the data analysis (See Data Management section above for details). Fourth, to avoid potential problems associated with comparing Euclidean distance (which was how cluster membership was determined), the five strategy types used in the analysis were standardized as z scores $(M=0, S D=1)$ before entry into the cluster analysis. Higher $z$ scores on a response style indicated a greater use of that strategy.

Based on the decisions outlined in the previous paragraph (e.g., outlier elimination), the following steps were taken to conduct and interpret the cluster analysis. First, using the 
Euclidean method, the proximity of the participants was calculated using the proportions of five strategy types. These strategies included the four originally-coded strategy types (problemfocused, cognitive-analytical, passive-dependent, avoidant-denial) as well as participant commentary remarks. Using the five strategies instead of the combined response styles differed from the previous analyses that collapsed the strategies into proactive and passive because (a) power would not be an issue in the cluster analysis, (b) important information about problem solvers could be lost if the strategy types were combined, (c) participants varied in their use of all five strategy types, and (d) detailed information about problem-solving strategies was needed in order to classify subgroups of problem solvers based on strategies reported.

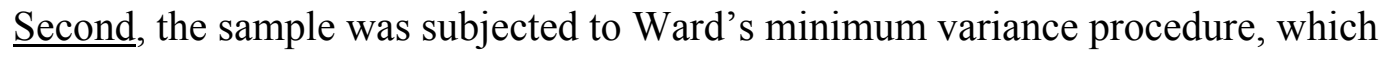
suggests the appropriate number of homogeneous clusters for the sample. The ideal number of clusters was determined by examining the distance statistic on the agglomeration schedule (the cut-off occurred when the statistic increased significantly from one result to the next compared to the other steps in the sequence). Norusis (2005) suggested that cluster formation should stop when the increase in the coefficient column between two adjacent steps is large. This technique has been shown to adequately address the number of clusters (Smith \& Baltes, 1997); however there are no set criteria to inform the researcher of the number of appropriate classifications to be selected (Borgen \& Barnett, 1987). Therefore, choices may differ from the cut-off decision made in this study regarding the number of clusters to examine.

$\underline{\text { Third, }}$, the $k$-means algorithm was used to determine final case location in the separate cluster subgroups. The $k$-means procedure was used to reproduce the $k$ number of disjoint clusters indicated by Ward's method. The $k$-means procedure aids in the interpretative step of cluster analysis described next. 
$\underline{\text { Fourth }}$, the profile means for each classification was examined to indicate defining peaks of the profiles (Smith \& Baltes, 1997). This is the part of the analysis that required interpretation of the output (Borgen \& Barnett, 1987). Means were inspected in order to derive labels for the subgroups as a potential means of ranking the various types of problem solvers from least to most proactive problem solvers. Again, various interpretations are possible.

Lastly, descriptive information regarding the number of participants, the average age and cognitive performance of subgroup members, and the breakdown of males/females and self/others instruction groups were examined for each separate classification to note group differences between the cluster formations.

To determine a potential taxonomy of problem-solving response styles and to explore ranking among the classifications, five response style proportions (problem-focused, cognitiveanalytical, passive-dependent, avoidant-denial, commentary) were entered into the agglomerative hierarchical cluster analysis. The selection of the five response styles was a result of the study's focus on classifying participants into subgroups of problem solvers based on the most specific information obtained about problem-solving styles and to avoid the potential bias of fluency. Due to the low frequencies and percentages of "nonsense" and "other" responses, these strategies were not included in the cluster analysis.

Number, Size, and Profiles of Subgroups. The entire sample excluding outliers $(N=123)$ was initially subjected to Ward's minimum variance method followed by the $k$-means procedure to assign subgroup membership. The results of Ward's method indicated that a 5-cluster solution was most representative of the sample. Table 10 provides an overview of the membership size of the 5 subgroups as well as the labels assigned to the subgroups of problem solvers. The clusters were ranked (1-5) to reflect the ranking from most proactive to least proactive, which 
characterizes subgroup profiles across the five problem-solving response styles (see Table 11). Note that higher means refer to a higher use of a strategy in comparison to other responses (e.g. the proportion of that strategy compared to total overall strategy types).

Individuals in clusters 1 and 2 could be defined as the most proactive problem solvers based on their above average means on the proactive strategy types (i.e., problem-focused or cognitive-analytical). Proactive strategies have been suggested to characterize better problem solving because these strategies tend to lead to accomplishments with solving the problem (Blanchard-Fields, et al., 1995). The cluster 1 subgroup $(n=35)$ reported an above average proportion of problem-focused strategies and a below average proportion of passive-dependent, avoidant-denial, and commentary strategies. Therefore, most of the strategies of individuals in cluster 1 were problem-focused in nature. Individuals in cluster $2(n=14)$ reported an above average proportion of cognitive-analytical strategies and a below-average use of passivedependent strategies. These people tended to respond as thinkers or planners.

Individuals in cluster $3(n=12)$ was comprised of individuals who responded close to the average on all strategy types. These individuals also tended to be the participants who asked questions about or commented on the problem. Although these individuals were average on most strategy types, they did tend to report less-than-average cognitive-analytical strategies. These participants commented more on the problem items compared to the other clusters; perhaps wanting to seek out more information about the problem scenario.

Individuals in clusters 4 and 5 could be defined as the least proactive problem solvers based on their low means on the proactive strategy types (i.e., problem-focused, cognitiveanalytical) and high means on the passive strategy types (i.e., passive-dependent, avoidantdenial). Cluster 4 participants $(n=38)$ reported an above average proportion of passive- 
dependent strategies and a below average proportion of problem-focused, avoidant-denial, and commentary strategies. These are the individuals who reported solutions that tended to delay solving the problems or tended to rely on other means besides themselves to get the problem reconciled. Individuals in cluster $5(n=24)$ reported an above average amount of both passivedependent and avoidant-denial strategies and a below average amount on all other strategy types. These people tended to report strategies that avoided the situation completely, involved emotional reactions, or relied on other means to get everyday problems solved.

RQ3: Relations between selected factors, fluency outcome, and problem-solver subgroups Analysis 4: Predicting Fluency Outcome on the EPSI

To evaluate how well selected factors predicted fluency outcome, two multiple regression analyses were conducted; one for the Instrumental fluency sum and one for Interpersonal fluency sum. The factors entered into the models included individual characteristics (i.e., age, education, sex), fundamental cognitive abilities (i.e., verbal and inductive reasoning abilities), current and past experience on the problems, task-related self-efficacy, and assigned instruction condition. The forward method was the form of entry used for both of the multiple regression analyses to designate which factors significantly influenced fluency outcome.

The first regression analysis was conducted with the Instrumental fluency sum as the dependent measure $(N=126)$. The linear combination of age, sex, education, verbal ability, and past experience significantly influenced Instrumental fluency, $F(5,120)=10.80, p=.001$. The sample multiple correlation coefficient was .56, indicating that approximately $31 \%$ of the variance of Instrumental fluency was accounted for by the linear combination of age, sex, education, verbal ability, and past experience. 
Table 12 provides the indices for the relative strength, direction, and variance of the five significant predictors and four nonsignificant factors. Verbal ability was the strongest predictor, explaining almost $13 \%$ of the variance of Instrumental fluency. Higher verbal ability was related to higher Instrumental fluency sums. Past experience with Instrumental (home) problems was also a strong predictor, explaining about $7 \%$ of the variance. Greater past experience with similar problems related to higher Instrumental fluency sums. Additionally, those who were younger, female, and had a higher education tended to have a greater Instrumental fluency score.

The second regression analysis was conducted with the Interpersonal fluency sum as the dependent measure. The only significant predictor of the selected factors was inductive reasoning performance, $F(1,124)=12.17, p=.001$. The correlation coefficient was .30 , indicating that approximately $9 \%$ of the variance on Interpersonal fluency was accounted for by inductive reasoning ability.

Table 13 provides the indices for the relative strength, direction, and variance of inductive reasoning and the other non-significant factors. Individuals who scored higher on the inductive reasoning assessment tended to score higher on Interpersonal fluency outcome.

\section{Analysis 5: Meaningful Characteristics of Problem-solver Subgroups}

In addition to ranking the types of problem solvers based on their reported proactive strategies to everyday problems, another central question was whether there were differences between the clusters based on several outcome variables. Prior to assessing group differences, cluster options were considered. Because the five clusters could essentially be considered proactive, average/commentary, or passive, I chose to combine clusters 1 and 2 , leave 3 as is, and combine 4 and 5 to create three cluster subgroups. This combination procedure targeted 
potential problems associated with power due to the small number of individuals in each of the five cluster subgroups.

Differences in status variables and other selected factors were examined in this last set of analyses. For the status variables (i.e., age group, sex, and instruction condition), chi-square analyses were conducted to examine the distribution of these variables across the 3 cluster subgroups. Table 14 provides cluster membership in relation to the status variables. There were no significant differences between the three cluster subgroups in these three status variables.

To examine group differences between the three clusters on other non-status factors (i.e., age, education, verbal and inductive reasoning ability, overall fluency, strategy types, experience, and self-efficacy), one-way analyses of variance (ANOVA) were conducted (see Smith \& Baltes, 1998 for similar analyses). The analyses revealed that there were group differences between the three clusters on age, $F(2,122)=4.96, p=.01$, inductive reasoning, $F(2$, $121)=3.42, p=.04$, fluency, $F(2,122)=3.30, p=.04$, and all five strategy types: problemfocused, $F(2,122)=44.49, p=.01$, cognitive-analytical, $F(2,122)=6.27, p=.01$, passivedependence, $F(2,122)=73.00, p=.01$, avoidant-denial, $F(2,122)=9.03, p=.01$, commentary, $F(2,122)=73.53, p=.01$. The most proactive $(M=47.79)$ and average $(M=57.27)$ problem solvers were older than the least proactive $(M=38.83)$ problem solvers. The least proactive problem solvers $(M=15.18)$ scored higher on inductive reasoning abilities and reported more overall solutions $(M=21.76)$ than the most proactive problem solvers (inductive reasoning $M=$ 12.96; fluency $M=17.18$ ). Lastly, the differences in the five strategy types supported the cut-off and labeling for the clustering procedure. Proactive and average problem solvers reported more proactive and cognitive strategies than the least proactive problem solvers, and the least proactive problem solvers reported more passive-dependent and avoidant-denial strategies 
compared to most proactive problem solvers. Table 15 provides the means and standard deviations of all selected factors and well as denotes differences between the three clusters.

\section{Discussion}

The sections below first provide a review of the study's research aims and findings (with brief interpretation). Next, a discussion of how the results related to current literature and statements regarding alternative hypotheses are provided. Lastly, the limitations and future directions of the study findings are discussed.

\section{Review of Research Questions and Hypotheses}

The current study focused on several methodological factors and individual characteristics that affect everyday problem-solving performance in adulthood, particularly how the variables affect age difference outcomes. This area of research has been given limited attention in the published everyday cognition literature, and there seems to be a greater emphasis on fluency when examining performance on everyday cognitive tasks. Thus, the aim of this study was to better understand adult problem-solving performance in terms of the effects of methodology on outcome/interpretation of age differences and how individual factors relate to performance. Clarifying these points may help to minimize any erroneous negative stereotypes about older adult problem solvers.

The specific research goals of the present study were to 1) note differential age group findings based on the scoring procedure implemented (fluency vs. proactive strategy use), 2) determine whether methodological differences in instruction delivery and problem domain affected everyday problem-solving performance; 3) examine whether there were identifiable subgroups of problem solvers based on their use of five different strategy types, 4) assess whether the same or different factors predicted Instrumental (home) versus Interpersonal (friend) 
problem-solving fluency, and 5) examine group differences between types of problem solvers based on status (age group, sex, instruction condition) and non-status variables (education, fundamental cognitive ability, experience, self-efficacy).

To explore these research aims, methodological factors were manipulated, individual characteristics were assessed, and participant performance on an everyday problem-solving task was recorded. The targeted methodological factors included scoring procedure, instruction, and problem content. These factors were examined by comparing the pattern of findings using two types of scoring methods (fluency vs. proactive strategies), manipulating the instructions given to participants (target of the problem: self vs. others), and administering two types of problems to the participants (Instrumental vs. Interpersonal items). Individual characteristics of interest were age, sex, education, fundamental cognitive abilities, past and current experience with the presented problems, and task-related self-efficacy. These individual characteristics were examined by administering timed cognitive tests and self-reported questionnaires to younger, middle-aged, and older adults. On the everyday problem-solving task, participants worked individually to generate solutions to four hypothetical situations. All participants were randomly assigned to complete the items based on Self or Others instructions.

\section{Review of Study Findings}

The following section provides a general summary of the major findings of this study. The subsections focus on the analyses used to address the five research aims mentioned above. The results highlight the importance of considering both methodological and individual factors when examining everyday problem-solving outcomes, particularly when making generalizations about group differences between younger, middle-aged, and older adults. $\underline{\text { First, }}$, the significant Age by Problem Content interactions for both fluency and proactive strategy use revealed 
differential findings for younger, middle-age, and older adults based on the type of scoring procedure used. Second, when assessing fluency outcome and proactive strategy use, group differences based on instruction method and problem content also emerged, suggesting that varied methodology may influence everyday cognitive performance. Third, five distinct subgroups varying in reported strategy use in five different categories were identified and ranked based on participant generation of proactive and passive strategies. Fourth, several individual characteristics related to fluency outcome on Instrumental everyday tasks, but only one characteristic predicted Interpersonal problem solving fluency. Fifth, problem solvers were clustered and ranked from most proactive to least proactive problem-solver subtypes. Status variables (i.e., age group, sex, instruction condition) did not significantly differentiate between the three subgroup classifications, but several other individual outcome variables did. Each of these findings is discussed in more detail in the subsections below.

\section{Differential Group Differences based on the Scoring Procedure Used}

The main question motivating this study was whether the type of scoring procedure used differentially affected everyday problem-solving outcome between adult age groups and across different methodological manipulations. As expected, the type of scoring procedure used contributed to varied outcomes across all three areas (age, instruction, and problem content), which strengthens the argument that researchers should not rely solely on fluency outcome to assess one's problem-solving ability. Otherwise, age difference findings could be misleading or lack comparability to other studies that use different methodologies. The main effects for Instruction and Problem Content were first compared between fluency outcome and proactive strategies to note the differential findings based on scoring. Any significant interactions were 
compared after the main effects. The following descriptions summarize the results pertaining to group differences based on scoring.

Instruction Main Effects. When assessing fluency outcome, participants receiving the Others instructions generated more solutions to the problems overall compared to the participants receiving the Self instructions. However, when examining strategy use, individuals receiving the Self instructions were more proactive than individuals receiving the Others instructions. Thus, participants receiving Others instructions may write down all of the possible solutions anyone could use, perhaps including more passive-dependent and avoidant-denial solutions. If this were the tendency, it would explain why individuals produced more solutions but less proactive strategies when given the Others instructions. Individuals receiving Self instructions could have limited their responses to only what they would do, perhaps resulting in more problem-focused and cognitive-analytical solutions. If individuals place themselves in a given situation, they may be more likely to strive to solve the problem effectively than if they were thinking about a nondescript person in a situation.

Problem Content Main Effects. The main effect of Problem Content for fluency outcome revealed that individuals generated more solutions to Instrumental home problems compared to Interpersonal friend problems. However, individuals were more proactive on Interpersonal friend problems compared to Instrumental home problems. Perhaps participants viewed friend problems as more important than home management problems; thus they focused on generating fewer but more proactive solutions to solve the friend problems. The potential negative sideeffects of acting passively with friend issues (e.g., ignoring a friend whom you offended) could prompt participants to provide more proactive than passive solutions. Asking someone (e.g., spouse, child) to clean up your home is often more acceptable than asking a third party to try to 
mend your friendship with another person. These findings stress the importance of context when assessing problem-solving performance in real-life situations.

A similar pattern of results emerged for the Instruction and Problem Content main effects. Considering the pattern of results for the two main effects together, one may conclude that more solutions may not necessarily be better when it comes to problem solving on openended cognitive assessments. As participants increase their number of responses (fluency score) to solve a problem, the proportion of proactive strategies may decrease. Participants may begin to report more passive or avoidant strategies as they try to exhaust their repertoire of solutions for a given problem. As mentioned in the literature review, perhaps arriving at the one best strategy to solve a problem would be all that matters, so perhaps it is important to move away from the emphasis on fluency and try to better understand strategy use in everyday life.

Age $x$ Problem Content Interactions. The Age and Problem Content main effects were qualified by the significant Age by Problem Content interactions for both scoring procedures used. These results allowed for comparability in the findings regarding age differences. For the Instrumental home problems, middle-aged adults generated more solutions than older adults, but all age groups were equally proactive in their strategy use. For the Interpersonal friend problems, younger adults generated more solutions than older adults, but when assessing the type of responses, older adults were actually more proactive than younger adults in their reported strategy use.

Although no a priori hypotheses for an Age by Problem Content interaction were generated for fluency outcome, the findings regarding proactive strategies were contrary to expectations. Blanchard-Fields and colleagues (1997) found that middle-aged and older adults were more proactive on instrumental problems compared to younger adults. The current study 
found no age differences in proactive strategies for instrumental problems. One explanation is that the participants across all three age groups reported similar levels of past and current experience on the problems. In terms of interpersonal friend problems, Blanchard-Fields and colleagues indicated no age differences in proactive strategy use; however, the current study found that older adults were more proactive than younger adults. Perhaps this is due to the size and function of friendship networks in younger and older adulthood, which will be discussed in more detail in the next major section.

Age $x$ Instruction Interactions. When assessing fluency outcome, there was a significant Age by Instruction interaction. When completing problems after receiving Self instructions, younger adults generated more solutions to the problems than older adults. For the Others instructions, middle-aged adults generated the most solutions. In both conditions, older adults demonstrated the lowest fluency scores, despite the instructions given to them. However, when examining proactive strategy use, there was no Age by Instruction interaction, suggesting that all age groups were equally proactive in the Self and Others instruction conditions, despite the number of solutions generated. These findings suggest that consistencies in the prior literature regarding the wording of instructions may be important to consider closely, as participants may interpret the task differently based on the instructions provided. Additionally, outcomes between adult age groups may also vary based on instruction group and/or scoring procedure used. Subgroups of Problem Solvers based on the Proportion of Five Strategy Types

As expected, participants' proportions of strategies classified them into identifiable subgroups of problem solvers. The proportions of problem-focused, cognitive-analytical, passive-dependent, and avoidant-denial strategies as well as commentary remarks varied enough to indicate five distinct subgroups of problem solvers. The five subgroups were ranked from 
most proactive to least proactive problem solvers. Two groups were considered the highly proactive problem solvers, one group was considered the average or commentary problem solvers, and the last two groups were considered the least proactive or highly passive problem solvers.

Due to the clear distinction between groups and statistical reasons, the top two clusters and the bottom two clusters were combined to form three final subgroups: most proactive, average/commentary, and last proactive problem solvers. These three groups were assessed for group differences on various status and non-status outcome variables used in the current study. Subgroups were expected to differ on age and sex, but no group biases were found. There were relatively equal percentages of younger, middle-aged, and older adults as well as males and females distributed across the various subgroups.

Although there was not an age group bias among the three groups, the cluster of problem solvers did differ on continuous age. The proactive and average/commentary problem solvers were typically older than the least proactive problem solvers. There are a few possible explanations for this age difference. Younger adults may be less likely than middle-aged or older adults to provide commentary remarks. Perhaps this difference is due to the experience of middle-aged and older adults. Middle-aged and older adults may be more aware of the various situations that could cause a problem, and thus prefer to seek out more information about the context of the problem. Previous studies also suggest that older adults experience a stereotype threat, which affects cognitive performance (e.g., Chasteen, Bhattacharyya, Horhota, Tam, \& Hasher, 2005). In other words, older adults are aware of the memory and/or cognitive stereotypes about older adults, thus when they participate in certain cognitive studies, they may feel compelled to comment on study questions to justify their responses (e.g., what type of clutter?). 
Additionally, the younger adults in this study were primarily college-aged students who may be more likely to rely on other people (act passively) when a problem arises because they are not yet fully independent.

The clusters also varied based on several other non-status outcome variables, including inductive reasoning, overall fluency outcome, and all five strategies. Likely related to the age difference described above, individuals in the least proactive cluster had higher inductive reasoning scores than those in the most proactive cluster. Additionally, individuals in the least proactive group generated more solutions than those in the most proactive group, particularly with the usage of passive-dependent and avoidant denial strategies. This finding, although it sounds contradictory to what would be expected, is actually in line with the study findings regarding group differences described in the first research question: a greater number of solutions is not necessarily better. Individuals may be generating more solutions to a problem, but those solutions may be of lower quality. When participants are told, "list as many solutions as possible to the problem", they may feel inclined to report any type of solution and ignore the type of the strategy that they are reporting because they feel the need to exhaust their possibilities.

Predicting Instrumental and Interpersonal Problem-solving Fluency

As mentioned and reviewed in the literature, several factors appear to affect problemsolving performance. Therefore, whether or not specific factors predicted Instrumental fluency compared to Interpersonal fluency was of interest. In fact, different factors did predict whether individuals generated more solutions to Instrumental (home) or Interpersonal (friend) items.

For Instrumental items, individuals who were younger, female, highly educated, obtained higher verbal ability scores, and had more past experience with home management issues tended 
to achieve higher response fluency. For Interpersonal items, the relationship with other factors is a bit unclear. Individuals who scored high on inductive reasoning ability tended to generate the most solutions. None of the other factors predicted Interpersonal fluency performance. Previous literature finds connections between age, sex, education, cognitive abilities, and experience with everyday problem-solving outcome; thus the related factors were expected to predict fluency performance. The interesting finding was that the same factors did not predict Interpersonal problem-solving fluency as they did Instrumental fluency. Perhaps there are other underlying fundamental abilities that should be assessed, or maybe the number of friends that one has is predictive of Interpersonal fluency outcome, which was not assessed in this study. The explanation for this finding is unclear, and further research should look into potential reasons why there may be dissimilar predictors for different types of problems. Again, this finding stresses the importance of examining the context of a problem before making conclusions about everyday problem solving ability.

\section{Implications and Published Research}

Pinpointing some of these factors leads to a better understanding of everyday cognitive performance, particularly in the domains of home management and resolving friend conflicts. In fact, the overall findings of the current study suggest that these two problem domains as well instructional techniques and scoring procedures need special attention in future studies, particularly due to the potential effect these methodological components may have on age differences in performance outcome. It may be how we assess everyday problem-solving performance in the laboratory that is affecting group differences that we find in the published literature. Laboratory studies of everyday problem-solving need to be as close to real-life as possible to better understand the complex and dynamic nature of problem solving in everyday 
life. Better yet, we need to take everyday cognitive studies into the field to ensure that our findings in the laboratory are meaningful and relevant to what actually occurs in the lives of adults in the real world.

\section{Differential Group Differences based on the Scoring Procedure Used}

The results for the first research question consistently strengthened the notion that the way researchers score everyday problem-solving tasks is a crucial component to consider when making assumptions about group differences or labeling problem solvers. Researchers who use open-ended assessments to gauge everyday problem-solving ability tend to define problemsolving ability based on fluency outcome, which is the number of solutions generated to a given problem (e.g., Allaire \& Marsiske, 2002; Artistico, et al., 2003; Berg, et al., 1999; Denney \& Pearce, 1989; Denney, et al., 1982; Heidrich \& Denney, 1994; Marsiske \& Willis, 1995; Strough, et al., 2003). We seem to emphasis fluency outcome in the published literature when, in fact, relying on fluency outcome as an indicator of problem-solving ability undermines the quality or the type of strategy used by an individual. Doing so could lead to erroneous assumptions about everyday cognitive ability in certain age groups. The findings of the present study suggest that researchers should contribute the extra effort to examine everyday problemsolving strategies when examining group differences, particularly when age differences are of interest. Quantitatively, individuals may report a greater frequency of responses; however, those responses may not be high quality responses.

In the current study, younger, middle-aged, and older adults performed similarly when no methodological components were manipulated. This finding differs from Denney and colleagues (i.e., 1982, 1989) who suggested problem-solving ability peaks in middle adulthood with older adults generating the least number of solutions overall. Although the current study does not 
support the idea that middle-aged adults may show the highest fluency performance overall, it is interesting to find that older adults did not differ significantly in fluency performance. In a previous study where adults were given seemingly age-relevant problems, younger and older adults did not differ in performance outcome, but middle-aged adults outperformed younger and older adults (Denney, et al., 1982, 1989). Perhaps the similarity between the age groups in fluency performance in the current study was party due to the fact that the items used in the present study were presumed to be equally relevant to all age groups (Strough, 2004).

Additionally, the problem perception questionnaire used in the current study did not indicate any age differences in past or previous experiences with the four problems, which strengthens the idea that these problems were equally relevant to all age groups. All age groups also provided qualitatively equal responses in terms of proactive strategies. Therefore, in this study, a nonsignificant age difference overall was interesting. This finding is in line with BlanchardFields and colleagues (1995) who suggested that older adults, like other age groups, are capable of using all types of strategies when solving everyday problems.

Even more compelling in terms of finding no overall age differences was the Age by Problem Content interactions for both fluency outcome and proactive responses. If one would rely solely on fluency outcome as an index of problem-solving ability, it may appear that middleaged or younger adults are better problem solvers than older adults. For example, the current study found that when completing Instrumental problems, middle-aged adults generated more solutions than older adults, and when completing Interpersonal problems, younger adults generated more solutions than older adults.

If the study were concluded after assessing fluency outcome only, a likely assumption would be that older adults are less effective problem solvers than their younger counterparts, 
despite the type of problem solved. However, the current study also examined the strategy types, with an emphasis on proactive responses. There were no age differences in proactive strategy use when completing Instrumental problems, suggesting older adults may perform just as well at problem solving than younger and middle-aged adults on home management issues. When completing Interpersonal problems, older adults actually provided more proactive strategies than younger adults. Taken together, these findings suggest that older adults are not necessarily at a disadvantage when approaching everyday problems in a laboratory setting and may actually be more likely to take the problem into their own hands when it comes to resolving issues with friends.

The findings regarding age differences in fluency and proactive results could be explained by the fact that older adults make conscious appraisals of a situation, note which solutions were most effective in the past, and as a result of this reasoning process, limit the number of strategies they report on fluency measures (as suggested by Berg, et al., 1999; Labouvie-Vief, et al., 1987). This process is likely a result of experience. It may be that older adults focus on the best strategies (e.g., what worked for them in the past) and neglect to report solutions they would not implement. On problems focused on resolving conflicts with friends, younger adults may have larger friendship networks than older adults (Carstensen, 1992) and can probably generate more solutions for these types of problems. With smaller friendship networks in older adulthood, the thought of using passive or avoidant strategies to approach a friend problem might be riskier for older adults than it would be for younger adults, resulting in higher proactive strategy use among older adults.

Based on the findings described thus far, there may be cohort differences between younger, middle-aged, and older adults, but it appears that scoring is very influential in terms of 
how we perceive individual problem solvers of differing ages. Methodological group differences in everyday problem solving within the areas of Instruction manipulation and Problem Content also emerged, suggesting that researchers need to be cognizant of their design before making assumptions about everyday cognitive performance. Instruction differences are discussed first, followed by differences in problem content.

If similar findings are found when utilizing different methodologies, we can be more certain that our findings are valid. However, the published literature fails to recognize the potential effects of various instructions given to participants on their everyday problem-solving performance. This fact makes it difficult to compare findings from study to study when the deliveries of instructions diverge across laboratories. Everyday problem-solving instructions tend to vary on two main dimensions: the target (self, others, specific person) and the expectation regarding solutions (as many as possible, only safe and effective). The findings from the current study are in line with Denney and colleagues (1992) and Kimbler (2006) who suggested that instruction delivery makes a difference in everyday cognitive performance. Researchers should be aware of the advantages and limitations of using certain instructional procedures over others.

In terms of fluency outcome, the current study found that individuals generated more solutions when given the Others instructions compared to the Self instructions. Based on this finding, one would assume that Others instructions elicit better problem solving. Interestingly, when proactive strategy use was examined, the reverse was found. Participants given the Self instructions reported more proactive strategies than participants given the Others instructions. Taken together, these findings suggest that although individuals may generate fewer solutions when presented with Self instructions, the solutions are actually more proactive compared to the Others instruction group. As individuals picture themselves in a given scenario (imagine you...) 
they may be more likely to designate solutions that would be effective and resolve the problem. However, individuals who take an outside perspective (imagine a person...) may care less about the resolution of the problem, and thus provide any possible solution that other person could try. Again, this finding strengthens the idea that researchers should not rely on fluency outcome as an indicator of problem-solving ability because when strategies are assessed, more responses does not necessarily indicate better problem-solving. Although the study took place in a laboratory setting, this finding could also have implications for how an individual may approach a problem in real life compared to advice they may give others in real life.

A similar interpretation can be made for Problem Content. Participants generated more solutions to Instrumental problems than Interpersonal problems. Therefore, participants have more ideas regarding home management issues than resolving friend conflicts. Whether more ideas are better is, again, questionable. When examining strategy use, individuals generated a higher proportion of proactive solutions on the friend problems than the home problems. A possible explanation for this could be based on the idea that if people act passively or avoid issues related to people (e.g., conflicts with friends), they risk losing personal contact with someone. The consequences of acting passively or avoiding home management problems (e.g., clutter) may result in less crucial long-term outcomes. One may easier adapt to neglecting clutter or chores around the home than to adapt to decreasing a friendship network, or asking someone to help you with your home management issues may be less evasive than asking someone to resolve a friend conflict for you.

Another important consideration about problem-solving content needs to be addressed. Oftentimes, problems of varying degrees and domains tend to be combined to create an everyday problem-solving measure. For example, the original Everyday Problem Solving Inventory targets 
six domains (i.e., friend, family, coworker, home, consumerism, information). Findings from other everyday cognitive researchers (e.g., Blanchard-Fields, et al., 1995, Thornton \& Dumke, 2005) as well as results from the present study suggest that people respond differently to whether the problem targets instrumental situations or interpersonal dilemmas. Future research should strongly consider how the domain or context of a problem affects the many dimensions of everyday problem-solving, such as performance outcome, self-efficacy beliefs, personal experience and salience (Diehl, et al., 1995).

Subgroups of Problem solvers based on the Proportions of Five Strategy Types

To date, researchers have not attempted to rank individuals into identifiable groups of problem solvers. Based on the two problem domains used in the current study, acting proactively was hypothesized to be the best method in solving the problem. Additionally, Blanchard-Fields and colleagues $(1995,1997)$ suggest that problem-focused and cognitive-analytical strategies tend to be the best methods in terms of guaranteeing the problem to get resolved. The current study found that proactive and passive strategies as well as commentary remarks differentiated problem solvers into five subgroups. By classifying individuals into separate clusters, it was possible to examine factors that may differentiate the groups in addition their problem-solving strategies.

One factor that differentiated between the clusters was age. The fact that the least proactive group was of younger age than the other two groups should lead researchers to question why younger individuals may report less proactive strategy use. Perhaps the younger college students comprising that cluster still live with their caregivers and expect their caregivers to aid in their everyday problems, or that younger adults tend to use more aggressive or fanciful strategies to get the problem solved (Neely, 2005). Another possibility is that younger adults tend 
to have less experience with everyday problem solving and have yet to test out several possibilities to realize that relying on others or avoiding the problem could result in dire consequences. Sometimes to get the problem solved, you need to do it yourself.

When looking at cluster differences, it is also interesting that individuals who scored higher on fundamental cognitive abilities actually performed less proactively than individuals who scored lower on traditional assessments of cognition. Perhaps this finding is the function of an age cohort difference, but the underlying explanation is still unknown. This finding is also contrary to other studies that find that fundamental abilities positively correlate with everyday cognition (e.g., Allaire \& Marsiske, 1999, 2002; Margrett, 1999); however, those studies tend to use fluency outcome to assess everyday cognitive performance. The next set of analyses address this issue.

Predicting Instrumental and Interpersonal Fluency Outcome

Based on the group differences between subgroups of problem solvers, one might expect similar findings for the relations between fundamental cognitive ability and fluency outcome. The discussion above questions why the least proactive problem solvers would score the highest on fundamental cognitive abilities. In other words, why would high fundamental cognitive abilities be a characteristic of passive everyday cognitive ability? Again, it may come down to scoring procedures. When assessing fluency outcomes, several factors predict performance, but the most interesting are the cognitive predictors because the results counter those of the cluster analysis. Better verbal ability predicts Instrumental fluency performance, but better inductive reasoning ability predicts Interpersonal fluency performance. Although cognitive performance appears to predict fluency outcome, higher cognitive abilities were indicative of the more passive 
problem solvers. These findings again point to the argument that the scoring procedure a research uses strongly influences the results of a study.

\section{Limitations and Future Directions}

Despite the findings described above regarding the importance of methodological and individual factors affecting everyday cognitive performance, some caveats should be considered when interpreting the results of the current study. The first limitation that should be mentioned is the power of the current study. Tabachnick and Fidell (2001) recommends that the sample size of regression analyses should be at least $50+(6 *$ the number of predictors). The current study, with 125 participants in the regression analyses, had adequate power to detect significant findings. Post-hoc power was also examined for the analyses of variance conducted in the current study (see Tables 16 and 17). There was sufficient power to detect medium and large effects for the two-way interactions detected in the sample; however, there was not ample power to detect small effects. For the 3-way analysis of variance, there was not ample power to detect small and medium effects. Therefore, it is important to take caution when interpreting the findings of this study, as the study was underpowered to detect small effects. Future studies with larger sample sizes should be able to better explain the differences between age groups and experimental manipulations of design.

Second, participants overall were performing exceptionally well, particularly in terms of generating problem-focused responses. This high quality of performance (large percentage of proactive strategies) provided minimal variance of strategies in the other strategy types, as the scoring was based on a proportion score. The nature of the task, the nature of the sample, or the coding scheme used could contribute to participants' minimized range of strategies. Examining problem-solving outcome using various measures (e.g., different problem types, different 
instructional methods) and coding schemes (more specific categories) as well as a more heterogeneous sample would help address this issue. This study provides the framework and a means of comparison for more methodological studies in the everyday cognitive literature.

Another limitation of the current study was that individuals may not have adhered to the directions as expected. Individuals receiving Self instructions were expected to generate only solutions that they would use, and individuals receiving Others instructions were expected to generate any possible solutions to a problem whether they would consider using the strategy or not. Based on the explicit verbal questions from a few of the participants, some individuals adhered to the expected manipulation, whereas others did not. Specifically, a few individuals in the Self instruction group imagined themselves as a third party who was supposed to tell a person how to solve the problem rather than putting themselves in the problem as the actual person. More precise wording (e.g., Write down solutions you/a person would use to the following problem. You/ A person borrowed.....) and a manipulation check (e.g., When providing solutions, did you imagine yourself in the situation and provide solutions that you would use?) could eliminate this problem in the future.

Although the study contributed to a clearer understanding of methodological differences, another methodological issue could be addressed in future studies. In the current study, participants were required to write out their solutions to the problems. Writing out solutions may create age biases if older adults experience cramping in their hands due to physical changes accompanying older adulthood. A future study could assess whether there are differences in performance outcome based on the style of answering (i.e., verbal versus written responses). Similarly, there may be a difference based on the presentation style of the instructions (e.g., verbal vs. written instructions). Researchers interested in methodological components affecting 
everyday problem-solving outcome could assess the effects of these factors. If responses are found to be affected by methodology as they were in this study, the validity of our strategies used in the laboratory come into question. This further emphasizes the need to examine problemsolving in actual real-life settings.

Due to the complexity of the design and the fact that this study was focused primarily on how methodological factors affect problem-solving performance, differences between males and females were not thoroughly examined. The finding that sex predicted Instrumental problemsolving fluency may indicate a need to examine sex differences in everyday problem-solving performance. Although a few studies have investigated sex differences in the published literature (e.g., Margrett \& Marsiske, 2002; Neely, 2005), it is an area in need of examination to better understand the nature of problem solvers and problem-solving ability.

There are also concerns related to the problem perception questionnaire. Internal validity was low, and this measure was designed for the use in the study. Improved assessment of experience and self-efficacy is warranted to better understand how these individual characteristics vary across domains and whether experience or self-efficacy relate to everyday problem-solving outcome.

This study was also limited in its use of two everyday problem-solving domains: home management and friend conflicts. Differential patterns of responding may occur in other content areas, as experience and self-efficacy may fluctuate from domain to domain. Additionally studies must consider how problem-solving outcome varies in different contexts and whether the everyday problems used are really "everyday" problems. To address this concern, future studies should continue to ask participants about their everyday problems to better inform this area of research in terms of what everyday problem solving really is. 
Additionally, this study was cross-sectional, so only inferences about age differences can be made. To target the concern about older adults' ability to maintain functioning and independence in later life, the subfield of cognitive aging must examine the developmental trajectory of everyday problem in adulthood more carefully. Longitudinal designs, which assess everyday cognition across adulthood, must be conducted to truly understand age change in everyday cognition. If these designs were implemented, there would be a broader understanding of basic cognitive abilities, everyday cognition, and how the two relate, which is needed more in the published literature.

Lastly, a clear definition of effective everyday problem solving has yet to exist (Thornton \& Dumke, 2005). Does being flexible and generating many solutions to a problem lead to better problem-solving outcome? Does generating problem-focused on cognitive-analytical strategies define effective problem solvers? Should the goal that the participant has in mind when approaching a problem be part of the definition of effective problem solving? The current study brings these ideas into consideration but does not provide a clear answer to this overarching question of what defines effective problem solving. Future studies should assess participant goals to see whether the goals match the solutions. Also, future studies should determine which strategies appear to actually resolve a problem. To do so, it would be important to investigate what types of problem individuals are actually encountering, how they approach the problems, the strategies they actually use, and whether the strategy worked. This design would require a researcher to examine problem solving in real life. To better understand the nature of everyday problem-solving and cognition, future studies must delve into real world settings and rely less on laboratory-based assessments. 


\section{Conclusions}

The findings from the current study are rich in what they convey about everyday problem-solving design and outcome and contributed to the literature in several ways. The most compelling finding suggests that methodological factors greatly influence everyday problemsolving performance. Results of younger, middle-aged and older adults varied based on the type of scoring procedure used, the instructions given, and the content of the problem solved. Therefore, we cannot yet assume that younger adults are better problem solvers than older adults, particularly in home management and friend conflict tasks. For example, the current study found differential patterns of age differences based on two different scoring methods on the same task (i.e., the EPSI). These findings should convince other researchers to thoroughly consider methodological issues when designing their studies, specifically when age differences are being considered.

Another contribution is that the findings of the current study should spark interest in how one defines everyday problem solving effectiveness. A limitation in everyday cognitive research is the lack of a clear definition of effective problem solving. This study provides another stepping stone in answering that question through the suggestion of not relying on one scoring procedure over another as an index of problem-solving ability. Participants may feel like they are doing well by generating a lot of solutions, but after a certain point, they may be providing solutions that could be labeled as ineffective. According to this study, more solutions may not always be better; it may matter where in the decision-making process the "good" solutions occur. If individuals can generate the most effective solution at the beginning of their thought process in real life, the problem may get resolved. If it doesn't get resolved, it would be important to have "good" back-up solutions. Due to the complexity of everyday problem solving, the current study 
only supports the need for information about various explanations and descriptions of effective problem solving. Real-life problem-solving studies will help to answer some of the questions in the everyday cognitive research.

Another contribution of this study is theoretical. Some researchers suggest that experience and knowledge accumulate in older adulthood, which helps elders preserve everyday cognitive abilities in later life (Baltes, 1993; Cornelius \& Caspi, 1987). Another viewpoint suggests that with age, everyday functioning linearly declines, particularly due to the fact that fundamental cognitive abilities decline (Marsiske \& Willis, 1995; Heidrich \& Denney, 1994; Schaie, 1993). The current study shows support for both positions. When examining strategy types, older adults performed just as well and as younger adults. This finding may be due to the fact that older adults only write down the most effective solutions from past experience, which would likely be proactive responses, particularly for the types of problems used in this study. Furthermore, the current study found differential relations between basic fundamental cognitive abilities and everyday cognitive performance outcome, emphasizing the need to further explore the complexity of everyday problem-solving performance.

This study also contributed to the beginnings of understanding how instruction delivery and problem content affect everyday problem-solving outcome. Differential patterns of performance were found based on these two methodological concerns. These are two areas of research that also need to be furthered considered. This study provides important information regarding these two methods and is a stepping stone in learning more about how methodological factors contribute to whether individuals perform better under one circumstance compared to another. Future studies should examine instruction and problem content differences, as one method may be affecting problem-solving outcome more than another. 
Lastly, the study examined how problem solvers clustered together based on their reported strategy use and whether individual factors differentiated these subgroups. This appears to be the first time that this type of categorization (i.e., with strategy types) was attempted in the everyday problem-solving literature. It is important to note that various interpretations of the study were possible. Individuals may also be characterized across many dimensions, whether it is their age, their education, or self-reported measures of ability and experience. This study demonstrated that individual characteristics are important when predicting problem-solving performance or classifying individuals into problem-solving subtypes. Focused studies that tease apart these individual characteristics will allow isolation of potentially influential factors, which may allow researchers to gain knowledge about the interesting yet complex process of everyday problem solving. 


\section{References}

Allaire, J.C., \& Marsiske, M. (1999). Everyday cognition: Age and intellectual ability correlates. Psychology and Aging, 14, 627-644.

Allaire, J. C., \& Marsiske, M. (2002). Well- and ill-defined measures of everyday cognition: Relationship to older adults' intellectual ability and functional status. Psychology and Aging, 17, 101-115.

Arenberg, (1982). Changes with age in problem solving. In F. I. M Craik \& S. Trehub (Eds.), Aging and cognitive processes (pp. 221-236). New York: Plenum.

Artistico, D., Cervone, D., \& Pezzuti, L. (2003). Perceived self-efficacy and everyday problemsolving among young and older adults. Psychology and Aging, 18, 68-79.

Baltes, P.B. (1993). The aging mind: Potentials and limits. Gerontologist, 33, 580-594.

Bandura, A. (1977). Self-efficacy: Toward a unifying theory of behavioral change. Psychological Review, 84, 191-215.

Berg, C. A., Meegan, S. P., \& Klaczynski, P. (1999). Age and experiential differences in strategy generation and information requests for solving everyday problems. International Journal of Behavioral Development, 23, 615-639.

Berg, C. A., Strough, J., Calderone, K. S., Sansone, C., \& Weir, C. (1998). The role of problem definition in understanding age and context effects on strategies for solving everyday problems. Psychology and Aging, 13, 29-44.

Berry, J. M., West, R. L., \& Dennehey, D. M. (1989). Reliability and validity of the Memory Self-Efficacy Questionnaire. Developmental Psychology, 25, 701-713.

Blanchard-Fields, F. (1986). Reasoning on social dilemmas varying in emotional saliency: An adult developmental perspective. Psychology and Aging, 1, 325-333. 
Blanchard-Fields, F., Chen, Y., \& Norris, L. (1997). Everyday problem-solving across the adult life span: Influence of domain specificity and cognitive appraisal. Psychology and Aging, 12, 684-693.

Blanchard-Fields, F., Jahnke, H. C., \& Camp, C. (1995). Age differences in problem-solving style: The role of emotional salience. Psychology and Aging, 10, 173-180.

Blieszner, R., Willis, S. L., \& Baltes, P. B. (1981). Training research in aging on the fluid ability of inductive reasoning. Journal of Applied Developmental Psychology, 2, 247-265.

Borgen, F. H., \& Barnett, D. C. (1987). Applying cluster analysis in counseling psychology research. Journal of Counseling Psychology, 34, 456-468.

Bosworth, H. B., \& Schaie, K. W. (1999). Survival effects in cognitive function, cognitive style, and sociodemographic variables in the Seattle Longitudinal Study. Experimental Aging Research, 25, 121-139.

Carstensen, L. L. (1992). Social and emotional patterns in adulthood: Support for socioemotional selectivity theory. Psychology and Aging, 7, 331-338.

Chasteen, A. L., Bhattacharyya, S., Horhota, M., Tam, R., \& Hasher, L. (2005). How feelings of stereotype threat influence older adults' memory performance. Experimental Aging Research, 31, 235-260.

Cornelius, S.W., \& Caspi, A. (1987). Everyday problem solving in adulthood and old age, Psychology and Aging, 2, 144-153.

Crawford, S., \& Channon, S. (2002). Dissociation between performance on abstract tests of executive function and problem solving in real-life-type situations in normal aging. Aging \& Mental Health, 6, 12-21. 
D’Zurilla, T. J., Maydeu-Olivares, A., \& Kant, G. L. (1998). Age and gender differences in social problem-solving ability. Personality and Individual Differences, 25, 241-252.

Denney, N. W. (1989). Everyday problem-solving: Methodological issues, research findings and a model. In L. W. Poon, D. C. Rubin, and B. A. Wilson (Eds.), Everyday cognition in adulthood and later life (pp. 330-351). New York: Cambridge University Press.

Denney, N. W., \& Pearce, K. A. (1989). A developmental study of practical problem solving in adults. Psychology and Aging, 4, 438-442.

Denney, N. W., Pearce, K. A., \& Palmer, A. M. (1982). A developmental study of adults' performance on traditional and practical problem-solving tasks. Experimental Aging Research, 8, 115-118.

Denney, N. W., Tozier, T. L., \& Schlotthauer, C. A. (1992). The effect of instructions on age differences in practical problem solving. Journals of Gerontology, 47, P142-P145.

Diehl, M. (1998). Everyday competence in later life: Current status and future directions. Gerontologist, 38, 422-433.

Diehl, M., Coyle, N., \& Labouvie-Vief, G. (1996). Age and sex differences in strategies of coping and defense across the life span. Psychology and Aging, 11, 127-139.

Diehl, M., Marsiske, M., Horgas, A. L., Rosenburg, A., Saczynski, J. S., \& Willis, S. L. (2005). The Revised Observed Tasks of Daily Living: A performance-based assessment of everyday problem solving in older adults. The Journal of Applied Gerontology, 24, 211230.

Diehl, M. Willis, S. L. \& Schaie, K. W. (1995). Everyday problem solving in older adults: Observational assessment and cognitive correlates. Psychology and Aging, 10, 478-491. 
Dimitrov, M, Grafman, J., \& Hollnagel, C. (1996). The effects of frontal lobe damage on everyday problem solving. Cortex, 32, 357-366.

Flinn, J. A. (2006). Examining problem-solving interpretations: The role of age, sex, and femininity. Unpublished master's thesis. West Virginia University.

Haught, P. A., Hill, L. A., Nardi, A. H., \& Walls, R. T. (2000). Perceived ability and level of education as predictors of traditional and practical adult problem solving. Experimental Aging Research, 26, 89-101.

Heckhausen, J. \& Schulz, R. (1995). A life-span theory of control. Psychological Review, 102, 284-304.

Heidrich, S. M., \& Denney, N. W. (1994). Does social problem solving differ from other types of problem solving during the adult years? Experimental Aging Research, 20, 105-126.

Kimbler, K. J. (2006). The effect of experimentally-provided supportive messages on middle-age and older adults' performance on everyday problems. Unpublished doctoral dissertation. West Virginia University.

Labouvie-Vief, G., Hakim-Larson, J., \& Hobart, C. J. (1987). Age, ego level, and the life-span development of coping and defense processes. Psychology and Aging, 2, 286-293.

Margrett, J. A. (1999). Collaborative cognition and aging: A pilot study. Unpublished doctoral dissertation, Wayne State University.

Margrett, J. A., \& Marsiske, M. (2002). Gender differences in older adults' everyday cognitive collaboration. Collaboration in later life. International Journal of Behavior Development, $26,45-59$. 
Marsiske, M., \& Margrett, J.A. (2006). Everyday problem solving and decision making. In J.E. Birren, \& K.W. Schaie (Eds.), Handbook of the psychology of aging (pp 315-342). New York: Academic Press.

Marsiske, M., \& Willis, S. L. (1995). Dimensionality of everyday problem solving in older adults. Psychology and Aging, 10, 269-283.

McClelland, D. C. (1973). Testing for competence rather than for "intelligence". American Psychologist, 28, 1-14.

Neely, T.L. (2005). The effects of contextual factors on dyadic everyday problem solving in adulthood. Unpublished master's thesis. West Virginia University.

Norusis, M. J. (2002). SPSS 11.0 guide to data analysis. New Jersey: Prentice Hall, Inc.

Norusis, M. J. (2005). Cluster Analysis. In SPSS 13.0 statistical procedures companion. New Jersey: Prentice Hall, Inc.

Salthouse, T. (1991). Cognitive facets of aging well. Generations, 15, 35-38.

Schaie, K. W. (1989). Perceptual speed in adulthood: Cross-sectional and longitudinal studies. Psychology and Aging, 4, 443-453.

Schaie, K. W. (1993). The Seattle Longitudinal Studies of Adult Intelligence. American Psychology Society, 2, 171-175.

Schaie, K. W. (1996). The course of adult intellectual development, American Psychologist, 49, 304-313.

Seeman, T., McAvay, G., Merril, S., Albert, M., \& Rodin, J. (1996). Self-efficacy beliefs and change in cognitive performance: MacArthur studies on successful aging. Psychology and Aging, 11, 538-551.

Sinnott, J. D. (1989). Everyday problem solving: Theory and Applications. New York: Praeger. 
Smith, J. \& Baltes, M. M. (1997). Profiles of psychological functioning in the old and oldest old. Psychology and Aging, 12, 458-472.

Smith, J, and Baltes, M. M. (1998). The role of gender in very old age: Profiles of functioning and everyday life patterns. Psychology and Aging, 13, 676-695.

Staudinger, U. M., \& Baltes, P. B. (1996). Interactive minds: A facilitative setting for wisdom-related performance? Journal of Personality and Social Psychology, 71, 746762.

Strough, J. (2004). Collaborative everyday problem solving: Gain or Loss? R-03 grant funded by the National Institute of Health.

Strough, J., Patrick, J. H., \& Swenson, L. M. (2003). Strategies for solving everyday problems faced by grandparents: The role of experience. In B. Hayslip, Jr., \& J. H. Patrick (Eds.), Working with custodial grandparents (pp. 257-275). New York: Springer Publishing Co.

Tabachnick, B., \& Fidell, L. (2001). Using Multivariate Statistics. Boston, MA: Allyn \& Bacon. Thornton, W. J. L., \& Dumke, H. A. (2005). Age differences in everyday problem-solving and decision-making effectiveness: A meta-analytic review. Psychology and Aging, 20, 8599.

Thurstone, T. G. (1962). Primary Mental Ability for Grades 9-12 (Rev. ed.). Chicago, IL: Science Research Associates.

Vitaliano, P. P., DeWolfe, D. J., Maiuro, R. D., Russo, J., \& Katon, W. (1990). Appraised changeability of a stressor as a modifier of the relationship between coping and depression: A test of the hypothesis of fit. Journal of Personality and Social Psychology, $59,582-592$. 
Watson, T. L., \& Blanchard-Fields, F. (1998). Thinking with your head and your heart: Age differences in everyday problem-solving strategy preferences. Aging, Neuropsychology, and Cognition, 5, 225-240.

Whitfield, K. E., Baker-Thomas, T., Heyward, K., Gatto, M., \& Williams, Y. (1999). Evaluating a measure of everyday problem solving for use in African Americans. Experimental Aging Research, 25, 209-221.

Willis, S. L. (1996). Everyday cognitive competence in elderly persons: Conceptual issues and empirical findings. Gerontologist, 36, 595-601.

Willis, S. L., \& Marsiske, M. (1997). Manual for the Everyday Problems Test. University Park, PA: Department of Human Development and Family Studies, The Pennsylvania State University. 
Table 1

Subsample characteristics by testing group size

\begin{tabular}{|c|c|c|c|c|c|}
\hline \multirow[b]{2}{*}{ Variable } & \multicolumn{2}{|c|}{$\begin{array}{l}\text { Individual Testing } \\
\qquad(N=25)\end{array}$} & \multicolumn{2}{|c|}{$\begin{array}{l}\text { Group Testing } \\
\quad(N=108)\end{array}$} & \multirow[b]{2}{*}{$p$} \\
\hline & $M$ & $S D$ & $M$ & $S D$ & \\
\hline $\operatorname{Age}^{\mathrm{a}}$ & 51.88 & 16.66 & 43.42 & 22.17 & 0.08 \\
\hline Education $^{\mathrm{a}}$ & 15.52 & 3.48 & 14.88 & 3.09 & 0.36 \\
\hline Median Income $^{\mathrm{a}}$ & $\$ 41,000$ & - & $\$ 41,000$ & - & 0.95 \\
\hline Verbal Ability & 20.39 & 6.65 & 19.43 & 5.29 & 0.45 \\
\hline \multirow[t]{2}{*}{ Inductive Reasoning } & 13.83 & 4.64 & 13.97 & 5.40 & 0.90 \\
\hline & $n$ & $\%$ & $N$ & $\%$ & \\
\hline Ethnicity ${ }^{\mathrm{b}}$ & & & & & 0.23 \\
\hline White & 24 & 96.0 & 100 & 94.3 & \\
\hline African American & 0 & 0.0 & 2 & 1.9 & \\
\hline Latino & 0 & 0.0 & 2 & 1.9 & \\
\hline American Indian & 0 & 0.0 & 2 & 1.9 & \\
\hline Asian & 1 & 4.0 & 0 & 0.0 & \\
\hline
\end{tabular}

Note. ${ }^{\mathrm{a}}=\mathrm{T}$-tests were conducted to detect differences between groups; ${ }^{\mathrm{b}}=\mathrm{A}$ Chi square test was performed to detect differences. 
Table 2

Subsample characteristics by testing location

\begin{tabular}{|c|c|c|c|c|c|}
\hline \multirow[b]{2}{*}{ Variable } & \multicolumn{2}{|c|}{$\begin{array}{c}\text { Home } \\
(N=35)\end{array}$} & \multicolumn{2}{|c|}{$\begin{array}{c}\text { Public } \\
(N=98)\end{array}$} & \multirow[b]{2}{*}{$p$} \\
\hline & $M$ & $S D$ & $M$ & $S D$ & \\
\hline $\mathrm{Age}^{\mathrm{a}}$ & 60.13 & 10.79 & 39.61 & 21.75 & 0.01 \\
\hline Education $^{\mathrm{a}}$ & 14.91 & 3.60 & 15.03 & 3.01 & 0.85 \\
\hline Median Income ${ }^{\mathrm{a}}$ & $\$ 40,000$ & - & $\$ 41,000$ & - & 0.56 \\
\hline Verbal Ability & 18.45 & 6.00 & 19.98 & 5.35 & 0.17 \\
\hline \multirow[t]{2}{*}{ Inductive Reasoning } & 10.48 & 4.56 & 15.11 & 5.00 & 0.01 \\
\hline & $n$ & $\%$ & $n$ & $\%$ & \\
\hline Ethnicity $^{\mathrm{b}}$ & & & & & 0.66 \\
\hline White & 34 & 97.1 & 90 & 93.8 & \\
\hline African American & 0 & 0.0 & 2 & 2.1 & \\
\hline Latino & 0 & 0.0 & 2 & 2.1 & \\
\hline American Indian & 1 & 2.9 & 1 & 1.0 & \\
\hline Asian & 0 & 0.0 & 1 & 1.0 & \\
\hline
\end{tabular}

Note. ${ }^{\mathrm{a}}=\mathrm{T}$-tests were conducted to detect differences between groups; ${ }^{\mathrm{b}}=\mathrm{A}$ Chi square test was performed to detect differences. 
Table 3

Subsample characteristics by instruction group status

\begin{tabular}{|c|c|c|c|c|c|}
\hline \multirow[b]{2}{*}{ Variable } & \multicolumn{2}{|c|}{$\begin{array}{l}\text { Self Instructions } \\
\qquad(N=66)\end{array}$} & \multicolumn{2}{|c|}{$\begin{array}{l}\text { Others Instructions } \\
\qquad(N=67)\end{array}$} & \multirow[b]{2}{*}{$p$} \\
\hline & $M$ & $S D$ & $M$ & $S D$ & \\
\hline $\operatorname{Age}^{\mathrm{a}}$ & 45.81 & 22.30 & 44.22 & 20.71 & 0.67 \\
\hline Education $^{\mathrm{a}}$ & 14.91 & 3.26 & 15.09 & 3.08 & 0.74 \\
\hline Median Income ${ }^{a}$ & $\$ 40,000$ & - & $\$ 41,000$ & - & 0.42 \\
\hline Verbal Ability & 18.73 & 5.67 & 20.48 & 5.29 & 0.07 \\
\hline \multirow[t]{2}{*}{ Inductive Reasoning } & 12.80 & 5.19 & 15.11 & 5.11 & 0.01 \\
\hline & $n$ & $\%$ & $n$ & $\%$ & \\
\hline Ethnicity ${ }^{\mathrm{b}}$ & & & & & 0.46 \\
\hline White & 61 & 95.3 & 63 & 94.0 & \\
\hline African American & 1 & 1.6 & 1 & 1.5 & \\
\hline Latino & 1 & 1.6 & 1 & 1.5 & \\
\hline American Indian & 1 & 1.6 & 1 & 1.5 & \\
\hline Asian & 0 & 0.0 & 1 & 1.5 & \\
\hline
\end{tabular}

Note. ${ }^{\mathrm{a}}=\mathrm{T}$-tests were conducted to detect differences between groups; ${ }^{\mathrm{b}}=\mathrm{A}$ Chi square test was performed to detect differences. 
Table 4

Descriptive statistics of background variables by age group

\begin{tabular}{|c|c|c|c|c|c|c|c|c|c|c|}
\hline \multirow[b]{2}{*}{ Variable } & \multicolumn{4}{|c|}{$\begin{array}{l}\text { Younger Adults } \\
\quad(N=52)\end{array}$} & \multicolumn{3}{|c|}{$\begin{array}{l}\text { Middle-aged Adults } \\
\qquad(N=41)\end{array}$} & \multicolumn{3}{|c|}{$\begin{array}{l}\text { Older Adults } \\
\qquad(N=40)\end{array}$} \\
\hline & $N$ & $M$ & $S D$ & Range & $M$ & $S D$ & Range & $M$ & $S D$ & Range \\
\hline $\operatorname{Age}^{\mathrm{d}}$ & 133 & $20.64^{\mathrm{a}, \mathrm{b}}$ & 3.02 & $18.11-33.57$ & $51.62^{\mathrm{a}, \mathrm{c}}$ & 4.88 & $41.16-59.53$ & $69.92^{\mathrm{b}, \mathrm{c}}$ & 6.82 & $60.34-85.95$ \\
\hline Education $^{\mathrm{d}}$ & 131 & $13.50^{\mathrm{a}, \mathrm{b}}$ & 1.77 & $12.00-19.00$ & $15.90^{\mathrm{a}}$ & 3.53 & $9.00-22.00$ & $16.08^{\mathrm{b}}$ & 3.48 & $11.00-22.00$ \\
\hline Marital Length $^{\mathrm{d}}$ & 53 & $1.41^{\mathrm{b}}$ & 0.18 & $1.28-1.54$ & $18.51^{\mathrm{c}}$ & 9.65 & $1.73-35.48$ & $36.22^{\mathrm{b}, \mathrm{c}}$ & 17.09 & $3.96-57.87$ \\
\hline Median Income ${ }^{\mathrm{d}}$ & 131 & $\$ 39000^{\mathrm{a}}$ & - & $\$ 2000-50000$ & $\$ 45000^{\mathrm{a}, \mathrm{c}}$ & - & $\begin{array}{c}\$ 19000- \\
50000\end{array}$ & $\$ 39000^{c}$ & - & $\begin{array}{c}\$ 7000- \\
50000\end{array}$ \\
\hline Physical Health $^{\mathrm{d}}$ & 132 & 1.96 & 0.71 & $1.00-4.00$ & 1.93 & 0.79 & $1.00-4.00$ & 2.03 & 0.84 & $1.00-4.00$ \\
\hline \multirow[t]{2}{*}{ Mental Health ${ }^{\mathrm{d}}$} & 132 & 1.87 & 0.82 & $1.00-4.00$ & 1.78 & 0.65 & $1.00-3.00$ & 1.64 & 0.78 & $1.00-4.00$ \\
\hline & $p$ & $n$ & & $\%$ & $n$ & & $\%$ & $n$ & & $\%$ \\
\hline Ethnicity $^{\mathrm{e}}$ & 0.33 & & & & & & & & & \\
\hline White & & 45 & & 88.2 & 40 & & 97.6 & 39 & & 100.00 \\
\hline African American & & 2 & & 3.9 & 0 & & 0.0 & 0 & & 0.00 \\
\hline Latino & & 2 & & 3.9 & 0 & & 0.0 & 0 & & 0.00 \\
\hline American Indian & & 1 & & 2.0 & 1 & & 2.4 & 0 & & 0.00 \\
\hline Asian American & & 1 & & 2.0 & 0 & & 0.0 & 0 & & 0.00 \\
\hline
\end{tabular}

Note. ${ }^{\mathrm{a}}$ Younger differed from middle-aged, $p<.05$; ${ }^{\mathrm{b}}$ Younger differed from older, $p<.05 ;{ }^{\mathrm{c}}$ Middle-aged differed from older, $p<.05$.

${ }^{\mathrm{d}}$ Analysis of variance was performed to detect age differences; ${ }^{\mathrm{e}} \mathrm{Chi}$-square tests were performed to detect differences. Age, education, and marital length are reported in years. Likert scales for Physical and Mental Health could range from 1-5, higher numbers indicating greater reported impairment. 
Table 5

Descriptive statistics of outcome variables by age group

\begin{tabular}{|c|c|c|c|c|c|c|c|c|c|c|}
\hline \multirow[b]{2}{*}{ Variable } & \multicolumn{4}{|c|}{$\begin{array}{l}\text { Younger Adults } \\
\qquad(N=52)\end{array}$} & \multicolumn{3}{|c|}{$\begin{array}{l}\text { Middle-Aged Adults } \\
\qquad(N=41)\end{array}$} & \multicolumn{3}{|c|}{$\begin{array}{l}\text { Older Adults } \\
\qquad(N=40)\end{array}$} \\
\hline & $N$ & $M$ & $S D$ & Range & $M$ & $S D$ & Range & $M$ & $S D$ & Range \\
\hline Verbal Ability & 131 & $17.63^{\mathrm{a}, \mathrm{b}}$ & 4.77 & $3.00-27.00$ & $20.58^{\mathrm{a}}$ & 5.54 & $7.00-28.00$ & $21.21^{\mathrm{b}}$ & 5.82 & $8.00-29.00$ \\
\hline Inductive Reasoning & 131 & $17.60^{\mathrm{a}, \mathrm{b}}$ & 3.43 & $12.00-26.00$ & $13.13^{\mathrm{a}, \mathrm{c}}$ & 2.28 & $4.00-22.00$ & $9.92^{\mathrm{b}, \mathrm{c}}$ & 4.89 & $1.00-23.00$ \\
\hline Home Past Experience & 133 & 2.18 & 1.18 & $1.00-6.00$ & 2.07 & 1.12 & $1.00-6.00$ & 2.39 & 1.06 & $1.00-6.00$ \\
\hline Home Current Problem & 133 & 3.63 & 1.18 & $1.00-6.00$ & 3.45 & 1.57 & $1.00-6.00$ & 3.60 & 1.34 & $1.00-6.00$ \\
\hline Home Self-efficacy & 133 & 2.13 & 0.71 & $1.00-3.75$ & 1.87 & 0.81 & $1.00-5.50$ & 2.18 & 0.59 & $1.00-4.25$ \\
\hline Friend Past Experience & 133 & 2.38 & 1.11 & $1.00-5.50$ & 2.73 & 1.26 & $1.00-6.00$ & 2.74 & 1.12 & $1.00-6.00$ \\
\hline Friend Current Problem & 133 & 5.03 & 0.90 & $2.00-6.00$ & 5.21 & 0.91 & $2.50-6.00$ & 4.98 & 0.76 & $3.00-6.00$ \\
\hline Friend Self-efficacy & 133 & 1.93 & 0.65 & $1.00-3.50$ & 1.79 & 0.68 & $1.00-4.50$ & 1.96 & 0.50 & $1.00-3.50$ \\
\hline
\end{tabular}

Note. ${ }^{\mathrm{a}}$ Younger differed from middle-aged, $p<.05 ;{ }^{\mathrm{b}}$ Younger differed from older, $p<.05 ;{ }^{\mathrm{c}}$ Middle-aged differed from older, $p<.05$. 
Table 6

Percent agreement during training and actual coding

\begin{tabular}{|c|c|c|c|c|c|c|c|c|}
\hline \multirow[b]{2}{*}{ Schedule of Coding } & \multirow[t]{2}{*}{ Bracketing } & \multicolumn{2}{|c|}{ Fluency } & \multicolumn{5}{|c|}{ Response Style } \\
\hline & & Home & Friend & $\mathrm{PF}$ & $\mathrm{CA}$ & PD & $\mathrm{AD}$ & $\mathrm{CO}$ \\
\hline \multicolumn{9}{|l|}{ Practice on other study protocols } \\
\hline Practice 1 & 86.6 & - & - & 89.2 & 89.2 & 94.6 & 91.9 & 100.0 \\
\hline Practice 2 & 91.6 & - & - & 93.8 & 94.8 & 97.9 & 99.0 & 100.0 \\
\hline Practice 3 & - & - & - & 93.2 & 98.4 & 95.3 & 99.5 & 99.0 \\
\hline \multicolumn{9}{|l|}{ Current Study Protocols } \\
\hline Meeting 2 & 94.6 & 98.6 & 94.3 & 97.8 & 100.0 & 100.0 & 100.0 & 97.8 \\
\hline Meeting 3 & 95.3 & 100.0 & 98.4 & 100.0 & 100.0 & 100.0 & 100.0 & 100.0 \\
\hline Meeting 4 & 91.8 & 91.5 & 95.4 & 100.0 & 100.0 & 100.0 & 100.0 & 100.0 \\
\hline Meeting 5 & - & 97.2 & 98.6 & 97.0 & 98.5 & 98.5 & 100.0 & 100.0 \\
\hline Meeting 6 & - & 100.0 & 94.5 & 100.0 & 100.0 & 100.0 & 97.7 & 97.7 \\
\hline Meeting 7 & - & - & - & 93.0 & 94.8 & 97.4 & 98.3 & 99.1 \\
\hline Meeting 8 & - & - & - & 100.0 & 100.0 & 100.0 & 100.0 & 100.0 \\
\hline Overall Current Study \% Agreement & 93.1 & 96.1 & 94.9 & 97.5 & 98.4 & 99.1 & 99.3 & 99.3 \\
\hline Overall Current Study Kappa & - & - & - & 0.94 & 0.90 & 0.96 & 0.89 & 0.89 \\
\hline
\end{tabular}

Note. $\mathrm{PF}=$ problem-focused, $\mathrm{CA}=$ cognitive-analytical, $\mathrm{PD}=$ passive-dependent, $\mathrm{AD}=$ avoidant-denial, $\mathrm{CO}=$ commentary, “_" indicates that reliability was not calculated. 
Table 7

Means and standard deviations of younger, middle-aged, and older adult groups on problem-solving performance outcome

\begin{tabular}{lcccccc}
\hline & \multicolumn{2}{c}{ Younger Adults } & Middle-aged Adults & \multicolumn{2}{c}{ Older Adults } \\
\cline { 2 - 7 } Outcome Measure & $M$ & $S D$ & $M$ & $S D$ & $M$ & $S D$ \\
\hline Total Participants & \multicolumn{2}{c}{52} & & 38 & & 40 \\
Instrumental Fluency & 10.63 & 4.35 & 12.39 & 6.22 & 9.73 & 4.51 \\
Interpersonal Fluency & 9.21 & 3.34 & 8.18 & 3.92 & 7.35 & 2.95 \\
Total Participants & & 52 & & 40 & & 40 \\
Instrumental Proportion & 0.80 & 0.13 & 0.78 & 0.16 & 0.79 & 0.16 \\
Interpersonal Proportion & 0.80 & 0.18 & 0.83 & 0.18 & 0.89 & 0.14 \\
Total Participants & & 52 & & 35 & & 36 \\
PF Proportion & 0.73 & 0.12 & 0.73 & 0.14 & 0.79 & 0.10 \\
CA Proportion & 0.06 & 0.05 & 0.08 & 0.08 & 0.04 & 0.05 \\
PD Proportion & 0.15 & 0.09 & 0.15 & 0.12 & 0.14 & 0.09 \\
AD Proportion & 0.04 & 0.06 & 0.04 & 0.05 & 0.02 & 0.04 \\
CO Proportion & 0.01 & 0.04 & 0.06 & 0.08 & 0.05 & 0.07 \\
\hline
\end{tabular}

Note. $\mathrm{PF}=$ problem-focused, $\mathrm{CA}=$ cognitive-analytical, $\mathrm{PD}=$ passive-dependent, $\mathrm{AD}=$ avoidant-denial, $\mathrm{CO}=$ commentary remarks; Instrumental refers to home management problems, Interpersonal refers to friend conflict problems; fluency refers to the total number of solutions, proportion refers to the percentage of a given response style compared to the overall total number of solutions. 
Table 8

Analysis of variance examining group differences in solution fluency outcome

\begin{tabular}{lccccc}
\hline Source & $d f$ & $M S$ & $F$ & $\eta$ & $p$ \\
\hline Age & 2 & 79.95 & 2.91 & .05 & .06 \\
Instruction & 1 & 140.21 & 5.52 & .04 & .02 \\
Problem Content & 1 & 453.23 & 47.46 & .28 & .01 \\
Age x Instruction & 2 & 97.85 & 3.86 & .06 & .02 \\
Age x Problem Content & 2 & 42.68 & 4.47 & .07 & .01 \\
Problem Content x Instruction & 1 & 18.67 & 1.96 & .02 & .17 \\
Age x Problem Content x Instruction & 2 & 7.12 & 0.75 & .01 & .48 \\
\hline
\end{tabular}


Table 9

Analysis of variance examining group differences in proactive response style proportions

\begin{tabular}{llllll}
\hline Source & $d f$ & $M S$ & $F$ & $\eta$ & $p$ \\
\hline Age & 2 & 0.04 & 1.27 & .02 & .29 \\
Instruction & 1 & 0.13 & 3.87 & .03 & .05 \\
Problem Content & 1 & 0.15 & 8.45 & .06 & .01 \\
Age x Instruction & 2 & 0.02 & 0.47 & .01 & .63 \\
Age x Problem Content & 2 & 0.07 & 4.01 & .06 & .02 \\
Problem Content x Instruction & 1 & 0.01 & 0.36 & .01 & .55 \\
Age x Problem Content x Instruction & 2 & 0.01 & 0.50 & .01 & .61 \\
\hline
\end{tabular}


Table 10

The 5 subgroups extracted from cluster analysis of 5 response styles

\begin{tabular}{clcccc}
\hline Cluster Rank & \multicolumn{1}{c}{ Cluster Description } & $n$ & \% of sample & S/O (\%) & M/F (\%) \\
\hline 1 & High PF and Low PD, AD, CO & 35 & 28.5 & $65.7 / 34.3$ & $45.7 / 54.3$ \\
2 & High CA and Low PD & 14 & 11.4 & $42.9 / 57.1$ & $50.0 / 50.0$ \\
3 & High CO and Low CA & 12 & 9.8 & $58.3 / 41.7$ & $33.3 / 66.7$ \\
4 & High PD and Low PF, AD, CO & 38 & 30.9 & $44.7 / 55.3$ & $42.1 / 57.9$ \\
5 & High PD, AD and Low PF, CO & 24 & 19.5 & $45.8 / 54.2$ & $33.3 / 66.7$ \\
\hline
\end{tabular}

Note. $\mathrm{S}=$ Self Instructions; $\mathrm{O}=$ Others Instructions, $\mathrm{M}=$ male; $\mathrm{F}=$ female; $\mathrm{PF}=$ problem-focused, $\mathrm{CA}=$ cognitive-analytical, $\mathrm{PD}=$ passive-dependent, $\mathrm{AD}=$ avoidant-denial, $\mathrm{CO}=$ commentary remarks. 
Table 11

Proportion profile means for the 5 subgroups identified in the cluster analysis

\begin{tabular}{lcccccc}
\hline Response Style & $\begin{array}{c}\text { Cluster 1 } \\
\text { (Most } \\
\text { effective) }\end{array}$ & Cluster 2 & Cluster 3 & Cluster 4 & $\begin{array}{c}\text { Cluster 5 } \\
\text { (Least } \\
\text { Effective) }\end{array}$ & $\begin{array}{c}\text { Overall Mean } \\
\text { of all Clusters }\end{array}$ \\
\hline Problem-Focused & .88 & .73 & .79 & .70 & .64 & .75 \\
Cognitive-Analytical & .05 & .18 & .02 & .06 & .05 & .06 \\
Passive-Dependent & .06 & .06 & .16 & .23 & .19 & .15 \\
Avoidant-Denial & .01 & .03 & .04 & .01 & .12 & .03 \\
Commentary & .01 & .06 & .18 & .01 & .02 & .04 \\
\hline
\end{tabular}


Table 12

Regression indices for instrumental fluency outcome

\begin{tabular}{lcccc}
\hline Variables & $R$ & $R^{2} \Delta$ & $\beta$ & $p$ \\
\hline Verbal Ability & .36 & .13 & .26 & .01 \\
Past Experience & .44 & .07 & .22 & .01 \\
Sex & .50 & .05 & .25 & .01 \\
Age & .53 & .03 & -.22 & .01 \\
Education & .56 & .03 & .23 & .02 \\
Instruction Condition & - & - & .08 & .34 \\
Inductive Reasoning Ability & - & - & -.18 & .11 \\
Current Problem Experience & - & - & .01 & .92 \\
Self-efficacy & - & - & .04 & .59 \\
\hline
\end{tabular}

Note. Forward entry method was used, so $R$ and $R^{2}$ change were not reported for nonsignificant predictors. Bolded variables indicate significant predictors. 
Table 13

Regression indices for interpersonal fluency outcome

\begin{tabular}{lcccc}
\hline Variables & $R$ & $R^{2} \Delta$ & $\beta$ & $p$ \\
\hline Inductive Reasoning Ability & .30 & .09 & .30 & .01 \\
Instruction Condition & - & - & .01 & .91 \\
Education & - & - & .09 & .30 \\
Sex & - & - & .13 & .15 \\
Age & - & - & -.12 & .30 \\
Verbal Ability & - & - & -.03 & .71 \\
Past Experience & - & - & -.07 & .40 \\
Current Experience & - & - & .05 & .60 \\
Self-efficacy & - & - & -.07 & .44 \\
\hline
\end{tabular}

Note. Forward entry method was used, so $R$ and $R^{2}$ change were not reported for nonsignificant predictors. Bolded variables indicate significant predictors. 
Table 14

Cluster composition (in \%) of status variables

\begin{tabular}{lccc}
\hline Status & $\begin{array}{c}\text { Revised } \\
\text { Cluster 1 } \\
\text { (Most Proactive) }\end{array}$ & $\begin{array}{c}\text { Revised } \\
\text { Cluster 2 } \\
\text { (Average) }\end{array}$ & $\begin{array}{c}\text { Revised } \\
\text { Cluster 3 } \\
\text { (Least Proactive) }\end{array}$ \\
\hline Younger & 34.7 & 16.6 & 53.2 \\
Middle-aged & 28.6 & 41.7 & 25.8 \\
Older & 36.7 & 41.7 & 21.0 \\
Total & $100 \%$ & $100 \%$ & $100 \%$ \\
Male & 46.9 & 41.5 & 38.7 \\
Female & 53.1 & 58.5 & 61.3 \\
Total & $100 \%$ & $100 \%$ & $100 \%$ \\
Self Instruction & 59.2 & 58.3 & 45.2 \\
Others Instruction & 40.8 & 41.7 & 54.8 \\
$\quad$ Total & $100 \%$ & $100 \%$ & $100 \%$ \\
\hline
\end{tabular}


Table 15

Cluster membership means on selected factors

\begin{tabular}{lcccc}
\hline Factors & $\begin{array}{c}\text { Revised } \\
\text { Cluster 1 } \\
\text { (Most Proactive) }\end{array}$ & $\begin{array}{c}\text { Revised } \\
\text { Cluster 2 } \\
\text { (Average) }\end{array}$ & $\begin{array}{c}\text { Revised } \\
\text { Cluster 3 } \\
\text { (Least Proactive) }\end{array}$ & F \\
\hline Age & $47.79^{\mathrm{b}}$ & $57.27^{\mathrm{c}}$ & $38.83^{\mathrm{b}, \mathrm{c}}$ & 4.96 \\
Education & 14.64 & 16.00 & 14.94 & .91 \\
Verbal Ability & & $22.92^{\mathrm{c}}$ & $19.18^{\mathrm{b}, \mathrm{c}}$ & 2.85 \\
Inductive Reasoning Ability & $18.88^{\mathrm{b}}$ & 11.92 & $15.18^{\mathrm{b}}$ & 3.42 \\
Past Problem Experience & $12.96^{\mathrm{b}}$ & 4.54 & 4.41 & .12 \\
Current Problem Experience & 2.26 & 2.36 & 2.29 & .20 \\
Self-efficacy & 5.98 & 5.82 & 5.06 & .79 \\
Overall Fluency & $17.18^{\mathrm{b}}$ & 21.33 & $21.76^{\mathrm{b}}$ & 3.30 \\
Problem-Focused & $0.84^{\mathrm{b}}$ & $0.79^{\mathrm{c}}$ & $0.67^{\mathrm{b}, \mathrm{c}}$ & 44.49 \\
Cognitive-Analytical & $0.08^{\mathrm{a}, \mathrm{b}}$ & $0.02^{\mathrm{a}}$ & $0.06^{\mathrm{b}}$ & 6.27 \\
Passive-Dependent & $0.06^{\mathrm{a}, \mathrm{b}}$ & $0.16^{\mathrm{a}, \mathrm{c}}$ & $0.22^{\mathrm{b}, \mathrm{c}}$ & 73.00 \\
Avoidant-Denial & $0.01^{\mathrm{b}}$ & 0.04 & $0.05^{\mathrm{b}}$ & 9.03 \\
Commentary & $0.03^{\mathrm{a}}$ & $0.18^{\mathrm{a}, \mathrm{c}}$ & $0.02^{\mathrm{c}}$ & 73.53 \\
\hline
\end{tabular}

Note. ${ }^{\mathrm{a}}$ Cluster 1 differs from $2, p<.05 ;{ }^{\mathrm{b}}$ Cluster 1 differs from $3, p<.05 ;{ }^{\mathrm{c}}$ Cluster 2

differs from $3, p<.05 ;{ }^{+}$indicates nonsignificant trend $p<.10$. 
Table 16

Power analyses for the fluency analysis of variance tests in the current study Type of Analysis $f=.10$ $f=.25$ $f=.40$ (small effect) (medium effect) (large effect)

\begin{tabular}{lccc}
\hline 2-way ANOVAs & .20 & .80 & .99 \\
3-way ANOVAs & .15 & .70 & .98 \\
\hline
\end{tabular}

Note. Power analyses were conducted based on a between-subjects design for the most conservative estimate of power in the study. 
Table 17

Power analyses for the proactive proportion analysis of variance tests in the current study

\begin{tabular}{lccc}
\hline Type of Analysis & $\begin{array}{c}f=.10 \\
\text { (small effect) }\end{array}$ & $\begin{array}{c}f=.25 \\
\text { (medium effect) }\end{array}$ & $\begin{array}{c}f=.40 \\
\text { (large effect) }\end{array}$ \\
\hline 2-way ANOVAs & .20 & .80 & .99 \\
3-way ANOVAs & .15 & .71 & .99 \\
\hline
\end{tabular}

Note. Power analyses were conducted based on a between-subjects design for the most conservative estimate of power in the study. 


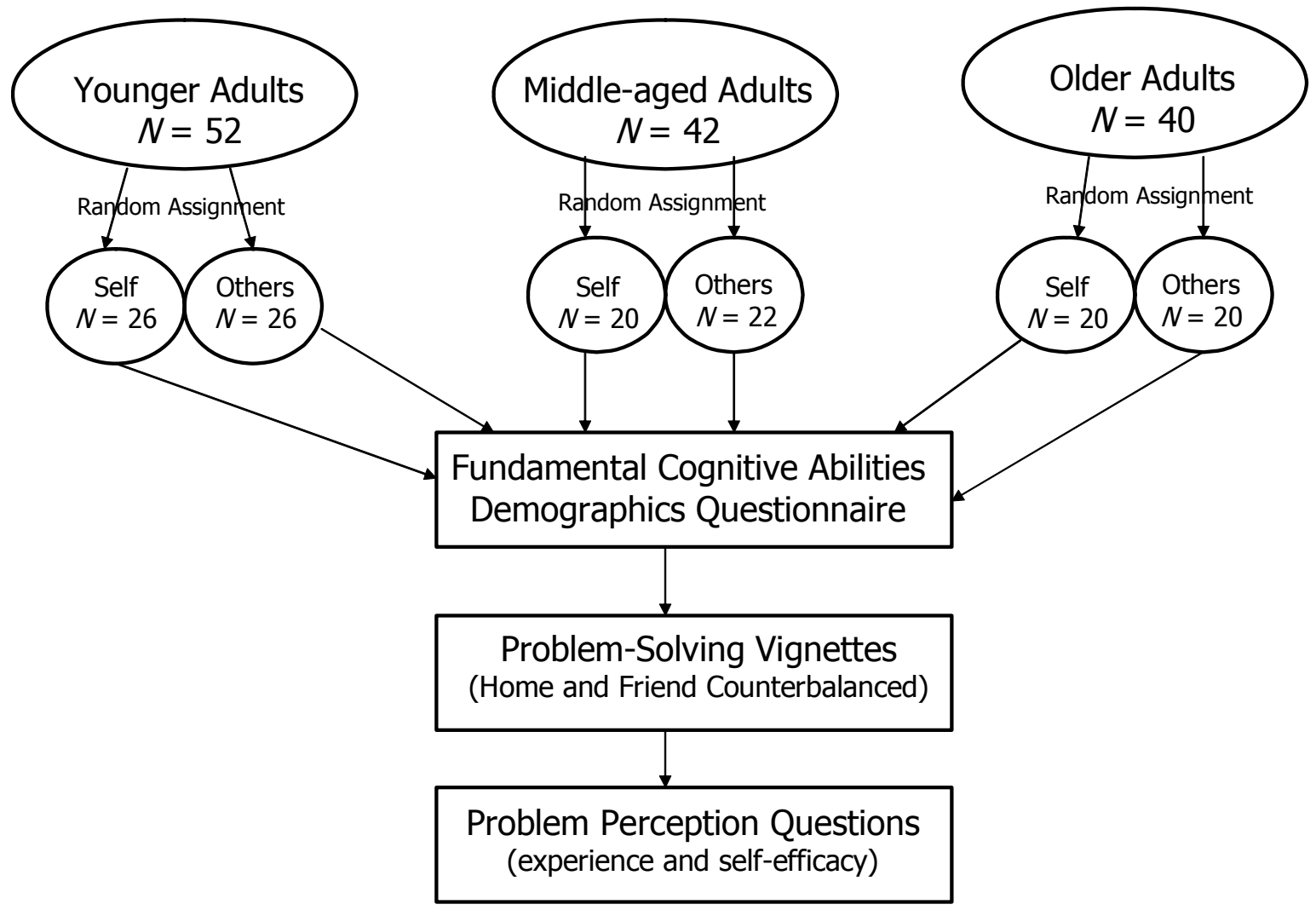

Figure 1. General Session Procedure and Measures Used 


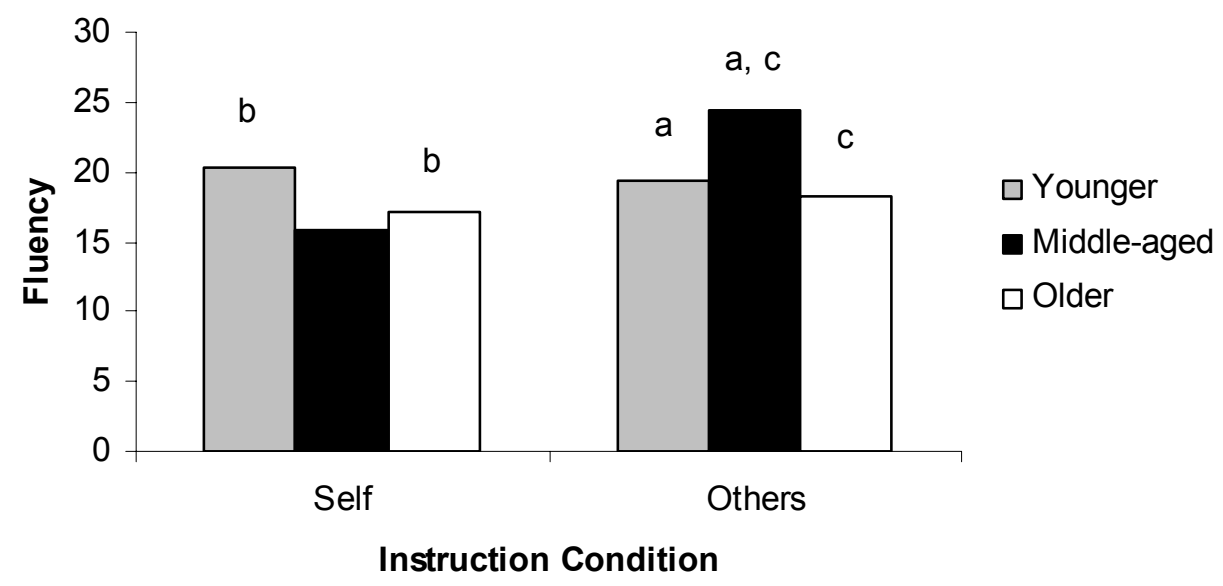

Note $. \mathrm{a}=$ Middle $>$ Younger $; \mathrm{b}=$ Younger $>$ Older; $\mathrm{c}=$ Middle $>$ Older.

Figure 2: Age x Instruction Group Interaction for Fluency Outcome 


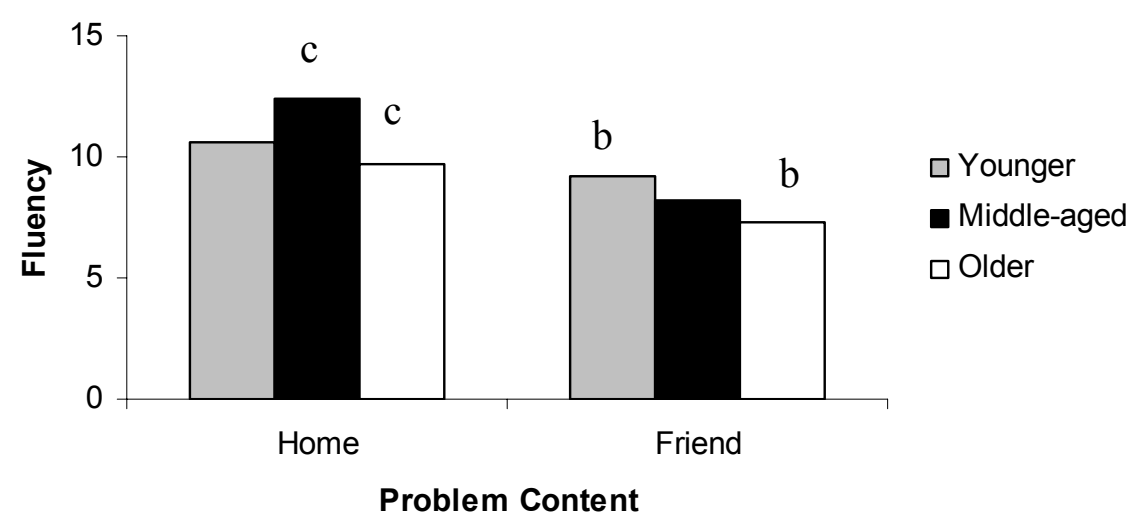

Note. $\mathrm{b}=$ Younger $>$ Older; $\mathrm{c}=$ Middle $>$ Older.

Figure 3. Age x Problem Content Interaction for Fluency Outcome 


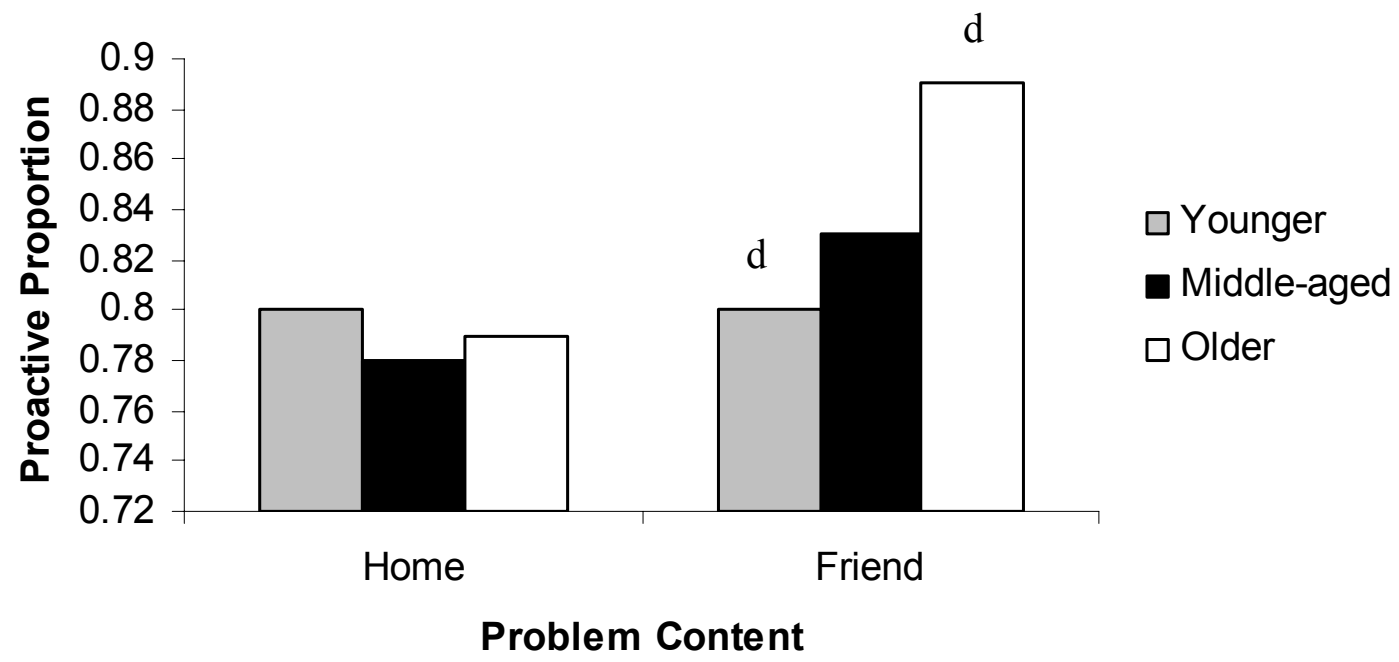

Note. $\mathrm{d}=$ Older $>$ Younger.

Figure 4. Age x Problem Content Interaction for Proactive Proportion 
Appendix A:

Everyday Problem-solving Methodologies for Tasks, Instructions, and Scoring Procedures

\begin{tabular}{|c|c|c|c|c|}
\hline Reference & Task Description & Instructions & Scoring Procedure & Relevant Findings \\
\hline $\begin{array}{l}\text { Allaire \& } \\
\text { Marsiske (2002) }\end{array}$ & $\begin{array}{l}\text { "You have lost your } \\
\text { blood pressure } \\
\text { medication. What do } \\
\text { you do?"- open-ended }\end{array}$ & $\begin{array}{l}\text { Generate as many safe and } \\
\text { effective solutions to each } \\
\text { problem as possible by } \\
\text { writing each solution on a } \\
\text { separate line }\end{array}$ & $\begin{array}{l}\text { Fluency - summing safe } \\
\text { and effective solutions } \\
\text { Quality - raters - } \\
\text { effectiveness from 1-7 }\end{array}$ & $\begin{array}{l}\text { Fluency and Quality were } \\
\text { not correlated } \\
\text { Basic knowledge related to } \\
\text { fluency } \\
\text { No basic cognitive measures } \\
\text { were related to quality }\end{array}$ \\
\hline $\begin{array}{l}\text { Artistico, } \\
\text { Cervone, \& } \\
\text { Pezzuti (2003) }\end{array}$ & $\begin{array}{l}\text { Problems from their } \\
\text { diary study: "A person } \\
\text { finds himself/herself } \\
\text { having difficulties } \\
\text { getting to sleep at night. } \\
\text { What should he/she do? } \\
\text { - open-ended }\end{array}$ & $\begin{array}{l}\text { Provide as many relevant } \\
\text { solutions as possible. } \\
\text { Encouraged to provide a } \\
\text { solution even if it were } \\
\text { one that they themselves } \\
\text { may not choose to adopt - } \\
\text { asked if they could think } \\
\text { of any additional solutions }\end{array}$ & Number of solutions & $\begin{array}{l}\text { On "younger problems", Y } \\
>\text { O } \\
\text { On "older problems", O > Y } \\
\text { On common problems, Y > } \\
\text { O } \\
\text { Self-efficacy interacted with } \\
\text { task }\end{array}$ \\
\hline
\end{tabular}

Blanchard-Fields, 15 vignettes varying in Jahnke, \& Camp emotional salience (all (1995) participants rated their level of "emotional involvement" that each vignette elicited "A man is playing poker with a group of people, and he finds that some of them are cheating. What should he do?" open-ended of any additional solutions (verbal)

Read each vignette and then write, in their opinion, how the situation should be resolved
Based on Cornelius \& Caspi (1987) - 4 response styles

All ages used problemfocused strategies the most. OA used passive-dependent and avoidant-denial strategies more than younger age groups. Younger participants used more cognitive analytical strategies than other age groups. Emotional salience of problem affected strategy use 
Appendix A (continued)

\begin{tabular}{|c|c|c|c|c|}
\hline Reference & Task Description & Instructions & Scoring Procedure & Relevant Findin \\
\hline $\begin{array}{l}\text { Berg, Meegan, \& } \\
\text { Klaczynski } \\
\text { (1999) }\end{array}$ & $\begin{array}{l}\text { Problem Scenarios - } \\
\text { visiting a doctor's } \\
\text { office, attending a } \\
\text { dinner party (between- } \\
\text { subjects) - open-ended }\end{array}$ & $\begin{array}{l}\text { "How would you deal } \\
\text { with this problem? Could } \\
\text { you add anything else? } \\
\text { What would you do if } \\
\text { your solution didn't work? } \\
\text { Are there other reasonable } \\
\text { ways of dealing with the } \\
\text { problem?" Also asked } \\
\text { how often they have been } \\
\text { in this type of situation (1- } \\
\text { 7) }\end{array}$ & $\begin{array}{l}\text { Fluency - mean scored } \\
\text { for each problem }\end{array}$ & $\begin{array}{l}\text { Younger generat } \\
\text { solutions than ol }\end{array}$ \\
\hline $\begin{array}{l}\text { Crawford \& } \\
\text { Channon (2002) }\end{array}$ & $\begin{array}{l}\text { Predicaments task - } \\
\text { everyday awkward } \\
\text { situations - "Anne is in } \\
\text { her office when Tony } \\
\text { comes in......" - open- } \\
\text { ended }\end{array}$ & $\begin{array}{l}\text { Generate as many } \\
\text { potential solutions as } \\
\text { possible within a two- } \\
\text { minute period. State what } \\
\text { the best solution is from } \\
\text { the perspective of the } \\
\text { main character. State what } \\
\text { you would do if in the } \\
\text { situation. Solutions did not } \\
\text { differ for these two } \\
\text { groups. }\end{array}$ & $\begin{array}{l}\text { Effectiveness, number } \\
\text { of solutions (scored for } \\
\text { quality and divided by } \\
\text { the number of solutions) } \\
\text { - proportion score used }\end{array}$ & $\begin{array}{l}\text { Fluency: } \mathrm{Y}>\mathrm{O} \\
\text { Quality: } \mathrm{O}>\mathrm{Y}\end{array}$ \\
\hline $\begin{array}{l}\text { Cornelius \& } \\
\text { Caspi (1987) }\end{array}$ & $\begin{array}{l}\text { Everyday Problem } \\
\text { Solving Inventory } \\
\text { (EPSI) w/ } 4 \text { response } \\
\text { style options: used an } \\
\text { experience/familiarity } \\
\text { rating - close-ended }\end{array}$ & $\begin{array}{l}\text { Imagine yourself in the } \\
\text { situations described and } \\
\text { rate the likelihood that } \\
\text { they would act in each of } \\
\text { the four response modes } \\
\text { listed after each situation }\end{array}$ & Judges' ratings & $\begin{array}{l}\mathrm{Y}<\mathrm{O} \\
\mathrm{Y}=\mathrm{M} \\
\mathrm{O}=\mathrm{M}\end{array}$ \\
\hline
\end{tabular}


Appendix A (continued)

\begin{tabular}{|c|c|c|c|c|}
\hline Reference & Task Description & Instructions & Scoring Procedure & Relevant Findings \\
\hline $\begin{array}{l}\text { Denney \& Pearce } \\
\text { (1989) }\end{array}$ & $\begin{array}{l}\text { Practical Problems Test } \\
\text { - verbal - "A } 65 \text {-year } \\
\text { old woman has just been } \\
\text { widowed and now lives } \\
\text { alone. What can she do } \\
\text { to continue associating } \\
\text { with people?" }\end{array}$ & $\begin{array}{l}\text { I would like you to tell me } \\
\text { how the person in each } \\
\text { situation could deal with } \\
\text { the problem - is that all } \\
\text { you have to say? }\end{array}$ & $\begin{array}{l}\text { Scored based on the } \\
\text { number of safe and } \\
\text { effective (S\&E) } \\
\text { solutions } 1 \text { pt for no } \\
\text { S\&E, } 2 \text { pts for } 1-2 \text { S\&E, } \\
3 \text { pts for } 3 \text { and } 4 \text { pts for } 4 \\
\text { or more } S \& E \text { solutions }\end{array}$ & $\begin{array}{l}\text { Fluency: highest in } 20-40 \\
\text { year groups and declined } \\
\text { thereafter }\end{array}$ \\
\hline $\begin{array}{l}\text { Denney, Pearce, } \\
\text { \& Palmer (1982) }\end{array}$ & $\begin{array}{l}\text { Practical Problems Test } \\
\text { (see above) }\end{array}$ & $\begin{array}{l}\text { Asked to tell how they } \\
\text { thought they would } \\
\text { respond if they were in } \\
\text { each of the hypothetical } \\
\text { situations }\end{array}$ & $\begin{array}{l}\text { Scoring the same as } \\
\text { above }\end{array}$ & $\begin{array}{l}\text { Fluency: highest in } 20-30 \\
\text { year group and declined } \\
\text { thereafter } \\
\text { Most drastic decrease in } 60 \text { - } \\
70 \text {-year-old group }\end{array}$ \\
\hline $\begin{array}{l}\text { Haught, Hill, } \\
\text { Nardi, \& Walls } \\
(2000)\end{array}$ & $\begin{array}{l}\text { Problem Solving } \\
\text { Inventory (PSI) - } \\
\text { described by Denney } \\
\text { and Palmer (1981)- } \\
\text { responses were tape } \\
\text { recorded }\end{array}$ & $\begin{array}{l}\text { "Tell me all the different } \\
\text { ways that the person in } \\
\text { this situation could deal } \\
\text { with the problem. That is, } \\
\text { I would like you to give } \\
\text { me as many different } \\
\text { solutions as you can think } \\
\text { of" (Denney, Tozier, \& } \\
\text { Schlotthauer, 1992) - } \\
\text { prompt }\end{array}$ & $\begin{array}{l}\text { Total number of } \\
\text { solutions for six } \\
\text { problems } \\
\text { Total number of quality } \\
\text { points summed - like } \\
\text { Denney above }\end{array}$ & $\begin{array}{l}\text { Fluency: } \mathrm{M}>\mathrm{Y} \\
\text { No age difference in quality } \\
\text { points }\end{array}$ \\
\hline
\end{tabular}


Appendix A (continued)

\begin{tabular}{|c|c|c|c|c|}
\hline Reference & Task Description & Instructions & Scoring Procedure & Relevant Findings \\
\hline $\begin{array}{l}\text { Heidrich \& } \\
\text { Denney (1994) }\end{array}$ & $\begin{array}{l}\text { Means-End Problem- } \\
\text { Solving Procedure } \\
\text { (MEPS) - social } \\
\text { problem solving } \\
\text { Practical Problems - } \\
\text { instructions and scoring } \\
\text { the same as other } \\
\text { Denney (think of as } \\
\text { many possible ways a } \\
\text { person could respond in } \\
\text { each situation, safe and } \\
\text { effective, total) }\end{array}$ & $\begin{array}{l}\text { "To see how you might go } \\
\text { about solving some real- } \\
\text { life kinds of problems, I } \\
\text { am going to tell you a } \\
\text { story. I will give you the } \\
\text { beginning of the story and } \\
\text { the end of the story. At the } \\
\text { beginning of each story, a } \\
\text { person has a problem. At } \\
\text { the end of the story, the } \\
\text { problem is solved. Your } \\
\text { job will be to tell me all of } \\
\text { the ways you can think of } \\
\text { that the person in the story } \\
\text { can solve his or her } \\
\text { problem." }\end{array}$ & $\begin{array}{l}\text { Counting the number of } \\
\text { relevant means provided } \\
\text { by participant - } \\
\text { statements that reflect } \\
\text { thoughts of actions of } \\
\text { the protagonist that lead } \\
\text { to a desired goal }\end{array}$ & $\begin{array}{l}\text { Age did not predict social or } \\
\text { practical problem solving }\end{array}$ \\
\hline $\begin{array}{l}\text { Margrett \& } \\
\text { Marsiske (2002) }\end{array}$ & $\begin{array}{l}\text { Everyday Problem } \\
\text { Solving Inventory } \\
\text { (EPSI; Cornelius \& } \\
\text { Caspi) }\end{array}$ & $\begin{array}{l}\text { Generate as many safe and } \\
\text { effective solutions as } \\
\text { possible - only move on } \\
\text { after you have exhausted } \\
\text { all possibilities }\end{array}$ & $\begin{array}{l}\text { Total number of safe } \\
\text { and effective solutions }\end{array}$ & $\begin{array}{l}\text { No age findings were } \\
\text { reported - sample was older } \\
\text { adults and focused on } \\
\text { collaborative cognition } \\
\text { Found that men were more } \\
\text { influential than women on } \\
\text { the collaborative EPSI } \\
\text { problem-solving task }\end{array}$ \\
\hline
\end{tabular}


Appendix A (continued)

\begin{tabular}{|c|c|c|c|c|}
\hline Reference & Task Description & Instructions & Scoring Procedure & Relevant Findings \\
\hline $\begin{array}{l}\text { Marsiske \& } \\
\text { Willis (1995) }\end{array}$ & $\begin{array}{l}\text { Practical Problems (PP) } \\
\text { Test (Denney \& Pearce, } \\
\text { 1989) } \\
\text { EPSI }\end{array}$ & $\begin{array}{l}\text { PP: Generate as many safe } \\
\text { and effective solutions as } \\
\text { possible for each problem } \\
\text { EPSI: Imagine they were } \\
\text { in the situation and rate } \\
\text { the likelihood they would } \\
\text { act in each of the } 4 \\
\text { response styles }\end{array}$ & $\begin{array}{l}\text { PP: Total number of safe } \\
\text { and effective solutions - } \\
\text { absolute number - } \\
\text { decreases ceiling effect } \\
\text { seen in other studies by } \\
\text { Denney using the point } \\
\text { system } \\
\text { EPSI: rating system - } \\
\text { correlated with judges } \\
\text { ratings }\end{array}$ & $\begin{array}{l}\text { "Age did not account for a } \\
\text { large proportion of the } \\
\text { variance in any of the } \\
\text { problem-solving factors." }\end{array}$ \\
\hline $\begin{array}{l}\text { Strough, Patrick, } \\
\text { Swenson (2002) }\end{array}$ & $\begin{array}{l}\text { Problem scenarios - } \\
\text { grandparent role } \\
\text { (experience - have you } \\
\text { ever faced this } \\
\text { problem?) }\end{array}$ & $\begin{array}{l}\text { What should the problem } \\
\text { solvers (grandparents) do } \\
\text { to solve the problem? }\end{array}$ & $\begin{array}{l}\text { Coding scheme - } \\
\text { strategy category, total } \\
\text { number of strategies } \\
\text { (included repeated } \\
\text { strategies), unique } \\
\text { strategies }\end{array}$ & $\begin{array}{l}\text { Experience affected types of } \\
\text { strategies used to solve two } \\
\text { types of problems - as } \\
\text { experience increased, the } \\
\text { number of unique strategies } \\
\text { reported decreased. }\end{array}$ \\
\hline $\begin{array}{l}\text { Staudinger \& } \\
\text { Baltes (1996) }\end{array}$ & $\begin{array}{l}\text { Wisdom-related } \\
\text { performance - various } \\
\text { life dilemmas ( } 3) \text { : } \\
\text { Somebody gets a phone } \\
\text { call from a good friend } \\
\text { who says that he/she } \\
\text { can't go on any more, } \\
\text { that she/he has decided } \\
\text { to commit suicide }\end{array}$ & $\begin{array}{l}\text { What should they/one do } \\
\text { and consider? }\end{array}$ & $\begin{array}{l}\text { Criteria for indexing } \\
\text { wisdom-related } \\
\text { knowledge and } \\
\text { judgment - averaged } \\
\text { judges' scores - each } \\
\text { participant received } 5 \\
\text { scores for each criteria }\end{array}$ & $\begin{array}{l}\text { Older adults may profit } \\
\text { more than younger adults } \\
\text { when thinking about another } \\
\text { person (collaboration). }\end{array}$ \\
\hline
\end{tabular}


Appendix A (continued)

\begin{tabular}{|c|c|c|c|c|}
\hline Reference & Task Description & Instructions & Scoring Procedure & Relevant Findings \\
\hline $\begin{array}{l}\text { Watson \& } \\
\text { Blanchard-Fields } \\
\text { (1998)90 }\end{array}$ & $\begin{array}{l}\text { Selected } 4 \text { vignettes } \\
\text { from Blanchard-Fields, } \\
\text { et al.: A person has a 16- } \\
\text { year old daughter who } \\
\text { keeps taking the car } \\
\text { several time a week. The } \\
\text { family only has one car. }\end{array}$ & $\begin{array}{l}\text { What should the person } \\
\text { do? }\end{array}$ & $\begin{array}{l}\text { Classified strategies } \\
\text { into: emotion-focused/ } \\
\text { individualistic, emotion- } \\
\text { focused/interpersonal, } \\
\text { problem-focused/ } \\
\text { individualistic, problem- } \\
\text { focused/interpersonal }\end{array}$ & $\begin{array}{l}\text { Participants preferred } \\
\text { problem-focused strategies } \\
\text { over emotion-focused } \\
\text { strategies for most problems } \\
\text { Older adults preferred a } \\
\text { combination of those } \\
\text { strategies, whereas younger } \\
\text { and middle-aged adults } \\
\text { typically preferred problem- } \\
\text { focused only. }\end{array}$ \\
\hline
\end{tabular}


Appendix B:

Current Study Measures

\begin{tabular}{lll}
\hline Construct & Measure & Source \\
\hline Demographic Information & Personal Data Form & US Census Data \\
Inductive Reasoning & Letter Series Test & Blieszner, et al., 1981 \\
Verbal Ability & Verbal Meaning Test & Thurstone, 1962 \\
Everyday Cognitive Ability & Home and Friend Vignettes & Cornelius \& Caspi, 1987 \\
Experience and Self-efficacy & Problem Appraisals Questionnaire & Designed for Study \\
\hline
\end{tabular}




\section{Appendix C: Personal Data Form}

1. Birthdate: Month Day Year

\section{Current Age:}

2. Current Marital Status (Check only one):
a. Single, not dating
b. Single, dating
c. Separated
d. Divorced
e. Married
f. Widowed
g. Other: Please describe:

If married, Date of Marriage: Month Day __ Year

3. I believe my physical health to be: (Circle one):

\begin{tabular}{cccccc}
1 & 2 & 3 & 4 & 5 & 6 \\
\hline Very good & Good & $\begin{array}{c}\text { Moderately } \\
\text { Good }\end{array}$ & $\begin{array}{c}\text { Moderately } \\
\text { Poor }\end{array}$ & Poor & Very Poor
\end{tabular}

4. I believe my mental health to be: (Circle one):

\begin{tabular}{cccccc}
1 & 2 & 3 & 4 & 5 & 6 \\
\hline Very good & Good & $\begin{array}{c}\text { Moderately } \\
\text { Good }\end{array}$ & $\begin{array}{c}\text { Moderately } \\
\text { Poor }\end{array}$ & Poor & Very Poor
\end{tabular}

5. Circle the highest level of education you have completed:

Grade School/

High School:

Trade, Business or

Technical School

College:

Graduate School

6. Sex: (Circle one):

\begin{tabular}{|c|c|c|c|}
\hline $2^{\text {nd }}$ & $3^{\mathrm{rd}}$ & $4^{\text {th }}$ & $5^{\text {th }}$ \\
\hline $8^{\text {th }}$ & $9^{\text {th }}$ & $10^{\text {th }}$ & $11^{\text {th }}$ \\
\hline
\end{tabular}

$1 \mathrm{yr} \quad 2 \mathrm{yr} \quad 3 \mathrm{yr} \quad 4 \mathrm{yr} \quad 5 \mathrm{yr}$

$1 \mathrm{yr} \quad 2 \mathrm{yr} \quad 3 \mathrm{yr} \quad 4 \mathrm{yr} \quad 5 \mathrm{yr}$

$1 \mathrm{yr} \quad 2 \mathrm{yr} \quad 3 \mathrm{yr} \quad 4 \mathrm{yr} \quad 5 \mathrm{yr} \quad 6 \mathrm{yr}$

Male Female 
7. I believe my life to be: (Circle one)

\begin{tabular}{ccccccc}
1 & 2 & 3 & 4 & 5 & 6 & 7 \\
\hline Extremely & Very & Somewhat & Average & Somewhat & Very & Extremely \\
Happy & Happy & Happy & & Unhappy & Unhappy & Unhappy
\end{tabular}

8. How many people, including yourself, live in your home?

9. How many living children do you currently have?

10. How many of your children live within a 60 -minute drive?

11. Total yearly family income: (Circle one)
a. Under $\$ 4,000$
i. $\$ 18,000$ to $\$ 19,999$
b. $\$ 4,000$ to $\$ 5,999$
j. $\$ 20,000$ to $\$ 21,999$
c. $\$ 6,000$ to $\$ 7,999$
k. $\$ 22,000$ to $\$ 23,999$
d. $\$ 8,000$ to $\$ 9,999$
1. $\$ 24,000$ to $\$ 25,999$
e. $\$ 10,000$ to $\$ 11,999$
m. $\$ 26,000$ to $\$ 27,999$
f. $\$ 12,000$ to $\$ 13,999$
n. $\$ 28,000$ to $\$ 29,999$
g. $\$ 14,000$ to $\$ 15,999$
o. $\$ 30,000$ to $\$ 50,000$
h. $\$ 16,000$ to $\$ 17,999$
p. Over $\$ 50,000$

12. I believe my eyesight to be: (Circle one)

\begin{tabular}{cccccc}
1 & 2 & 3 & 4 & 5 & 6 \\
\hline Very good & Good & $\begin{array}{c}\text { Moderately } \\
\text { Good }\end{array}$ & $\begin{array}{c}\text { Moderately } \\
\text { Poor }\end{array}$ & Poor & Very Poor
\end{tabular}

13. I believe my hearing to be: (Circle one)

\begin{tabular}{cccccc}
1 & 2 & 3 & 4 & 5 & 6 \\
\hline Very good & Good & $\begin{array}{c}\text { Moderately } \\
\text { Good }\end{array}$ & $\begin{array}{c}\text { Moderately } \\
\text { Poor }\end{array}$ & Poor & Very Poor
\end{tabular}

14. Do you wear a hearing aid? (Circle one) Yes No

15. Do you use a walker or wheel chair? Yes No

16. Do you use other assistive devices? Yes No

If yes, specify

17. Approximately how many times have you seen a doctor in the last $\underline{\text { six months? }}$ ? times

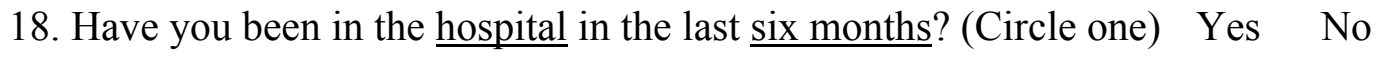
If yes, for how many days? days

19. What is your height? feet and inches 
20. What is your weight? pounds

21. How far can you walk without needing to take a break (without stopping)?

Cannot walk
A few steps
10-99 yards
100-499 yards
500 yards -1 mile
1-3 miles
more than 3 miles

The next eighteen (18) questions ask you about activities that you do everyday. For each of the following categories, please circle the ONE answer you feel best applies to you. PLEASE ANSWER EVERY QUESTION.

22. ABILITY TO USE THE TELEPHONE (Circle one)

a. I use the telephone without assistance (I look up and dial number, etc.).

b. I dial a few memorized numbers.

c. I answer the telephone, but don't dial out.

d. I don't use the telephone at all.

23. SHOPPING (Circle one)

a. I shop alone and return home independently with purchases.

b. When I shop, somebody must provide transportation.

c. When I shop, I need somebody's help.

d. I am completely unable to shop.

24. FOOOD PREPARATION (Circle one)

a. I plan, prepare, and serve good meals independently.

b. I can prepare my own meals if supplied with the ingredients.

c. I can heat and serve prepared meals.

d. I need to have meals prepared and served.

25. HOUSEKEEPING (Circle one)

a. I maintain my home alone or I need occasional help (e.g., heavy work, domestic help)

b. I perform light daily tasks such as dishwashing and bed making.

c. I perform most light daily tasks, and I keep it very clean and tidy.

d. I need help with all home maintenance tasks.

e. I don't participate in any housekeeping tasks. 


\section{LAUNDRY (Circle one)}

a. I do all of my laundry.

b. I only launder small items - rinse socks, stockings, etc.

c. All of my laundry is done by others.

27. TRANSPORTATION (Circle one)

a. I drive my own car for long-distance and short trips.

b. I drive my own car for local (short) shorts only.

c. I depend on someone else to help me get around (relative, friend, taxi driver).

d. I am not able to travel by car.

28. RESPONSIBILITY FOR OWN MEDICATION (Circle one)

a. I am responsible for taking my own medication in the correct dosage at the correct time

b. I am responsible for taking my own medication, but someone needs to prepare it (e.g., load syringe, open pill bottle).

c. Someone gives me my medication (e.g., gives me a shot, reminds me when to take medication, brings me my pills).

\section{ABILITY TO HANDLE FINANCES (Circle one)}

a. I manage my financial matters independently (budgets, banking, write checks, pay rent, bills), collect and keep track of income.

b. I manage day-to-day purchases, but need help with banking, major purchases, etc.

c. Someone must help me with all of my finances.

30. When it comes to writing checks, paying bills, and keeping financial records:

a. I never did the task, and would have difficulty now.

b. I never did the task, and could do it now.

c. I have no difficulty performing the task by myself.

d. I do have difficulty, but I perform the task myself.

e. I require some assistance to get the task done.

f. I require total assistance; someone must do the task for me.

31. When it comes to assembling tax records and making out business and insurance papers:

a. I never did the task, and would have difficulty now.

b. I never did the task, but could do it now.

c. I have no difficulty performing the task by myself.

d. I do have difficulty, but I perform the task myself.

e. I require some assistance to get the task done.

f. I require total assistance; someone must do the task for me. 
32. When it comes to shopping alone for clothes, household necessities, and groceries:

a. I never did the task, and would have difficulty now.

b. I never did the task, but could do it now.

c. I have no difficulty performing the task by myself.

d. I do have difficulty, but I perform the task myself.

e. I require some assistance to get the task done.

f. I require total assistance; someone must do the task for me.

33. When it comes to playing a game of skill such as bridge, other card games, or chess:

a. I never did the task, and would have difficulty now.

b. I never did the task, but could do it now.

c. I have no difficulty performing the task by myself.

d. I do have difficulty, but I perform the task myself.

e. I require some assistance to get the task done.

f. I require total assistance; someone must do the task for me.

34. When it comes to heating water for coffee or tea and turning off the stove:

a. I never did the task, and would have difficulty now.

b. I never did the task, but could do it now.

c. I have no difficulty performing the task by myself.

d. I do have difficulty, but I perform the task myself.

e. I require some assistance to get the task done.

f. I require total assistance; someone must do the task for me.

35. When it comes to preparing a balanced meal:

a. I never did the task, and would have difficulty now.

b. I never did the task, but could do it now.

c. I have no difficulty performing the task by myself.

d. I do have difficulty, but I perform the task myself.

e. I require some assistance to get the task done.

f. I require total assistance; someone must do the task for me.

36. When it comes to keeping track of current events:

a. I never did the task, and would have difficulty now.

b. I never did the task, but could do it now.

c. I have no difficulty performing the task by myself.

d. I do have difficulty, but I perform the task myself.

e. I require some assistance to get the task done.

f. I require total assistance; someone must do the task for me. 
37. When is comes to paying attention to, and understanding, a TV program, book, or magazine:

a. I never did the task, and would have difficulty now.

b. I never did the task, but could do it now.

c. I have no difficulty performing the task by myself.

d. I do have difficulty, but I perform the task myself.

e. I require some assistance to get the task done.

f. I require total assistance; someone must do the task for me.

38. When it comes to remembering appointments, family occasions, and medications:

a. I never did the task, and would have difficulty now.

b. I never did the task, but could do it now.

c. I have no difficulty performing the task by myself.

d. I do have difficulty, but I perform the task myself.

e. I require some assistance to get the task done.

f. I require total assistance; someone must do the task for me.

39. When it comes to traveling outside my neighborhood:

a. I never did the task, and would have difficulty now.

b. I never did the task, but could do it now.

c. I have no difficulty performing the task by myself.

d. I do have difficulty, but I perform the task myself.

e. I require some assistance to get the task done.

f. I require total assistance; someone must do the task for me.

40. What kind of work have you done most of your life?

a. For what kind of business, company, or agency is that?

41. Are you currently employed? Yes No

42. Are you currently a student? Yes No

a. If yes, are you attending full-time or part-time? Full Part

43. Are you current retired? Yes No

44. How many hours in a typical week do you spend in paid work? Hours

45. How many hours in a typical week do you spend in unpaid volunteer work? Hours

46. How much financial difficulty do you have paying your bills? Would you say: (Circle one)

\begin{tabular}{|c|c|c|c|c|}
\hline 1 & 2 & 3 & 4 & 5 \\
\hline $\begin{array}{c}\text { A great deal of } \\
\text { difficulty }\end{array}$ & Some difficulty & A little difficulty & No difficulty & Does not apply \\
\hline
\end{tabular}


47. For descriptive purposes, could you please check the ethnicity category to which you most belong:

African American/Black

American Indian/Alaskan Native

Asian/Pacific Islander

Caucasian/White

Latino/Hispanic

Other: Please indicate 
Appendix D: Everyday Problem Solving Inventory 1

Cornelius \& Caspi (1987)

\section{Please read all of the directions below:}

On the following pages, situations are listed that people might experience in their daily lives. We are interested in how people deal with situations like these when they arise. Certainly people can react in a variety of ways. For each of the four situations (described on the following pages), imagine how you would approach the problem.

After you imagine how you would approach the problem, write down as many solutions as possible to the problem, until you can not think of any more solutions to offer. Please list each separate solution on a separate line. If possible, you should try to come up with more than one solution for each problem. There is no limit on the number of solutions you can generate. If you can not think of a solution to a problem, please write "none" so that we know you attempted to answer the question. When you can think of no further solutions for a particular problem, go on to the next one. Please note that there are no "right" or "wrong" answers. An example is given below.

\section{Example}

How could you deal with this problem?

Sample problem:

After inviting a friend to lunch, a person discovers when they are ready to pay the bill that they have forgotten their money.

Sample solutions:

1. Discuss with manager

2. Ask friend to pay this time

3. Go home for money

4. Pay with a credit card 
How could you deal with this problem?

Problem: A person has done something that offended one of their friends. 
Could you do anything else?

Problem: A person has done something that offended one of their friends. 
Of all of the solutions that you listed on the previous two pages, which ONE solution would you try first to solve this problem? Place a star (*) next to that ONE solution that you would attempt first. 
What could you do if the solution that you just starred (*) did not work? 
How could you deal with this problem?

Problem: A person has let their home become too cluttered with items they use infrequently but which have much sentimental value for them. 
Could you do anything else?

Problem: A person has let their home become too cluttered with items they use infrequently but which have much sentimental value for them. 
Of all of the solutions that you listed on the previous two pages, which ONE solution would you try first to solve this problem? Place a star (*) next to that ONE solution that you would attempt first. 
What could you do if the solution that you just starred (*) did not work? 
How could you deal with this problem?

Problem: A person lost or broke an expensive item they borrowed from a friend. 
Could you do anything else?

Problem: A person lost or broke an expensive item they borrowed from a friend. 
Of all of the solutions that you listed on the previous two pages, which ONE solution would you try first to solve this problem? Place a star (*) next to that ONE solution that you would attempt first. 
What could you do if the solution that you just starred (*) did not work? 
How could you deal with this problem?

Problem: Because of a lack of time, a person has let household chores pile up. 
Could you do anything else?

Problem: Because of a lack of time, a person has let household chores pile up. 
Of all of the solutions that you listed on the previous two pages, which ONE solution would you try first to solve this problem? Place a star (*) next to that ONE solution that you would attempt first. 
What could you do if the solution that you just starred (*) did not work? 
Appendix E: Everyday Problem Solving Inventory 2

Cornelius \& Caspi (1987)

\section{Please read all of the directions below:}

On the following pages, situations are listed that people might experience in their daily lives. We are interested in how people deal with situations like these when they arise. Certainly people can react in a variety of ways. For each of the four situations (described on the following pages), imagine how the person could approach the problem.

After you imagine how the person could approach the problem, write down as many solutions as possible to the problem, until you can not think of any more solutions to offer. Please list each separate solution on a separate line. If possible, you should try to come up with more than one solution for each problem. There is no limit on the number of solutions you can generate. If you can not think of a solution to a problem, please write "none" so that we know you attempted to answer the question. When you can think of no further solutions for a particular problem, go on to the next one. Please note that there are no "right" or "wrong" answers. An example is given below.

\section{Example}

How could the person deal with this problem?

Sample problem:

After inviting a friend to lunch, a person discovers when they are ready to pay the bill that they have forgotten their money.

Sample solutions:

1. Discuss with manager

2. Ask friend to pay this time

3. Go home for money

4. Pay with a credit card 
How could the person deal with this problem?

Problem: A person has done something that offended one of their friends. 
Could the person do anything else?

Problem: A person has done something that offended one of their friends. 
Of all of the solutions that you listed on the previous two pages, which ONE solution should the person try first to solve this problem? Place a star (*) next to that ONE solution that the person should attempt first. 
What could the person do if the solution that you just starred (*) did not work? 
How could the person deal with this problem?

Problem: A person has let their home become too cluttered with items they use infrequently but which have much sentimental value for them. 
Could the person do anything else?

Problem: A person has let their home become too cluttered with items they use infrequently but which have much sentimental value for them. 
Of all of the solutions that you listed on the previous two pages, which ONE solution should the person try first to solve this problem? Place a star (*) next to that ONE solution that the person should attempt first. 
What could the person do if the solution that you just starred $\left({ }^{*}\right)$ did not work? 
How could the person deal with this problem?

Problem: A person lost or broke an expensive item they borrowed from a friend. 
Could the person do anything else?

Problem: A person lost or broke an expensive item they borrowed from a friend. 
Of all of the solutions that you listed on the previous two pages, which ONE solution should the person try first to solve this problem? Place a star (*) next to that ONE solution that the person should attempt first. 
What could the person do if the solution that you just starred $\left({ }^{*}\right)$ did not work? 
How could the person deal with this problem?

Problem: Because of a lack of time, a person has let household chores pile up. 
Could the person do anything else?

Problem: Because of a lack of time, a person has let household chores pile up. 
Of all of the solutions that you listed on the previous two pages, which ONE solution should the person try first to solve this problem? Place a star (*) next to that ONE solution that the person should attempt first. 
What could the person do if the solution that you just starred $\left({ }^{*}\right)$ did not work? 


\section{Appendix F: \\ Directions/Guidelines for Bracketing EPSI forms Adapted from Margrett, 1999; Neely, 2005}

1. Do not be concerned with spelling, punctuation, or grammar mistakes. You are not concerned with the quality or type of solution at this point. See the next guideline.

2. Punctuation such as commas, periods, slashes, and dashes is typically a good indicator for separate thoughts; however solutions may or may not be separated by punctuation. View each solution and phrase carefully.

a. Example: I would tell them: they are wrong, to work harder next time, that I don't care.

i. You would bracket like this: (I would tell them: they are wrong), (to work harder next time), (I don't care). They are all independent thoughts. You can not assume they go together.

ii. Note: When you type this up in Excel, you would type: I would tell them they are wrong, I would tell them to work harder next time, I would tell them I don't care as separate items. Do not just put "to work harder next time" because that will not mean anything to the response style coder later on.

3. Although numbered or bulleted solutions are generally useful guidelines, independent thoughts may or may not be numbered. And there might be more than one solution in any given number or bullet. Be careful!

4. Do not assume that the participant wanted a solution to go together. There might be more than one solution per line.

a. Example: I would call the friend and apologize.

i. You would bracket like this: (I would call the friend) and (apologize). In this example, there are two solutions on one line.

b. Example: Make a joke of it but do it yourself.

i. You would bracket like this: (Make a joke of it) but (do it yourself)

5. Each solution must be able to stand alone. This does not mean that the solution has to make sense with the problem at hand. The solution does not have to relate to the problem. I will code for this later. Bracketing only involves the division of independent thoughts.

a. Example: I would call him aside and tell him to calm down and get control of himself. Although the participant has this all on one line, there are independent thoughts that can stand alone.

i. You would bracket like this: (I would call him aside) and (tell him to calm down) and (get control of himself).

b. Example: Ask if the item will go on sale and when.

i. You would bracket like this: (Ask if the item will go on sale) and (when). Asking if and when are two different things that could stand alone. 


\section{Appendix F (continued)}

c. Example of when NOT to bracket separate thoughts: Check to see if adequate safe parking is available.

i. You would NOT bracket like this: (Check to see if adequate) (safe parking is available.). The first part does not stand alone. You need the second half of the sentence.

ii. You would bracket like this: (Check to see if adequate safe parking is available.)

6. Be very cautious when you see the words "and", "or", "yet", and "but". Sometimes these words are good indicators of separate thoughts, but sometimes they are not. Refer to the rules above (e.g., can it stand alone, is it a separate source of information). When in doubt, separate the solutions. I can always go back and merged them if necessary. The key question is whether a part of the solution can stand alone as an independent thought. If so, bracket it as separate. If not, leave it as one.

a. Example: I would resolve the issue and get the parties on the same page.

i. This is vague and will be difficult to bracket. When in doubt separate like this: (I would resolve the issue) and (get the parties on the same page). Each solution can stand alone.

ii. Another point to make is that you should not assume that the participant meant for the solution to go together. See Guideline 4 above.

7. Bracket commentary

a. Example: I am miserable - I would have to confess.

i. You would bracket like this: (I am miserable) - (I would have to confess). "I am miserable", although it is not a solution, can stand alone and should be bracketed. Remember you are not coding right now, you are just bracketing for independent thoughts that can stand alone.

b. Example: I am currently having this problem. It is a real pain.

i. You would bracket like this: (I am currently having this problem). (It is a real pain).

c. Example: This problem is stupid.

i. You would bracket like this: (This problem is stupid.)

8. Bracket words of wisdom.

a. Example: Choose friends wisely. They should not gossip.

i. You would bracket like this: (Choose friends wisely.) (They should not gossip.) This is an example of one words of wisdom statement and one commentary statement, so that is why it is important to separate independent thoughts like in this example.

b. Example: Be polite and listen - you might learn something.

i. You would bracket like this: (Be polite) and (listen) - (you might learn something.) For this example, there are two solutions and one piece of wisdom. Again, that is why it is important to recognize words of wisdom as separate thoughts. 


\section{Appendix F (continued)}

9. Bracket each separate source of information as separate thoughts.

a. Example: I would tell my friend, neighbor, and family.

i. You would bracket like this: (I would tell my friend), (neighbor), and (family).

ii. Note: Do not just type up "family". Provide the action portion of the solution. See Guideline 2 note.

10. Bracket each individual/specific source of help as separate thoughts.

a. Example: I would talk to my mom, dad, and brother.

i. You would bracket like this: (I would talk to my mom), (dad,) and (brother)

ii. Note: Do not just type up "dad". Provide the action portion of the solution. See Guideline 2 note.

11. Bracket each method as separate thoughts.

a. Example: I would contact them by phone, mail, and in person.

i. You would bracket like this: (I would contact them by phone), (mail), and (in person).

ii. Note: Do not just type up "mail". Provide the action portion of the solution. See Guideline 2 note.

12. Bracket solutions, which say "Do nothing," "Sleep on it", "Think it Over".

a. Example: I would forget about it.

i. You would bracket like this: (I would forget about it).

13. Bracket phrases that mention things like "I don't know", "Not sure", "None". This will be coded as a non-response or other category later, but for bracketing purposes consider it as a separate thought.

14. Bracket different emotions as separate thoughts.

a. Example: I would get frustrated and worry.

i. You would bracket like this: (I would get frustrated) and (worry).

15. Bracket religious convictions such as "I would pray about it".

16. Even if there are solutions that are the same but reworded differently, bracket them. I will catch redundancy later.

a. Example: Face the music, own up and tell them.

i. You would bracket like this: (Face the music), (own up) and (tell them).

Although all three things basically mean the same, bracket them separately. Fluency coding will catch this later. 


\section{Appendix F (continued)}

17. Bracket both positive and negative reactions. Negative reactions are statements such as "I would not hire a maid service." That would be bracketed, and may be coded as "negative phrases" later.

18. Bracket "If, then" statements ALONG WITH the solution. The "If, then" statements do not stand alone and should not be counted as a separate solution.

a. Example: If it is several sets of sheets, I would keep just a set.

i. You would bracket like this: (If it is several sets of sheets, I would keep just a set).

ii. NOTE: Enter all of the bracketed information. If there are two solutions that follow a "If, then" statement, retype the "If, then" part.

*Example: If it is several sets of sheets, I would keep one set and donate the rest to charity. You would bracket like this: (If it is several sets of sheets, I would keep one set) and (donate the rest to charity). You would enter like this: If it is several sets of sheets, I would keep one set. If it is several sets of sheets, I would donate the rest to charity. - We need to have the qualifier for most phrases to make sense when looking at them separately in Excel. 


\section{Appendix G: \\ Fluency Coding and Data Entry Guidelines (done all at once) Adapted from, Margrett, 1999; Neely, 2005}

1. All responses on the EPSI protocol have already been bracketed to denote independent solutions (e.g., "Call my friend and apologize" is bracketed as two solutions: "Call my friend" and "apologize").

2. The bracketed solutions can stand alone; however there may be solutions that overlap (e.g., the participant writes "apologize" twice or says it in two different ways:

"apologize" and "say I'm sorry"). These two solutions would be bracketed separately, but it should only count as one solution for fluency coding.

3. The goal of fluency coding is to determine how many SEPARATE or UNIQUE solutions the participant generated. If they write "apologize" 5 times, they would only get a score of 1 NOT 5.

4. Each independent solution has already been entered into an Excel file: Edc_lab/Everyday Life Study/Data Files/EPSI. This is the file that you want to work with.

5. Because the file is very large (range might go up to 38 solutions!!), each original EPSI file has been transposed so that the solutions go down instead of across. These are denoted by the yellow tabs. These are the sheets that you want to code on.

6. There is a column after each solution for the fluency coding (e.g., Off01f, Off02f).

7. You want to take each COLUMN (id) at a time and look downward.

8. It might be easier to hide some rows (e.g., hide Off01st and Off01RS). You would want to keep the rows labeled Off01pg and Off01f. Knowing the page number of the solution might help determine what the participant meant by something.

9. Place a " 1 " in the fluency row if it is a solution. Place a " 0 " next to the solution if it is not a solution.

A. Solutions (1) are: independent solutions that make sense and are not repeated.

B. Non-Solutions ( 0 ) are: solutions that are repeated, solutions that do not make sense, solutions that are commentary, solutions that say "no"

C. Example: Off01 = "Apologize", Off02 = "Call my Friend", Off03 "Say I'm sorry". You would fluency code like this: "1" next to "Apologize", "1" next to "Call my Friend", and " 0 " next to "Say I'm sorry". The $1^{\text {st }}$ and $3^{\text {rd }}$ "solutions are the same. Always code the first solution as 1 and the second as 0 if they are the same. Also, in the computer, enter the solution \# of the similar solution (e.g., enter in the Off01 row "Off03")

D. You are coding with 0 's and 1's so that eventually we can just add up the "1's" to determine the fluency score of each participant. Response Style coding is done after fluency coding. 
10. Some exemplars:

\section{Appendix G (continued)}

A. DO COUNT:

i. "I would not" solutions (e.g., I would not cry, I would not approach the person). These are still considered solutions that the person would not attempt and are involved in problem-solving.

ii. Some solutions start off with a "no" then a comma and a solution. Do not worry about the no and code the solution part. If the second part of the phrase is comprehensible and not commentary, count it (e.g., No, I would apologize). Do not count it if the second part is commentary or nonsense (e.g., No, good friends are hard to find).

B. DO NOT COUNT

i. No solutions (e.g., none, no, I don't know, I don't think I could, nope, not in good conscience, other than what I already put, no). These are not solutions.

ii. Commentary (e.g., Good friends would not do that, This study is boring)

iii. Nonsense Phrases (e.g., His thoughts). This phrase is not comprehensible, and we have no idea what the participant meant. Do not infer meaning.

11. If you come across a solution that is not entered correctly, which means it probably was not bracketed correctly, you can fix it in the file (e.g., Let it pass, they'll get over it). That should be entered as two separate solutions - it is ok to fix it, but please note it in the EDL binder under the "information" tab. List the ID and what you changed. It would be a good idea to discuss this with Tara before changing the EPSI file.

12. If there is a statement that is questionable (might have been typed incorrectly), please pull the actual protocol (hardcopy) and verify before changing anything (e.g., Oh vs. No vs Or). 
Appendix H:

Response Style Coding Guidelines

(Taken from Cornelius \& Caspi, 1987 and Blanchard-Fields, Jahnke, \& Camp, 1995)

1) Problem-Focused Action (entered into Excel as PF)

a. Cornelius \& Caspi: involves self-initiated, overt behaviors that deal directly with a problem and its effects (e.g., taking direct action to alter a situation, seeking information or advice about it [from the problem source - if the participant mentions a source such as a relative or friend that isn't related to the problem it would be passive-dependent]).

i. Examples: Try to make the repairs yourself. Try to find out why you did not get the job. Invite them to your home. Try to change your behavior. Take precautions to insure your safety. Obtain more information on how to complete the form correctly.

b. Hypothetical examples from EDL: Clean up the mess. Have a garage sale. Approach the offended friend. Talk about the situation. Apologize. Buy a new item. Ask a friend what they have done in the past to get rid of the clutter. Call my friend for advice about household chores.

2) Cognitive-Analytical Thinking (entered into Excel as CA)

a. Cornelius \& Caspi: refers to intrapsychic or cognitive efforts to manage one's subjective appraisal of a situation, to understand it better, to solve the problem through logical analysis, or to reinterpret the situation from a different perspective.

i. Examples: Try to understand your landlord's view and decide whether they are necessary repairs. Try to figure out on your own what was wrong. Re-evaluate how important it is to attend. Try to evaluate realistically whether the criticism is valid. Try to see the positive side of the situation. Try to figure out why they do not seem to make an effort to visit you.

b. Hypothetical Examples from EDL: Evaluate the friendship. Figure out how sentimental the stuff really is. Try to figure out why the person is offended. Question my needs. Determine why I let my chores pile up.

c. Additional Comments

i. Precursors, Others' perspectives, reevaluate situation

3) Passive-Dependent Behavior(entered into Excel as PD)

a. Cornelius \& Caspi: includes attempts to avoid or withdraw from a situation, the absence of self-initiated behaviors to alter a situation (e.g., doing nothing in situation), or actions involving dependence on another person to solve the problem.

i. Examples: Try to get someone to settle the dispute between you and your landlord. Ask someone to fill out the form for you. Ask someone to accompany you. Do not pursue it. Do not change your habit but avoid it when the person is around you. Do nothing. 


\section{Appendix H (continued)}

b. Hypothetical Examples from EDL: Learn to live with the mess. Do nothing. Die. Move to Canada. Ask my mom to clean up the mess. Hire a maid. Ask a friend for help to clean up. Avoid situation where that friend is.

c. Additional Comments

i. Action - behavior or lack of behavior, inaction (do nothing)

4) Avoidant Thinking-Denial (entered into Excel as $\mathrm{AD}$ )

a. Cornelius \& Caspi: includes attempts to control the meaning of a situation through cognitive avoidance, denial of the situation or of one's personal responsibility in it, selective attention to things other than the situation itself, and attempts to manage one's affective reaction (emotions) to a situation through the suppression of one's emotions

i. Examples: Accept the situation. Don't dwell on the situation. Blame the company for not making the instructions more clear. Avoid worrying about it. Ignore the criticism. Do not be overly concerned about it and turn your attention to other things. Complain to a friend or other person about the unfairness of the decision.

b. Hypothetical Examples from EDL: Dwell on the problem. Complain to my friend about the mess. Avoid crying. Cry about the problem. Accept that you will lose sentimental items. Blame my children for the messy house. Ignore it.

c. Additional Comments

i. Complaining is avoiding your personal responsibility in the situation/with the problem. Blaming is ignoring your personal responsibility.

ii. Do not lead to a concrete solution to actually solve the problem at hand.

5) Commentary (entered into Excel as $\mathrm{CO}$ )

a. Participants often do not come up with solutions; instead they offer "words of wisdom" or commentary about the problem or the person in the problem or the student in general. Context.

b. Hypothetical Examples from EDL: Good friends are hard to find. He will get over it. This study is dull. I currently have this problem. I'm dealing with an old person's house right now.

6) Nonsense Stuff (entered into Excel as NO)

a. These are simply statements that are incomprehensible or do not make any sense with the problem at hand. Fragments/unfinished thoughts

b. Hypothetical Examples from EDL: His words.

7) Other (entered into Excel as OT)

a. If the solution does not fit into any other category, place it into this one. 


\section{Appendix H (continued)}

Note: Problem-Focused and Cognitive Analysis represent more instrumental proactive modes of problem solving than the other two modes. They also involve direct efforts to solve the problem either through direct action or logical analysis. Passive-Dependent and Avoid-Denial modes represent more emotional management styles than the other two, and they deal more with emotional withdrawal and managing one's emotions. (This paragraph was taken almost verbatim from Blanchard-Fields, et al., 1995, p. 175).

Questions to address when coding actual protocols:

1. Action (PF or $\mathrm{PD})$ vs. Thinking (CA or $\mathrm{AD})$

2. Does solution lead to concrete result? If yes, $\mathrm{PF}$ or $\mathrm{CA}$. If no, $\mathrm{PD}, \mathrm{AD}$.

3. Self (PF) vs. Others (PD) doing the action. 
Appendix I

Because of a lack of time, a person has let household chores pile up.

Response Style Exemplar Solutions

Problem-focused

- Offer person your help to catch up on chores

- Take a day off

- Set aside one day to catch up

- Use a weekend to do all of them at once

- Start cleaning

- Do them instead of doing other things

- I would work at night to catch up

Cognitive-Analytical

- Make a to-do list

- Get organized and plan out each day

- Set up a schedule

- Prioritize chores

- Set goal

- Reschedule tasks to make room for time

- The person should analyze the situation

Passive-Dependent

- Do nothing

- Get/Hire a maid

- Take a deep breath

- Enlist family to help with chores

- Grin and bear it

- Ask for some help

- Live with it

Avoidant-Denial

- If it wasn't my house I wouldn't care

- Be kind to self

- Deny the problem

- Don't worry

- Not stress out

- Enjoy your weekend

- Just keep ignoring chores until next week 
Appendix I (continued)

Commentary

- Welcome to my world

- The chores will still be there when they die

- This is a problem? I thought this was normal

- One person should not be responsible for all chores

- I'm a nice guy

- It will get done

- People think chores will take more time than they actually do

Nonsense

- Vacation time

- Less sleep

- Stop

Other

- Yell 
Appendix J: Problem Perceptions

On the following pages are statements about how you perceived each of the 4 hypothetical problems that you recently completed. Each problem is presented at the top of the page followed by several questions. Be sure to note the problem at the top of the page. Read each statement on this questionnaire and select the answer on the right which best reflects your level of agreement.

Circle the number in front of the answer which indicates the extent to which you agree or disagree with each statement. There are no "right" or "wrong" answers-we want to know which choice best describes you in each case. Be sure to answer every question.

\section{As you answer the items on the next pages, please keep these points in mind:}

1. When you feel you can, please use the entire scale and avoid using only the middle numbers, unless of course, that is the best answer.

2. Do not spend too much time thinking about your answer. Give the first natural answer as it comes to you.

3. Answer every question, even if it doesn't seem to apply to you very well.

4. Be as honest as possible about what is true of you.

5. Circle the number in the right columns that corresponds to your answer. 


\section{Problem: A person has done something that offended one of their friends.}

1. I have had experience solving problems similar to the problem about offending a friend.
1. strongly agree

2. agree

3. slightly agree

4. slightly disagree

5. disagree

6. strongly disagree
2. Dealing with offending a friend is currently a problem for me.
1. strongly agree

2. agree

3. slightly agree

4. slightly disagree

5. disagree

6. strongly disagree
3. In real life, if I offended a friend, I would be able to approach and solve the problem effectively.
1. strongly agree

2. agree

3. slightly agree

4. slightly disagree

5. disagree

6. strongly disagree
4. I think I did well today when solving the problem about offending a friend.
1. strongly agree

2. agree

3. slightly agree

4. slightly disagree

5. disagree

6. strongly disagree 


\section{Problem: A person has let their home become too cluttered with items they use infrequently but which have much sentimental value for them.}

1. I have had experience solving problems similar to the problem about the cluttered home with sentimental items.
1. strongly agree

2. agree

3. slightly agree

4. slightly disagree

5. disagree

6. strongly disagree
2. Dealing with a cluttered home with sentimental items is currently a problem for me.
1. strongly agree

2. agree

3. slightly agree

4. slightly disagree

5. disagree

6. strongly disagree
3. In real life, if my home were cluttered with sentimental items, I would be able to approach and solve the problem effectively.
1. strongly agree

2. agree

3. slightly agree

4. slightly disagree

5. disagree

6. strongly disagree
4. I think I did well today when solving the problem about the cluttered home with sentimental items.
1. strongly agree

2. agree

3. slightly agree

4. slightly disagree

5. disagree

6. strongly disagree 


\section{Problem: A person lost or broke an expensive item they borrowed from a friend.}

1. I have had experience solving problems similar to the problem about a lost/broken item of a friend.
1. strongly agree

2. agree

3. slightly agree

4. slightly disagree

5. disagree

6. strongly disagree

2. Dealing with a lost/broken item of a friend is currently a problem for me.

1. strongly agree

2. agree

3. slightly agree

4. slightly disagree

5. disagree

6. strongly disagree
3. In real life, if I lost/broke an item of a friend, I would be able to approach and solve the problem effectively.
1. strongly agree

2. agree

3. slightly agree

4. slightly disagree

5. disagree

6. strongly disagree
4. I think I did well today when solving the problem about a lost/broken item of a friend.
1. strongly agree

2. agree

3. slightly agree

4. slightly disagree

5. disagree

6. strongly disagree 


\section{Problem: Because of a lack of time, a person has let household chores pile up.}

1. I have had experience solving problems similar to the problem about chores piling up.
1. strongly agree

2. agree

3. slightly agree

4. slightly disagree

5. disagree

6. strongly disagree

2. Dealing with chores piling up is currently a problem for me.

1. strongly agree

2. agree

3. slightly agree

4. slightly disagree

5. disagree

6. strongly disagree
3. In real life, if I let chores pile up, I would be able to approach and solve the problem effectively.
1. strongly agree

2. agree

3. slightly agree

4. slightly disagree

5. disagree

6. strongly disagree
4. I think I did well today when solving the problem about chores piling up.
1. strongly agree

2. agree

3. slightly agree

4. slightly disagree

5. disagree

6. strongly disagree 